\title{
Acupuncture for treatment of irritable bowel syndrome
}

\author{
Eric Manheimer ${ }^{1}$, Ke Cheng ${ }^{2}$, L. Susan Wieland ${ }^{1}$, Li Shih Min $^{3}$, Xueyong Shen ${ }^{2}$, Brian M \\ Berman ${ }^{1}$, and Lixing Lao 4 \\ ${ }^{1}$ Center for Integrative Medicine, University of Maryland School of Medicine, Baltimore, Maryland, \\ USA.
}

${ }^{2}$ College of Acupuncture-Moxibustion and Tuina, Shanghai University of Traditional Chinese Medicine, Shanghai Research Center for Acupuncture and Meridians, Shanghai, China.

${ }^{3}$ Departamento de Clinica Medica, Universidade Federal de Santa Catarina - Brasil, Florianopolis, SC, Brazil.

${ }^{4}$ Complementary Medicine Program, University of Maryland School of Medicine, Baltimore, Maryland, USA

\begin{abstract}
Background-Irritable bowel syndrome (IBS) is a common, costly, and difficult to treat disorder that impairs health-related quality of life and work productivity. Evidence-based treatment guidelines have been unable to provide guidance on the effects of acupuncture for IBS because the only previous systematic review included only small, heterogeneous and methodologically unsound trials.
\end{abstract}

Objectives-The primary objectives were to assess the efficacy and safety of acupuncture for treating IBS.

Search methods-MEDLINE, the Cochrane Central Register of Controlled Trials, EMBASE, the Cumulative Index to Nursing and Allied Health, and the Chinese databases Sino-Med, CNKI, and VIP were searched through November 2011.

Selection criteria-Randomized controlled trials (RCTs) that compared acupuncture with sham acupuncture, other active treatments, or no (specific) treatment, and RCTs that evaluated acupuncture as an adjuvant to another treatment, in adults with IBS were included.

Data collection and analysis-Two authors independently assessed the risk of bias and extracted data. We extracted data for the outcomes overall IBS symptom severity and healthrelated quality of life. For dichotomous data (e.g. the IBS Adequate Relief Question), we

Copyright () 2012 The Cochrane Collaboration. Published by John Wiley \& Sons, Ltd.

Contact address: Eric Manheimer, Center for Integrative Medicine, University of Maryland School of Medicine, $520 \mathrm{~W}$. Lombard St, Room 101D, Baltimore, Maryland, 21201, USA. emanheimer@compmed.umm.edu.

CONTRIBUTIONS OF AUTHORS

Study concept and design: Eric Manheimer, L. Susan Wieland, Brian Berman, Ke Cheng, Lixing Lao, Xueyong Shen

Data extraction: Eric Manheimer, Ke Cheng, Shih Min Li, L. Susan Wieland

Acupuncture adequacy assessments: Lixing Lao, Shen Xueyong

Analysis and interpretation of data: Eric Manheimer

Drafting the manuscript: Eric Manheimer, with L. Susan Wieland contributing to the Methods section

Critically revised manuscript for important intellectual content and provided final approval of the version to be published: Brian

Berman, Ke Cheng, Lixing Lao, Shih Min Li, Eric Manheimer, Xueyong Shen, L. Susan Wieland

Obtained funding: Brian Berman, Eric Manheimer

DECLARATIONS OF INTEREST

None known 
calculated a pooled relative risk (RR) and 95\% confidence interval (CI) for substantial improvement in symptom severity after treatment. For continuous data (e.g. the IBS Severity Scoring System), we calculated the standardized mean difference (SMD) and 95\% CI in posttreatment scores between groups.

Main results-Seventeen RCTs (1806 participants) were included. Five RCTs compared acupuncture versus sham acupuncture. The risk of bias in these studies was low.We found no evidence of an improvement with acupuncture relative to sham (placebo) acupuncture for symptom severity (SMD-0.11, 95\%CI -0.35 to 0.13 ; 4 RCTs; 281 patients) or quality of life (SMD $=-0.03,95 \%$ CI -0.27 to $0.22 ; 3$ RCTs; 253 patients). Sensitivity analyses based on study quality did not change the results. A GRADE analysis indicated that the overall quality of the evidence for the primary outcomes in the sham controlled trials was moderate due to sparse data. The risk of bias in the four Chinese language comparative effectiveness trials that compared acupuncture with drug treatment was high due to lack of blinding. The risk of bias in the other studies that did not use a sham control was high due to lack of blinding or inadequate methods used for randomization and allocation concealment or both. Acupuncture was significantly more effective than pharmacological therapy and no specific treatment. Eighty-four per cent of patients in the acupuncture group had improvement in symptom severity compared to $63 \%$ of patients in the pharmacological treatment group (RR $1.28,95 \%$ CI 1.12 to $1.45 ; 5$ studies, 449 patients). A GRADE analysis indicated that the overall quality of the evidence for this outcome was low due to a high risk of bias (no blinding) and sparse data. Sixty-three per cent of patients in the acupuncture group had improvement in symptom severity compared to $34 \%$ of patients in the no specific therapy group (RR $2.11,95 \%$ CI 1.18 to $3.79 ; 2$ studies, 181 patients). There was no statistically significant difference between acupuncture and Bifidobacterium (RR 1.07, 95\% CI 0.90 to $1.27 ; 2$ studies; 181 patients) or between acupuncture and psychotherapy (RR 1.05, 95\% CI 0.87 to 1.26; 1 study; 100 patients). Acupuncture as an adjuvant to another Chinese medicine treatment was significantly better than the other treatment alone. Ninety-three per cent of patients in the adjuvant acupuncture group improved compared to $79 \%$ of patients who received Chinese medicine alone (RR 1.17, 95\% CI 1.02 to 1.33; 4 studies; 466 patients). There was one adverse event (i.e. acupuncture syncope) associated with acupuncture in the 9 trials that reported this outcome, although relatively small sample sizes limit the usefulness of these safety data.

Authors' conclusions-Sham-controlled RCTs have found no benefits of acupuncture relative to a credible sham acupuncture control for IBS symptom severity or IBS-related quality of life. In comparative effectiveness Chinese trials, patients reported greater benefits from acupuncture than from two antispasmodic drugs (pinaverium bromide and trimebutine maleate), both of which have been shown to provide a modest benefit for IBS. Future trials may help clarify whether or not these reportedly greater benefits of acupuncture relative to pharmacological therapies are due entirely to patients' preferences for acupuncture or greater expectations of improvement on acupuncture relative to drug therapy.

\section{Medical Subject Headings (MeSH)}

*Acupuncture Therapy; Irritable Bowel Syndrome [*therapy]; Randomized Controlled Trials as Topic

\section{MeSH check words}

Humans 


\section{PLAIN LANGUAGE SUMMARY}

\section{Acupuncture for irritable bowel syndrome}

Irritable bowel syndrome (IBS) is a chronic gastrointestinal condition characterized by altered bowel habits and abdominal pain and discomfort. It is a common, costly, and difficult to treat disorder that also impairs health-related quality of life and work productivity. Some pharmacological (i.e. drug) therapies for treating IBS have modest benefits and a risk for side effects, and therefore, it is important to evaluate the effectiveness and safety of non-drug therapies, including acupuncture. One problem with trials in IBS is that placebo effects are often seen in IBS treatment. Placebo effects are improvements in symptoms that are due to patient beliefs in a particular treatment rather than the specific biological effects of the treatment.

This review included 17 randomized controlled trials (RCTs) including a total of 1806 participants. Five RCTs (411 participants) compared acupuncture to sham acupuncture for the treatment of IBS. Sham acupuncture is a procedure in which the patient believes he or she is receiving true acupuncture. However, in sham acupuncture the needles either do not penetrate the skin or are not placed at the correct places on the body, or both. Sham acupuncture is intended to be a placebo for true acupuncture. The sham-controlled studies were well designed and of high methodological quality. These studies tested the effects of acupuncture on IBS symptom severity or health-related quality of life. None of these RCTs found acupuncture to be better than sham acupuncture for either of these two outcomes, and pooling the results of these RCTs also did not show acupuncture to be better than sham acupuncture. Evidence from four Chinese language comparative effectiveness trials showed acupuncture to be superior to two antispasmodic drugs (pinaverium bromide and trimebutine maleate), both of which provide a modest benefit for the treatment of IBS, although neither is approved for treatment of IBS in the United States. It is unclear whether or not the greater benefits of acupuncture reported by patients in these unblinded studies are due entirely to patients' greater expectations of improvement from acupuncture than drugs or preference for acupuncture over drug therapy. There was one side effect (i.e. fainting in one patient) associated with acupuncture in the nine trials that reported side effects, although relatively small sample sizes limit the usefulness of this safety data.

\section{BACKGROUND}

Irritable bowel syndrome (IBS) is a chronic, relapsing gastrointestinal disorder characterized by altered bowel habits and abdominal pain and discomfort (Brandt 2009). A systematic review (Saito 2002) has estimated that 10 to $15 \%$ of adults in North America have IBS, as diagnosed by either the Rome (Vanner 1999) or Manning (Saito 2000) objective diagnostic criteria. IBS is associated with significant reductions in both health-related quality of life (El-Serag 2002) and work productivity (Maxion-Bergemann 2006; Brandt 2009) and increased consumption of medical resources. Indeed, people with IBS consume over 50\% more health care resources than age-matched controls without IBS (Longstreth 2003; Talley 1995). The combined direct and indirect costs associated with IBS patients in the United States in 2004 were estimated at over $\$ 1$ billion (Everhart 2008).

Effective treatments for IBS are needed to relieve symptoms, improve quality of life, and to reduce healthcare utilization. In 2009, the American College of Gastroenterology Task Force conducted a series of systematic reviews to evaluate the efficacy of both pharmacological and non-pharmacological therapies for treating IBS (Brandt 2009). In terms of pharmacological treatments, the Task Force found "poor quality of evidence" for certain antispasmodics and "moderate quality of evidence" for tricyclic antidepressants, selective serotonin reuptake inhibitors, non-absorbable antibiotics (for diarrhea-predominant IBS), 
and C-2 chloride channel activators (for constipation-predominant IBS). TheTask Force found "good quality of evidence" for $5 \mathrm{HT}_{3}$ antagonists and $5 \mathrm{HT}_{4}$ agonists, but noted that these agents carry a possible risk of ischemic colitis and cardiovascular events, respectively, which may limit their utility. A subsequent systematic review showed that the benefits of these $5 \mathrm{HT}_{3}$ antagonists and $5 \mathrm{HT}_{4}$ agonists relative to placebo are "modest" (Ford 2009a). In terms of non-pharmacological therapies, the Task Force found "poor quality of evidence" for psyllium fiber and peppermint oil. The Task Force also noted that preliminary evidence suggested that some probiotics may be effective in reducing IBS symptoms (Brandt 2009). A subsequent systematic review (Brenner 2009) concluded that the specific probiotic $B$. infantis 35624 has shown repeated efficacy in well-designed randomized controlled trials (RCTs), and can be considered an effective treatment for IBS.

The Task Force was unable to make any recommendations either for or against acupuncture for treating IBS because the only systematic review available at the time was a Cochrane review (Lim 2006) which was inconclusive because it included only small, heterogeneous, and methodologically unsound trials. Given the safety of acupuncture (MacPherson 2001; White 2001;Melchart 2004) and the limited availability of other safe and effective treatments for IBS, the question of whether acupuncture is effective for treating IBS is highly relevant. Recently, RCTs have been published which provide greater evidence to estimate the effects of acupuncture for treating IBS. We have therefore updated our previous Cochrane systematic review and meta-analysis of acupuncture for IBS (Lim 2006) to assess whether the pooled effects of currently available trials show any benefit of acupuncture for improving symptoms or health-related quality of life in patients with IBS.

\section{OBJECTIVES}

The primary objectives were to assess the efficacy and safety of acupuncture for treating IBS.

\section{METHODS}

\section{Criteria for considering studies for this review}

Types of studies-We included randomized controlled trials (RCTs) in any language, published as either full articles or abstracts. Recent research indicates that a large proportion of Chinese-language RCT reports are of studies that are not truly randomized (Wu 2009). An author $(\mathrm{KC})$ therefore contacted the investigators of Chinese-language RCTs by telephone to determine whether they had used randomization. The interviews were conducted using questions adapted fromthe survey developed byWu et al to verify the authenticity of "claimed" randomized trials (Wu 2009). Responses were recorded and forwarded to a second review author (EM) for confirmation of RCT authenticity. The same questions were asked of authors of English-language RCTs that did not include details about randomization methods in their published reports. Trials that were found to assign patients by alternation, rotation, or hospital record number were excluded. Trials that used a random method of assignment, but with flaws or suspected flaws in the random assignment process were included, but with their limitations described.

Types of participants-We included trials involving adult participants diagnosed with irritable bowel syndrome (IBS). Examples of diagnostic criteria included but were not limited to the Manning criteria (Manning 1978), andRome I (Drossman 1994), Rome II (Thompson 2000), or Rome III criteria (Longstreth 2006). We did not exclude trials in which patients were stated to be diagnosed with IBS but no diagnostic criteria were described. 
Types of interventions-We included trials evaluating Traditional Chinese Medicine (TCM) acupuncture. TCM acupuncture involves inserting needles into traditional meridian points, usually with the intention of influencing energy flow in the meridian. Needles may also be inserted at additional tender points and electrical stimulation of the needles may be used. Since TCM acupuncture is often accompanied by moxibustion, we included trials using moxibustion as a cointervention with acupuncture. We excluded trials of dry needling or trigger point therapy, a therapy which is based on principles of Western anatomy and physiology and rejects TCM concepts of energy and meridians. We also excluded RCTs of laser acupuncture, non-invasive electrostimulation (i.e. using electrodes on the skin rather than needles to stimulate acupuncture points (Ezzo 2005)), and acupressure, to restrict our focus to the effects of traditional needle acupuncture. Finally, we excluded trials of micropuncture, a non-traditional acupuncture practice which is based on the principle that the ear (or nose, eye, etc.) is a microsystem of the entire body, and in which needles are only inserted on that microsystem. Identified trials using types of interventions that are not eligible are described in the 'Characteristics of excluded studies' table. We included trials comparing acupuncture to any of the following control interventions: sham (placebo) acupuncture, no (specific) treatment, an active non-TCM treatment, or evaluated acupuncture as an adjuvant to another treatment. Because our objective was to evaluate the effects of TCM acupuncture compared to a sham treatment, no treatment or a Western medicine control, we excluded RCTs in which one form of acupuncture was compared with another form of acupuncture or a different type of TCM(e.g. Chinese herbal medicine). Adjunctive treatments, either Western or TCM, were allowed as long as they had been given to both the acupuncture and control groups.

Types of outcome measures-Our primary outcomes were overall IBS symptom severity and IBS health-related quality of life. Studies that did not report at least one of these outcomes were excluded. Although there is no consensus on how to define and measure clinically meaningful improvement in IBS (Irvine 2006), two recent evaluations of symptom and quality of life measures in IBS concluded that the IBS Adequate Relief question (IBSAR) (Mangel 1998) and the IBS Symptom Severity Scale (IBS-SSS) (Francis 1997) possessed responsiveness, face and construct validity and were two of the most appropriate IBS symptom outcome measures, while the IBS Quality of Life measure (IBS-QoL) (Patrick 1998) was the most extensively validated quality of life scale (Bijkerk 2003; Irvine 2006). When an individual study reported more than one overall IBS symptom severity measure, and either the IBS-AR question or the IBS-SSS scale was present, we gave preference to the IBS-AR question for dichotomous outcomes and to the IBS-SSS scale for continuous outcomes. When an individual study reported more than one quality of life measure, we gave preference to the IBS-QoL if present. In cases where dichotomous outcomes such as improvement in IBS symptoms were presented in the form of multiple strata, such that we had the option of choosing cutpoints for the dichotomous outcome, we followed the model of Ford et al. and created a dichotomous measure in which positive outcomes were combined into a positive category (i.e. improvement) and the remaining strata constituted the negative category (i.e. no improvement) (Ford 2009a; Ford 2009b). In cases where investigators selected a cutpoint on a continuous scale to dichotomise between improvement and no improvement, we used the same cutpoint to define the dichotomous outcome (Ford 2009a).

Timing of outcome assessment-We extracted outcome data for both short and longterm follow-up points. Short-term follow-up was defined as three months or less after randomization, and long-term follow-up was defined as closest to six months but more than three months after randomization. When we observed multiple short-term follow-up points, we chose to extract the data closest to eight weeks after randomization, which coincided 
with end of treatment. In randomized crossover trials, only outcomes from the first period were eligible for inclusion, due to the risk of carry-over effects.

Adverse outcomes-We extracted data on adverse events when such data were present in the trial report.

\section{Search methods for identification of studies}

Electronic searches-To identify RCTs, we searched the Cochrane Central Register of Controlled Trials (The Cochrane Library, Issue 11, 2011), the Cochrane Inflammatory Bowel Disease and Functional Bowel Disorders Review Group Specialized Register, the Cochrane Complementary Medicine Field Specialized Register, MEDLINE/PubMed, EMBASE, the Cumulative Index to Nursing and Allied Health, and the Chinese databases Sino-Med, CNKI and VIP, during November 15 to 28, 2011. We developed search strategies for each database, based upon the original Medline search strategy constructed for the previous version of this review (Lim 2006). The strategies and results for each database are presented in Appendix 1.

Searching other resources-We considered all RCTs included in the previous version of this review for inclusion in this update. We scanned bibliographies of included articles and systematic reviews for further references. Finally, we searched ClinicalTrials.gov to identify trials that may be relevant for future updates of this review.

\section{Data collection and analysis}

Selection of studies-All records identified by searching were independently screened by at least one author. The full text of potentially relevant reports was obtained and independently reviewed by two authors for eligibility. Disagreements between reviewers were resolved by discussion.

Data extraction and management-All data were independently extracted by two authors. In addition to the outcomes of overall IBS symptom severity and IBS health related quality of life for all time points reported, we extracted data pertaining to the methods of the trial, characteristics of the participants, details of the acupuncture and control interventions, and treatment outcomes. Any disagreements were resolved by discussion. When reported data were incomplete or ambiguous, we requested additional information or clarification from the corresponding authors.

The method of selecting acupuncture points was categorized as fixed, flexible or individualized. For the fixed method, the same points are used for all participants. For the flexible method, a fixed formula is used and some additional points are chosen for the individual participant, based upon individual diagnosis or symptoms. In individualized point selection, the practitioner is free to choose any points.

Assessment of risk of bias in included studies-We assessed risk of bias using the Cochrane Collaboration's risk of bias tool (Higgins 2011a). We used the following six criteria:

- Adequate sequence generation: Was the allocation sequence adequately generated?

- Allocation concealment: Was the allocation adequately concealed?

- Blinding: Was knowledge of the allocated intervention adequately prevented during the study?

- Incomplete outcome data: Were incomplete outcome data adequately addressed? 
- Selective reporting: Were reports of the study free of suggestion of selective outcome reporting?

- Other risk of bias: Was the study apparently free of other problems that could put it at a high risk of bias?

For each risk of bias question, an answer of 'Yes' indicates low risk of bias, 'No' indicates high risk of bias and 'Unclear' indicates unclear or unknown risk of bias. We used the criteria described in the Cochrane Handbook for Systematic Reviews of Interventions (Higgins 2011a) for judgments of 'Yes', 'No' and 'Unclear'. For "Blinding”, we assigned sham-controlled trials a judgment of "Unclear" unless we felt certain that the sham control was sufficiently credible in fully blinding participants to the treatment being evaluated (Manheimer 2007; Manheimer 2010). We assigned the "Yes" score to sham-controlled trials that either 1) evaluated the credibility of the sham and found the sham to be indistinguishable from true acupuncture or 2) used a penetrating needle or a previously validated sham needle (i.e. Streitberger needle). There is no universally agreed-upon instrument to measure outcomes in trials of IBS treatment, however overall IBS symptom severity is a key outcome in the majority of IBS trials and health-related quality of life is an important secondary outcome that may legitimately be considered as a primary outcome measure (Irvine 2006). For the selective reporting item, we assigned the "Yes" score to trials that both 1) reported outcomes for overall IBS symptom severity or health-related quality of life, or both, and 2) reported, at the end of treatment (and follow-up, if done), the results of each outcome measured according to the Methods section. For "Other risk of bias", we evaluated 2 other risk of bias-related criteria: baseline comparability and use of an intention to treat analysis. For the baseline comparability criterion to be considered adequate, a comparison of the symptom scores between the treatment and control group(s) at baseline needed to be reported Although we did not explicitly consider this to be a risk of bias measure, we also extracted data on the sources of funding for each trial.

As a first step in evaluating risk of bias, we copied information relevant for making a judgment on a criterion from the original publication into a table. If available, we also entered any additional information from the RCT authors into this table. Two review authors (EM and LSW or KC for English-language trials, and LL and KC for Chinese-language trials) independently judged whether the risk of bias for each criterion should be considered low, high or unclear. Any disagreement was resolved by discussion. We used the GRADE approach to rate the overall quality of evidence for the primary outcomes. RCTs start as high quality evidence, but may be downgraded due to: (1) limitations in design and implementation (risk of bias), (2) indirectness of evidence, (3) inconsistency (unexplained heterogeneity), (4) imprecision (sparse data), and (5) reporting bias (publication bias). The overall quality of evidence for each outcome was determined after considering each of these elements, and categorized as high quality (i.e. further research is very unlikely to change our confidence in the estimate of effect); moderate quality (i.e. further research is likely to have an important impact on our confidence in the estimate of effect and may change the estimate); low quality (i.e. further research is very likely to have an important impact on our confidence in the estimate of effect and is likely to change the estimate); or very low quality (i.e. we are very uncertain about the estimate) (Guyatt 2008; Schünemann 2011).

Assessment of acupuncture adequacy: Two acupuncturists (LL, XS) who have a combined clinical experience of nearly fifty years in treating IBS with acupuncture, and who have previously worked on RCTs of acupuncture, independently assessed the adequacy of the acupuncture administered in the trials. Six aspects of the acupuncture intervention were assessed for adequacy: choice of acupuncture points; total number of sessions; treatment duration; treatment frequency; needling technique; and acupuncturist's experience (Furlan 2005). The likelihood of the sham intervention to have physiological activity was also 
assessed, using an open-ended question. The acupuncturist assessors were provided with only the part of the publications that described the acupuncture and sham procedures, so that their assessments could not be influenced by the results of the trials. To test the success of blinding the assessors to the study publication and results, we asked the assessors to guess the identity of each study being assessed. The acupuncturists assessed adequacy independently and achieved consensus by discussion.

\section{Measures of treatment effect}

Dichotomous data: Dichotomous outcomes (e.g. adequate symptom relief ) were expressed as relative risks (RR) with $95 \%$ confidence intervals $(\mathrm{CI})$.

Continuous data: For continuous outcomes on the same scale (e.g. symptom severity as measured by the IBS-SSS), the mean difference (MD) and $95 \%$ confidence intervals were calculated. For continuous outcomes on different scales that assess the same underlying construct (e.g. different measures of symptom severity), the standardized mean difference (SMD) and $95 \%$ confidence intervals were calculated.

Dealing with missing data-In cases where participants were lost to follow-up, and intention to-treat (ITT) analyses were conducted using baseline observations carried forward, multiple imputation, or other methods to impute the missing values, we used the ITT data for our primary analysis, if group means and standard deviations were present or could be estimated, and if the method for imputing data was described and did not bias the effect size calculation. If only the ITT data were reported, and not the available case data, we used the ITT data. When statistics such as standard deviations were not present in the study report, we used the methods suggested in Chapter 16 of the Cochrane Handbook for Systematic Reviews of Interventions (Higgins 2011b) to calculate or estimate the values of the missing statistics.

Assessment of heterogeneity-We evaluated heterogeneity using the $\mathrm{I}^{2}$ statistic (Higgins 2003), which indicates the proportion of variability across trials not explained by chance alone. Roughly, $\mathrm{I}^{2}$ values of $50 \%$ to $90 \%$ may represent substantial heterogeneity, and $\mathrm{I}^{2}$ values of $75 \%$ to $100 \%$ represent considerable heterogeneity (Higgins 2003; Deeks 2011). We also checked for heterogeneity by visual examination of forest plots. When heterogeneity was observed, we attempted to determine potential reasons for it by examining individual study characteristics, such as study population, type and duration of treatment, and type of control intervention.

Data synthesis-Data from individual trials were combined when the trials were sufficiently similar in terms of control interventions (sham (placebo) acupuncture, no treatment, another active treatment, or acupuncture as adjuvant to another treatment), outcome measures (overall IBS symptom severity, IBS-related quality of life), and timing of outcome assessment (short-term, long-term). For pooled data, summary test statistics were calculated using a random-effects effect model to account for expected heterogeneity. If the $\mathrm{I}^{2}$ statistic was greater than or equal to $50 \%$, the summary measures of effect were interpreted with caution, and heterogeneity between trials was investigated.

For the acupuncture versus sham comparison, data for the symptom severity outcome were presented in some studies as dichotomous data (e.g. adequate symptom relief ) and in other studies as continuous data (e.g. symptom severity as measured by the IBS-SSS). We reexpressed odds ratios as standardized mean differences (SMDs), thereby allowing dichotomous and continuous data to be pooled together for this comparison/outcome (Deeks 2011), using the generic inverse variance method in RevMan. 
Sensitivity analysis-We conducted sensitivity analyses using fixed-effect and randomeffects meta-analytic estimates, and for available case and imputed data, when such data were available.

To assess whether treatment effects varied with internal validity of studies or treatment adequacy, we attempted sensitivity analyses to evaluate whether any pooled results that were significant in analyses of all the trials remained significant when we restricted them to trials judged adequate on each of the risk of bias and treatment-adequacy criteria.

\section{RESULTS}

\section{Description of studies}

See: Characteristics of included studies; Characteristics of excluded studies; Characteristics of ongoing studies.

Results of the search-Figure 1 shows details of the search and selection process.

Included studies-Seventeen studies with a total of 1806 participants were included (Liu 1997; Lowe 2000; Forbes 2005; Schneider 2006; Reynolds 2008; Xiong 2008a; Anastasi 2009; Chen 2009; Lembo 2009; Li 2009; Xue 2009; An 2010; Liu 2010; Shi 2010; Zeng 2010; Chen 2011; Sun 2011; See 'Characteristics of included studies' table). Five of the studies were small, including between 29 and 59 participants (Lowe 2000; Forbes 2005; Schneider 2006; Reynolds 2008; Anastasi 2009). The largest study included 230 participants (Lembo 2009). The studies were conducted in theUS (Anastasi 2009; Lembo 2009), the UK (Forbes 2005; Reynolds 2008), China (Liu 1997; Xiong 2008a; Chen 2009; Li 2009; Xue 2009; An 2010; Liu 2010; Shi 2010; Zeng 2010; Chen 2011; Sun 2011), Canada (Lowe 2000) and Germany (Schneider 2006). The studies conducted in China were published in Chinese, and the remaining studies were published in English. All were published as full articles, with the exception of the Lowe 2000 trial, which was published as an abstract. Three of the studies included in our 2006 Cochrane review (Liu 1995; Liao 2000; Fireman 2001) were excluded from this update because either an adequate randomization process was not used (Liao 2000; Fireman 2001) or the randomization procedure could not be recalled by the author (Liu 1995). Appendix 2 includes an overview description of trial characteristics and acupuncture and control interventions.

Excluded studies-The 'Characteristics of excluded studies' table lists the studies that we excluded as well as the reasons for exclusion.

\section{Risk of bias in included studies}

All sham-controlled trials reported adequate methods for sequence generation and allocation concealment, and all trials except the Lowe 2000 trial adequately described and addressed losses to follow- up. The Lowe 2000 trial was reported only as an abstract, and the completeness of outcome data ascertainment could not be assessed.

In 4 out of 5 of the sham-controlled trials (Forbes 2005; Schneider 2006; Lembo 2009; Anastasi 2009), we judged that the shams were likely to be indistinguishable from true acupuncture. In two of these sham-controlled trials (Schneider 2006; Lembo 2009), the Streitberger placebo needle was used, which has been previously validated as a sufficiently credible sham (Streitberger 1998). The Streitberger needles were placed close to the genuine acupuncture points in both trials. In both trials, the participants were acupuncture naïve. In the Anastasi 2009 trial, the investigators superficially inserted needles at non points which were 2 to $3 \mathrm{~cm}$ away from the true points, and placebo moxibustion was performed above 
the same sham points without generating a heat sensation. In the Forbes 2005 trial, acupuncture needles were inserted at areas on the body that do not correspond to acupuncture points and are deemed to have no therapeutic value. The points and needling technique were varied somewhat each week, as was also done in the true acupuncture group, who received individualized point selection. In each of these four trials, the sham was likely to be indistinguishable from true acupuncture. For the Lowe 2000 trial, the sham was judged to have been potentially detectable as a fake treatment by the trial participants. The sham procedure involved tapping a blunt needle on the skin and then taping the needle in place. Although this procedure was described as "validated" in the Lowe 2000 abstract, we are unaware of a validation study for this procedure. Also, in the trial report there was no description of whether or not the patients were required to have never previously used acupuncture, and there were no reported tests for checking the success of the blinding.

In the trials comparing acupuncture with another active treatment (Liu 1997; Li 2005;Xue 2009; An 2010; Liu 2010; Shi 2010;Zeng 2010; Chen 2011; Sun 2011), no (specific) treatment (Reynolds 2008; Lembo 2009), or evaluating acupuncture as an adjuvant to another treatment received by all trial participants (Liu 1997; Xiong 2008a; Chen 2009; Li 2009; Liu 2010), blinding of participants was not possible, and this likely represents the major risk of bias in these trials. In these pragmatic trials, there were also risks of bias associated with the randomization procedure and the follow-up of patients. Although all of these trials reported to use a random sequence generation for the treatment assignment, 5 of these trials (Liu 1997; Chen 2009; Li 2009; Xue 2009; Liu 2010) reported an equal number of participants in each group, which would be unlikely to occur by chance with the simple randomization methods used in these trials. The authors of the Chen 2009 and Li 2009 trials confirmed in telephone interviews that a few patients were non-randomly assigned to achieve identical sized treatment groups. The authors of the other 3 trials (i.e. Liu 1997; Xue 2009; Liu 2010), were unable to explain how equal sample sizes were achieved. In 6 of the Chinese language trials (Liu 1997; Xiong 2008a; Chen 2009; Li 2009; An 2010; Liu 2010), incomplete outcome data were not adequately addressed. In four trials (Liu 1997; Xiong 2008a; Li 2009; An 2010), the authors did not report the numbers of drop-outs in the publication, and did not have records of the numbers of drop-outs to provide during the telephone interviews. For the Liu 2010 trial, the authors reported no drop-outs, which would be unusual in a 4 week trial of 300 participants. For the Chen 2009 trial, the authors endeavoured to maintain equal group sizes, by eliminating participants who withdrew during the trial and replacing them with new patients, and the number of such replacements was not recorded by the author. A 'risk of bias graph' displays the judgments for each risk of bias item for each included study (Figure 2).

Acupuncture adequacy-All trials included in this review were judged adequate on "Choice of acupoints" and "Needling technique", except for the Lowe 2000 trial, for which the acupuncture points and needling technique were not reported. The acupuncture frequency was judged adequate in all trials except for the Forbes 2005 and Reynolds 2008 trials. All trials that reported on the acupuncturist's experience were judged adequate, except for the Lowe 2000 trial, for which a physiotherapist with Level 1 accreditation in acupuncture was used, which was judged inadequate. Also, for two trials (Forbes 2005; Anastasi 2009), the acupuncture adequacy assessors noted that the sham needling may have had physiologic activity. The results of the acupuncture adequacy assessments are reported in Appendix 3.

\section{Effects of interventions}

See: Summary of findings for the main comparison Acupuncture versus sham acupuncture for irritable bowel syndrome; Summary of findings 2 Acupuncture versus pharmaceutical 
medications for irritable bowel syndrome The GRADE analyses for the main comparisons are presented in Summary of findings for the main comparison and Summary of findings 2.

Acupuncture versus sham-Five trials (Lowe 2000; Forbes 2005; Schneider 2006; Anastasi 2009; Lembo 2009) compared the effects of acupuncture and sham acupuncture. The Schneider 2006 trial did not measure the outcome of symptom severity and the Anastasi 2009 and Lowe 2000 trials did not report quality of life. The 5 individual sham-controlled RCTs, and also the pooled analyses, found no statistically significant differences between acupuncture and sham acupuncture for the outcomes symptom severity or quality of life. Data for the symptom severity outcome were presented as dichotomous data (e.g. adequate symptom relief ) in some studies and as continuous data (e.g. symptom severity as measured by the IBS-SSS) in other studies. We re-expressed odds ratios as standardized mean differences (SMDs), thereby allowing dichotomous and continuous data to be pooled together for this comparison/outcome (Deeks 2011), using the generic inverse variance method in RevMan. This pooled analysis for symptom severity included 4 studies and 281 patients. There was no statistically significant difference between acupuncture and sham acupuncture (SMD-0.11, 95\% CI -0.35 to 0.13; See Figure 3). The GRADE analysis indicated that the overall quality of the evidence for this outcome was moderate due to sparse data (less than 400 events; See Summary of findings for the main comparison). Three studies (231 patients) reported symptom severity as a continuous outcome. There was no statistically significant difference between acupuncture and sham acupuncture (SMD - 0.09, 95\% CI -0.35 to 0.17; See Analysis 1.1). Three studies (262 patients) reported on adequate symptom relief. Fifty-five per cent of patients in the acupuncture group had adequate symptom relief compared to $49 \%$ of patients in the sham acupuncture group. There was no statistically significant difference between acupuncture and sham acupuncture (RR 1.09, $95 \% \mathrm{CI}$ is 0.87 to 1.37 ; See Analysis 1.2 ).

For the acupuncture versus sham comparison, all 3 studies (253 patients) that included the quality of life outcome reported continuous data. There was no statistically significant difference in quality of life scores between acupuncture and sham acupuncture groups (SMD $-0.03,95 \%$ CI -0.27 to 0.22 ; See Figure 4). A GRADE analysis indicated that the overall quality of the evidence for this outcome was moderate due to sparse data (less than 400 events; See Summary of findings for the main comparison). One study reported quality of life as a dichotomous outcome (153 patients).

Seventeen per cent of acupuncture patients had an improvement in quality of life compared to $14 \%$ of sham acupuncture patients. There was no statistically significant difference (RR $1.25,95 \%$ CI 0.58 to 2.68; See Analysis 1.5). For both outcomes, the results of all shamcontrolled trials were homogeneous $\left(\mathrm{I}^{2}=0 \%\right.$; See Figure 3; Figure 4). One trial (Schneider 2006) assessed quality of life at long-term follow-up, and this trial did not find a difference in effect between acupuncture and sham acupuncture at six months (SMD 0.07, 95\% CI -0.54 to $0.69 ; 41$ patients; See Analysis 1.6).

\section{Acupuncture versus other active treatments, as an adjuvant to other active treatments, and versus no specific treatment-All trials reported dichotomous} outcome data for all non-sham comparisons, We pooled these trials as relative risks (see Figure 5). In cases where continuous outcome data were also reported in the trials, we pooled the available continuous data as well, and present these as additional forest plots (See Analysis 2.2; Analysis 7.2; Analysis 7.3). There were no important differences between continuous and dichotomous results for any comparison or outcome.

Acupuncture versus other active treatments-The five trials (Xue 2009; Shi 2010; Zeng 2010; Chen 2011; Sun 2011) that compared acupuncture to pharmacological therapies 
for IBS found that participants receiving acupuncture reported a significantly greater improvement in symptom severity than participants receiving pharmacological therapies. Eighty-four per cent of acupuncture patients reported improvement in symptom severity compared to $63 \%$ of patients in the pharmacological treatment group. (RR $1.28,95 \%$ CI 1.12 to $1.45,449$ patients, See Figure 5; Analysis 2.1). The GRADE analysis indicated that the overall quality of the evidence for this outcome was low due to risk of bias (i.e. all studies were not blinded) and sparse data (less than 400 events; See Summary of findings 2). Three studies (190 patients) reported symptom severity as a continuous outcome. Acupuncture patients had significantly lower mean symptom severity scores than patients in the pharmacological treatment group (WMD - 0.72, 95\% CI -1.02 to -0.43; See Analysis 2.2).

Two studies (181 patients) compared acupuncture with probiotics (An 2010; Liu 2010). There was no statistically significant difference in improvement between patients treated with acupuncture and probiotics (Bifidobacterium). Seventy-six per cent of acupuncture patients improved compared to $71 \%$ of probiotic patients (RR 1.07, 95\% CI 0.90 to 1.27 ; See Figure 5; Analysis 3.1). Participants receiving acupuncture were not more likely to have responded to treatment than those treated with psychotherapy (Liu 1997). Eight-four per cent of patients in the acupuncture group improved symptomatically compared to $80 \%$ of patients in the psychotherapy group (RR 1.05, 95\% CI 0.87 to $1.26,100$ patients (See Figure 5; Analysis 4.1).

Acupuncture as an adjuvant to other active treatments-Five trials (Liu 1997; Xiong 2008a; Chen 2009; Li 2009; Liu 2010) compared the combination of adjuvant acupuncture plus another IBS treatment received by all trial participants to the other IBS treatment alone. Patients who received acupuncture and psychotherapy were significantly more likely to have improvements in symptom severity than patients who received psychotherapy alone. Ninety-six per cent of patients in the combined acupuncture and psychotherapy group improved compared to $82 \%$ of patients in the psychotherapy group (RR 1.16, 95\% CI 1.04 to 1.29, 2 studies, 182 patients; See Analysis 5.1). Pooled results (4 studies, 466 patients) showed that participants receiving adjuvant acupuncture were significantly more likely to have reported improvement than those treated with another Chinese medicine treatment alone (although there was substantial heterogeneity of results and high risks of bias in these trials).Ninety-three per cent of patients in the adjuvant acupuncture group reported improvement in symptom severity compared to $79 \%$ of patients who received traditional Chinese medicine alone (RR 1.17, 95\% CI 1.02 to 1.33; See Figure 5; Analysis 6.1).

Acupuncture versus no specific treatment-Two trials (Lembo 2009; Reynolds 2008) compared the effects of acupuncture to no specific treatment. In both trials, all participants were allowed to continue receiving standard medical care for IBS, including any prescribed medications, but control group participants were not assigned to any additional IBS treatment. Both of these trials showed a statistically significant benefit of acupuncture for improving IBS symptom severity, although there was substantial heterogeneity of results between the 2 trials (181 patients). Sixty-three per cent of patients in the acupuncture group reported improvement in IBS symptom severity compared to $34 \%$ of patients in the no treatment group (RR 2.11, 95\% CI 1.18 to 3.79; See Figure 5; Analysis 7.1). At short-term follow-up in a single trial (Lembo 2009), post-treatment quality of life scores showed acupuncture to be associated with significant improvement for the continuous quality of life measure (Analysis 7.3), but not the dichotomous quality of life measure (Analysis 7.4).

Sensitivity analyses-For the sham-controlled trials, sensitivity analyses based on risk of bias or treatment adequacy-related variables would be uninformative because all shamcontrolled trials had similar results and no combination of these trials resulted in a pooled 
statistically significant benefit, for either the symptom severity or quality of life outcome. For the five trials comparing acupuncture versus pharmacological therapies, restriction to the four trials that compared acupuncture versus evidence-based (Ruepert 2011) antispasmodic pharmacological therapies (Shi 2010; Zeng 2010; Chen 2011; Sun 2011) had similar results (RR $1.21,95 \%$ CI 1.07 to $1.37,249$ participants, $I^{2}=0$ ). For the other comparisons, there were too few trials to attempt sensitivity analyses (Deeks 2011).

For the Forbes 2005 trial, which reported both intent-to-treat (ITT) and available case data for the symptom severity outcome, a sensitivity analysis using ITT values instead of the available case values did not result in important differences in the SMDs for this trial. The statistical significance of the pooled results did not change depending on whether the random-effects or fixed-effect analyses were used.

Safety of acupuncture-Nine trials included descriptions of adverse events associated with acupuncture (Forbes 2005; Reynolds 2008; Anastasi 2009; Lembo 2009; An 2010; Liu 2010; Shi 2010; Chen 2011; Sun 2011). For 8 of these 9 trials, no serious adverse events were reported, while the Shi 2010 trial reported that 1 participant in the electro-acupuncture group withdrew because of syncope (see Appendix 4).

\section{DISCUSSION}

\section{Summary of main results}

Five sham-controlled RCTs have tested the effects of acupuncture for treating IBS, and four of these trials used adequate methods for randomization and blinding, and had few withdrawals or dropouts. None of these sham-controlled RCTs found a statistically significant benefit of acupuncture relative to sham acupuncture for the outcomes symptom severity or quality of life. Similarly, pooling the data from these sham-controlled trials did not result in statistically significant benefits of acupuncture for either outcome. Five unblinded Chinese-language comparative effectiveness trials found that patients receiving acupuncture reported greater improvements in IBS symptoms compared to patients receiving pharmacological therapies for IBS.

How should physicians, researchers, and policy-makers interpret these seemingly contradictory trial findings, i.e., that acupuncture had no greater effects than a sham placebo, but acupuncture did show greater effects compared with two pharmacological treatments (pinaverium bromide and trimebutine maleate) that have both previously been shown to be superior to a placebo (Jailwala 2000; Ruepert 2011)? First, both the comparative effectiveness trials and the sham-controlled trials have important limitations that complicate their interpretations. An important limitation of the trials comparing acupuncture to pharmacological therapy is that the patients in these trials are not "blinded" to whether they received acupuncture or drug therapy, and expectation effects (i.e. defined as "the impact of expectations on subjective outcomes" (Flum 2006)), may differ between acupuncture and drug treatment (Kaptchuk 2006; Manheimer 2007;O'Connell 2009). That is, if patients randomized to acupuncture expect greater improvements than patients randomized to drugs, the greater expectations of benefits from acupuncture may contribute to a larger placebo effect (i.e. a larger improvement in symptoms due to an inert treatment, or an inert component of a treatment) in the acupuncture group than in the drug treatment group. Because of the possibility of differential expectations of a benefit from acupuncture versus drugs in these trials (Linde 2007; Manheimer 2007; O'Connell 2009), it cannot be determined whether any of the reported benefits of acupuncture are due to a larger biological effect of acupuncture needling relative to drugs, or rather due entirely to the impact of the trial participants' greater expectations of a benefit of acupuncture, on the subjective outcomes that they reported. 
A limitation of the sham-controlled trial design is that the high placebo effects of sham acupuncture may preclude the detection of any small, true biological benefits of true acupuncture relative to a credible sham acupuncture control, when subjective patient self reports are the outcome measures used. Two "methodological" trials have evaluated the placebo effects of sham acupuncture, on both subjective and objective outcome measures (Kaptchuk 2006; Wechsler 2011).One such methodological trial (Kaptchuk 2006), designed to compare placebo effects of placebo pills and sham acupuncture, found that, relative to placebo pills, sham acupuncture was more credible as an authentic treatment and resulted in higher subjective patient self reports of improvement. This trial also found that the placebo effect was confined to self-reported, subjective outcomes (e.g. pain) and that there was no placebo effect (i.e. no improvement from baseline) for either the placebo acupuncture or placebo pill on the objective outcome that they measured (i.e. grip strength). Another recent methodological trial (Wechsler 2011) compared albuterol (i.e. a proven asthma drug) versus sham acupuncture for asthma patients, and found that while only the albuterol had a biological effect on the objective outcome of airway flow, both the sham acupuncture and albuterol groups had dramatic and comparable improvements from baseline on the subjective outcome of patient self-reports of improvement, such that the albuterol showed no benefit relative to the sham acupuncture on self-reported improvement.

These methodological studies suggest that relying exclusively on subjective patient reports, such as those used as outcomes in IBS trials, may result in a failure to detect small biological effects of an active treatment (i.e. true acupuncture) relative to a highly credible, but physiologically inert, sham acupuncture control. Thus, while the high placebo effects among IBS patients (Spiller 1999) make it difficult to show that any pharmacological treatment is superior to an inert placebo pill, demonstrating such an effect may be even more difficult when the placebo control is sham acupuncture.

\section{Overall completeness and applicability of evidence}

How externally valid are the results of this review? Namely, do the types of interventions investigated in these studies represent current best practice of acupuncture treatment for IBS? Assessing the adequacy of the acupuncture treatment procedure is important because, for instance, basing conclusions about acupuncture efficacy on a suboptimal procedure is "analogous to a pharmaceutical trial formulating conclusions about the efficacy of a drug based on an inadequate dose" (Ezzo 2001).

For the sham-controlled trials, a possible reason for the lack of benefit might be explained by the fact that only the Forbes 2005 trial used individualized acupuncture, in which the acupuncturist tailors the point selection individually to each patient, and which is the typical approach used in everyday acupuncture clinical practice. Among the other four shamcontrolled trials that did not use an individualized approach, two (Anastasi 2009; Lembo 2009) used a "flexible formula" approach, and two (Lowe 2000; Schneider 2006) used a fixed formula approach. With the fixed formula approach, the same acupoints are used for all trial participants. With the flexible formula approach, some acupoints are required for all patients but other acupoints could be selected based on the individual patient's specific constellation of symptoms. In terms of RCT design, an advantage of the flexible formula approach over the entirely individualized approach is that using a flexible formula allows for the results of the RCT to be relatively reproducible and externally valid (Lembo 2009) while at the same time allowing for some discretion of the acupuncturist to individualize point selection. In an RCT setting, this flexible formula approach is also easier to blind than an individualized approach, because individualization requires increased contact between the patient and the acupuncturist, which increases the risk of unblinding. Thus, although four trials did not use individualized acupuncture, the two acupuncturist systematic reviewers who assessed the adequacy of the acupuncture judged that, when reported, the point 
selection, the needling technique, and the experience of the acupuncturists to be adequate in all four of these trials. For the reasons described above, it seems unlikely that the use of a flexible or fixed formula instead of individualized acupuncture in four of the five shamcontrolled trials is the reason for the lack of a benefit.

Alternative explanations for the negative results in these trials might include an inadequate number of treatment sessions, an insufficient duration of treatment, or an inadequate treatment frequency. All sham-controlled trials were judged by our acupuncture adequacy assessors to have used an adequate number of treatment sessions and a sufficient duration of treatment. Only the Forbes 2005 sham-controlled trial was judged to use an inadequate treatment frequency because this trial involved only one acupuncture session per week (for 13 weeks), which even though judged inadequate, probably still well reflects clinical practice in Western countries. The other sham-controlled trials all used two sessions per week, which was judged by the acupuncture adequacy assessors as an adequate treatment frequency, so it seems unlikely that an inadequate frequency of treatments explains the lack of benefit. While one trial (Lembo 2009) did not meet the Rome criteria recommendations for a minimum treatment duration of four weeks (Irvine 2006), the acupuncturist adequacy assessors judged that this trial's three week treatment duration, with twice weekly treatments, was adequate. Although the acupuncture assessors judged the treatment frequency of the sham-controlled trials to be largely adequate, the Chinese language comparative effectiveness trials used a much greater treatment frequency, with daily acupuncture treatments used in 9 out of 11 of these comparative effectiveness trials, and in all five of these trials that compared acupuncture to drug treatment. The higher acupuncture treatment frequency in the Chinese comparative effectiveness trials, relative to the sham controlled trials, might also help explain the different benefits of acupuncture relative to the controls in these two subsets of trials.

\section{Quality of the evidence}

For the sham-controlled trials, the continuous outcomes symptom severity and quality of life were rated as 'moderate' quality using the GRADE criteria because of sparse data (i.e. less than 400 events). This indicates that further research could have an impact on our confidence in the estimates of effect and may change the estimates. Four out of the five sham-controlled trials in this review (Forbes 2005; Schneider 2006; Anastasi 2009; Lembo 2009) did not have limitations related to a risk of bias criterion. Each of these four trials used adequate randomization (which was not reported in the publications but ascertained by contacting the corresponding authors), each adequately addressed incomplete outcome data, and each used a sham control that was likely to adequately blind participants to the treatment received. Only the Lowe 2000 trial used a sham intervention that might not have been sufficiently believable as true acupuncture, such that this sham could adequately blind study participants as to whether they were receiving true acupuncture or a sham. However, if the sham acupuncture group participants realized they were getting a sham treatment, then this unblinding to the treatment received would likely have resulted in an overestimate of the effects of true acupuncture in this trial (Higgins 2011a).

A potential methodological limitation is that two of the five sham-controlled RCTs (Forbes 2005;Anastasi 2009) used a sham control that involved skin penetrating needles inserted at non-acupuncture points, that the acupuncture assessors in our review judged to have potential weak physiological activity that might influence the outcome, and which might therefore have biased these two RCTs to the null. However, we would not expect this to explain the lack of benefit of acupuncture relative to sham, both because these two shams were judged to have potential for only weak physiological activity and also because the other three sham-controlled RCTs (Lowe 2000; Schneider 2006; Lembo 2009) used non- 
penetrating shams that were judged to be unlikely to have physiological effects. These three RCTs also found no benefit of acupuncture relative to sham.

The quality of the evidence is also limited by the fact that all sham controlled trials except the Lembo 2009 study had small sample sizes and were each underpowered to detect a small benefit of the acupuncture protocol evaluated. Although these trials may have been adequately powered to detect a moderate to large benefit of acupuncture relative to sham, an effect size of this magnitude may have been unreasonable to expect, considering that specific $5 \mathrm{HT}_{4}$ agonists (i.e. tegaserod) and $5 \mathrm{HT}_{3}$ antagonists (i.e. alosetron and cilansetron), which are the only treatments with "good quality of evidence" for treating IBS (Brandt 2009) provide only a modest benefit. Although a meta-analysis of the five sham-controlled trials increases the statistical power to detect an effect, a limitation of pooling trials with different acupuncture protocols is that we cannot rule out the possibility that larger trials or meta-analyses focusing on one of these protocols might show a benefit of treatment. In addition, although the meta-analysis point estimates suggest no effect, the $95 \%$ confidence intervals include the possibility that there could be small benefits which could be important to patients. A final limitation of the sham-controlled trial evidence base, related to the small sample sizes, and also the heterogeneity of participants, is that these trials did not restrict eligibility to specific subtypes of IBS patients, and the proportions of patients with different IBS subtypes differed across trials. An individual patient data meta-analysis would be necessary to address whether acupuncture has different effects on different subtypes of IBS patients, although the relatively small numbers of patients would be unlikely to provide a confident answer to this question.

For the Chinese language comparative effectiveness trials the dichotomous outcome symptom severity was rated as 'low' quality using the GRADE criteria because of high risk of bias (e.g. none of the studies were blinded) and sparse data (i.e. less than 400 events). This indicates that further research is likely to have an important impact on our confidence in the estimate of effect and is likely to change the estimate.

In the Chinese language comparative effectiveness trials, in addition to the primary risk of bias associated with the absence of patient blinding, there were also risks of bias associated with the randomization procedure and the follow-up of patients. Notably, for five of these trials (Liu 1997; Chen 2009; Li 2009; Xue 2009; Liu 2010), there were equal sized treatment groups, and during our telephone surveys the trial investigators either stated that some participants were non-randomly assigned to treatment or could not adequately explain how the equal group sizes were achieved. This raises the possibility that the randomization might not have been adequately generated or concealed (Schulz 2002). The notion that randomized trials should have equal numbers in each treatment group has been shown to commonly lead clinical trial investigators to force equality by unscientific means (Schulz 2002). Indeed, previous methodological reviews of this issue have found that over one-half of trials using simple, unrestricted randomization schemes report equal numbers in each group (Adetugbo 2000; Schulz 2002), and $88 \%$ of reported randomized trials have been shown to exclude some randomized participants from their analysis (Adetugbo 2000). The Chinese trials with high risks of bias associated with randomization or the accounting of randomized patients in the outcomes assessments evaluated acupuncture as an adjuvant to either another Chinese medicine treatment or psychotherapy; or compared acupuncture to psychotherapy, probiotics, or a drug not indicated or commonly used for IBS (i.e. sulfasalazine (Xue 2009)). Therefore, the findings from these studies should be considered to be hypothesis generating, and are not included in our overall conclusions. In contrast, there was a lower overall risk of bias in the four comparative effectiveness trials that found acupuncture to be more effective than two antispasmodic pharmacological therapies shown to be effective for IBS (Jailwala 2000; Ruepert 2011) (i.e. pinaverium bromide (Chen 2011; Shi 2010; Sun 2011) and 
Trimebutine maleate (Zeng 2010)). These four studies were rated as high risk of bias due to lack of blinding but were otherwise methodologically sound studies.

\section{Potential biases in the review process}

Potential biases in the review process were avoided by conducting comprehensive searches to identify all relevant studies, conducting dual and independent data extraction, and blinding the acupuncture treatment adequacy assessors to the results of the trials they assessed. In addition, we contacted the corresponding authors of all potentially eligible, claimed "randomized" trials published in Chinese language journals, as well as English language RCTs that did not include details about randomization methods in their published reports, to confirm their authenticity.

\section{Agreements and disagreements with other studies or reviews}

The conclusions of this review have changed from the conclusions of our 2006 Cochrane review (Lim 2006) which is the only other systematic review focused on acupuncture for IBS. While our 2006 Cochrane review found that it is "inconclusive whether acupuncture is more effective than sham acupuncture", the current review concludes that currently available sham-controlled trials suggest that acupuncture is not superior to sham acupuncture for reducing symptom severity or improving quality of life in patients with IBS. Comparative effectiveness Chinese trials have found that patients report greater benefits from acupuncture than from pharmacological therapies. However, the results of the comparative effectiveness studies should be interpreted with caution due to risk of bias (lack of blinding) and expectation effects.

\section{AUTHORS' CONCLUSIONS}

\section{Implications for practice}

People with IBS have few treatment options available. Pharmacological therapies provide modest benefits (Ford 2009a), can have high costs, and some of the newer drugs have been withdrawn from the market because of adverse events (Thompson 2001; Pasricha 2007). Safe, non-pharmacological therapies that may allow patients to feel more empowered and more in control of their symptoms should be evaluated for effectiveness. However, evaluating complex non-pharmacological therapies for IBS (e.g. mindfulness meditation (Gaylord 2011) or hypnotherapy (Lindfors 2012)) poses challenges, particularly in regards to selecting a placebo control or a credible alternative treatment control.

While acupuncture can theoretically be compared with a sham acupuncture "placebo" control, a fundamental challenge has been developing a sham acupuncture control that is sufficiently believable to patients so as to be indistinguishable from true acupuncture, and yet at the same time not so similar to true acupuncture that the sham has a therapeutic effect of its own and is therefore not an inert placebo. The sham acupuncture controls used in four of the five sham-controlled trials in this review appeared to be believable as authentic treatments (Forbes 2005; Schneider 2006; Lembo 2009; Anastasi 2009), but two of the five sham-controlled trials used sham controls that might have had weak physiological activity (Forbes 2005; Anastasi 2009), and therefore these shams may not have been completely inert placebos. While none of the sham-controlled trials showed a benefit of acupuncture relative to sham acupuncture, it is still not clear whether these findings are because acupuncture has no true biological effect above and beyond a placebo; or whether instead acupuncture has small biological effects, but the small sample sizes and heterogeneity of participants and interventions in these trials precluded detecting a statistically significant pooled benefit of acupuncture over sham; or whether any biological effects of true acupuncture cannot be detected because they are overridden and obscured by the large 
placebo effects of the sham control (Kaptchuk 2006; Wechsler 2011). Evidence from four Chinese language comparative effectiveness trials (Shi 2010; Zeng 2010; Chen 2011; Sun 2011) showed acupuncture to be superior to two antispasmodic drugs (pinaverium bromide and trimebutine maleate), both of which have consistently been shown to provide a modest benefit in high quality trials (Jailwala 2000; Ruepert 2011), although neither is approved for treatment of IBS in the United States (Jailwala 2000). Patient preferences and expectations may partly explain the positive findings of these trials comparing acupuncture to drug treatment. That is, if the trial participants had pretreatment preferences for acupuncture over drugs, these preferences may have influenced the participants' later assessments of their subjective states, as reported on the patient- reported outcome measures used (Kalauokalani 2001; Linde 2007; Manheimer 2007; O'Connell 2009).

In addition to efficacy, safety and costs are other considerations. Safety is best determined with large prospective surveys of practitioners and three such surveys (MacPherson 2001; White 2001; Melchart 2004) show that serious adverse events after acupuncture are rare. There was one adverse event associated with acupuncture in the nine trials that reported this outcome (Forbes 2005; Reynolds 2008; Anastasi 2009; Chen 2009; Lembo 2009; An 2010; Liu 2010; Shi 2010; Sun 2011), although relatively small sample sizes limit the usefulness of these safety data. Finally, patients would also need to consider costs because acupuncture treatment often needs to be paid for out of pocket.

\section{Implications for research}

Considering that our meta-analysis found no differences between acupuncture and sham, and also considering that there are limited resources available to conduct trials of acupuncture, a non-proprietary therapy, additional sham-controlled trials of acupuncture among IBS patients should not be a high priority in acupuncture research, at least until the large, ongoing sham-controlled trial, which is expected to complete data collection in March 2013 , is published (Anastasi). This trial $(n=171)$ (Anastasi) compares a sham control with two different acupuncture test treatment groups, one test group using a fixed formula and the other test group using an individualized treatment approach, for patients with diarrheapredominant IBS (See Characteristics of ongoing studies). If this trial shows no benefit of acupuncture relative to the sham, then the need for additional sham-controlled trials would seem questionable. However, if this ongoing sham-controlled trial shows a benefit, then it would certainly be warranted to conduct future sham-controlled trials building upon the results of this trial (e.g. restriction to diarrhea predominant IBS patients; using the same acupoints as used in this trial). Such future sham-controlled trials should use nonpenetrating, but demonstrably credible, shams to control for placebo effects, and ideally these sham needles should be placed far away from the true acupuncture points.

Because of the difficulties of controlling for placebo effects in acupuncture for IBS trials, which typically evaluate strictly subjective, patient-reported outcomes (e.g. symptom severity, quality of life), another approach forward for research is the evaluation of objective or semi-objective outcomes in IBS patients, using pragmatic and cost-effectiveness trials. Indeed, a recently completed trial $(\mathrm{n}=220)$ (Principal Investigator: MacPherson) compared the effectiveness and cost-effectiveness of acupuncture plus usual general practitioner (GP) care versus usual GP care alone, on the semi-objective outcomes of medication use, health service use, and days lost from work (MacPherson 2010). Although this trial does not include a placebo control, because the outcome measures being assessed in this trial are semi-objective, its results will be less influenced by expectation effects (Wood 2008; Hrobjartsson 2010; Manheimer 2011), than trials that assess only strictly subjective outcomes (i.e., patient reports of symptom improvement). Indeed, the Rome criteria for design of IBS treatment trials note that placebo effects "are especially a problem where end points are subjective" (Irvine 2006). If this recently completed cost-effectiveness trial shows 
that acupuncture reduces healthcare utilization, then whether the resulting cost-savings are due to a specific effect of acupuncture needling or non-specific effects (e.g. greater autonomy and empowerment of patients, positive patient-practitioner relationship) seems of secondary importance. However, it must be borne in mind that the patient population who elected to participate in this acupuncture trial may have stronger a priori beliefs about the benefits of acupuncture, than does the average population of IBS patients, and therefore, the non-specific effects experienced by the patients in this unblinded trial may not be generalizable to the results that would be obtained among an average population of IBS patients. However, the results of this trial may be generalizable to the subset of IBS patients in general practice who would elect to receive acupuncture because such patients may also have a priori expectations for acupuncture to be beneficial. To produce results generalizable to the average population of IBS patients, investigators of future pragmatic trials might minimize the recruitment of participants with an a priori preference for acupuncture by not specifying, in the recruitment of patients, that acupuncture is one of the treatment options being investigated.

Future comparative effectiveness trials would also be helpful to validate and extend the preliminary evidence in this review, which suggests that acupuncture is associated with greater improvements in subjective patient self-assessments than pharmacological therapies. As previously mentioned, a limitation of the acupuncture versus pharmacological therapy trials in this review is that they did not use a design that controlled for the effects of patients' expectations for improvement, patient preferences, and non-specific therapeutic factors. Indeed, in the Chinese trials included in this review, the patients may well have had pretreatment preferences for acupuncture, considering that these trials were conducted at hospitals of traditional Chinese medicine. Because acupuncture may elicit a greater expectation effect than pharmacological therapies or other active treatments (Kaptchuk 2006; Manheimer 2007; O'Connell 2009), particularly among participants who have a preference for acupuncture, investigators conducting future trials that compare acupuncture with other active therapies should consider asking participants about their preferences and expectations (before and after the intervention), and studying the potential effects of pretreatment preferences on study outcomes. Such trials should also include a credibility questionnaire to establish that the treatments being compared are perceived by the patients as equally credible treatments for IBS symptoms (Gaylord 2011). Future comparative effectiveness trials in the West should also consider using a daily frequency of acupuncture, as was used in the Chinese trials in this review. However, even with additional welldesigned trials, the truth about the effects of acupuncture for IBS will likely always be difficult to assess because the complexities and potential biases inherent to both the comparative effectiveness and sham acupuncture control designs makes it difficult to evaluate the subjective, patient-reported outcomes typically used in IBS trials.

\section{Supplementary Material}

Refer to Web version on PubMed Central for supplementary material.

\section{Acknowledgments}

Brian Berman, Lixing Lao, Eric Manheimer, and L. Susan Wieland were partially funded by Grant Number R24 AT001293 from the National Center for Complementary and Alternative Medicine (NCCAM) of the US National Institutes of Health. Brian Berman and Lixing Lao were also partially funded by NIH Grant Number 1 U19 AT003266. The contents of this article are solely the responsibility of the authors and do not necessarily represent the official views of the NCCAM, or the National Institutes of Health.

Xueyong Shen and Ke Cheng were funded by the National Basic Research Program of China (973 Program, 2009CB522901, 2012CB518502), Key Program of Shanghai and State Administration of TCM of China (S30304), 
Science Foundation of Shanghai Municipal Commission of Science and Technology (09DZ1976600, 09DZ1974303, 10DZ1975800), and Shanghai Leading Academic Discipline Project (T0302 and B112).

Funding for the IBD/FBD Review Group (September 1, 2010 - August 31, 2015) has been provided by the Canadian Institutes of Health Research (CIHR) Knowledge Translation Branch (CON - 105529) and the CIHR Institutes of Nutrition, Metabolism and Diabetes (INMD); and Infection and Immunity (III) and the Ontario Ministry of Health and Long Term Care (HLTC3968FL-2010-2235).

Miss Ila Stewart has provided support for the IBD/FBD Review Group through the Olive Stewart Fund.

\section{SOURCES OF SUPPORT}

Internal sources

- $\quad$ No sources of support supplied

External sources

- $\quad$ NIH National Center for Complementary and Alternative Medicine, R24 AT001293, USA.

- NIH National Center for Complementary and Alternative Medicine, 1U19AT003266-01, USA.

\section{REFERENCES}

* Indicates the major publication for the study

\section{References to studies included in this review}

An G, Li N, Zhai G, Liu H, Sun J, Liang H, et al. Evaluation of the therapeutic effect of acupuncture and moxibustion on irritable bowel syndrome. Shanghai Journal of Acupuncture and Moxibustion. 2010; 29(6):354-356.

Anastasi JK, McMahon DJ, Kim GH. Symptom management for irritable bowel syndrome: a pilot randomized controlled trial of acupuncture/moxibustion. Gastroenterology Nursing. 2009; 32(4): 243-255. [PUBMED: 19696601]. [PubMed: 19696601]

Chen, Y. Master's thesis of Guangzhou University of Traditional Chinese Medicine. 2006. Clinical reseach on treating irritable bowel syndrome mainly by acupuncture with warmed needles at Tiansh (ST25) and Dangchangshu (BL25).

*. Chen Y, Lai X. Clinical observation on combined warming needle and patented Chinese medicine for irritable bowel syndrome. Journal of Acupuncture and Tuina Science. 2009; (7):274-277.

Chen, Q. Master's thesis of Guangzhou University of Traditional Chinese Medicine. 2011. Clinical study on irritable bowel syndrome of diarrhea type with Chang-three-needle technique].

Forbes A, Jackson S, Walter C, Quraishi S, Jacyna M, Pitcher M. Acupuncture for irritable bowel syndrome: a blinded placebo-controlled trial. World Journal of Gastroenterology. 2005; 11(26): 4040-4044. [PUBMED: 15996029]. [PubMed: 15996029]

Lembo AJ, Conboy L, Kelley JM, Schnyer RS, McManus CA, Quilty MT, et al. A treatment trial of acupuncture in IBS patients. American Journal of Gastroenterology. 2009; 104(6):1489-1497. [PUBMED: 19455132]. [PubMed: 19455132]

$\mathrm{Li}$ W. Treatment of warming needle moxibustion combined with spinal manipulation on irritable bowel syndrome. China Practical Medicine. 2009; 4(31):212-213.

Liu G. Treatment of acupuncture and moxibustion plus psychotherapy for irritable bowel syndrome. Chinese Acupuncture and Moxibustion. 1997; (10):611-612.

*. Liu Q, Wang Z, Zhang W, Zhang X. Clinical observation on Geshanxiaoyao Decoction combining acupuncture effect on the life quality of patients with irritable bowel syndrome. Journal of Zhejiang University of Traditional Chinese Medicine. 2010; 34(4):510-511. 513.

Wang Z, Liu Q, Zhang X, Wang Y, Su X. Clinical observation of “Geshan Xiaoyao Decoction” plus acupuncture in treating diarrhea-predominant irritable bowel syndrome. Shanghai Journal of Traditional Chinese Medicine. 2010; 44(3):41-43. 
Wang Z, Liu Q, Zhang X, Zhang W. Geshanxiaoyao Decoction combining with acupuncture on 150 patients with diarrhea-predominant irritable bowel syndrome. Liaoning Journal of Traditional Chinese Medicine. 2010; 37(2):276-277.

Lowe C, Depew W, Vanner S. A placebo-controlled, double-blind trial of acupuncture in the treatment of irritable bowel syndrome (IBS). Gastroenterology. 2000; 118(4 Suppl 2):A3168.

Reynolds JA, Bland JM, MacPherson H. Acupuncture for irritable bowel syndrome - an exploratory randomised controlled trial. Acupuncture in Medicine. 2008; 26(1):8-16. [PUBMED: 18356794]. [PubMed: 18356794]

Schneider A, Enck P, Streitberger K, Joos S, Weiland C, Bagheri S, et al. Specific physiological and unspecific psychological effects during acupuncture treatment in patients with irritable bowel syndrome: Results of a randomised controlled trial. Deutsche Zeitschrift fur Akupunktur. 2008; 51(1):8-16. [EMBASE: 2008174159].

Schneider A, Enck P, Streitberger K, Joos S, Weiland C, Bagheri S, et al. Specific physiological and unspecific psychological effects during acupuncture treatment in patients with irritable bowel syndrome: Results of a randomised controlled trial. Revista Internacional de Acupuntura. 2008; 2(3):146-154. [EMBASE: 2009165775].

*. Schneider A, Enck P, Streitberger K, Weiland C, Bagheri S, Witte S, et al. Acupuncture treatment in irritable bowel syndrome. Gut. 2006; 55(5):649-654. [PUBMED: 16150852]. [PubMed: 16150852]

Shi X, Luo J, Tan T. Clinical observation of electro-acupuncture on diarrhea-predominant irritable bowel syndrome. Journal of New Chinese Medicine. 2010; 42(5):72-74.

Sun JH, Wu XL, Xia C, Xu LZ, Pei LX, Li H, et al. Clinical evaluation of soothing Gan and Inbigorating $\mathrm{Pi}$ acupuncture treatment on dfiarrhea-predominant irritable bowel syndrome. Chinese Journal of Integrative Medicine. 2011; 17(10):780-785. [PubMed: 22101701]

Xiong X, Lin Y. Acupuncture plus traditional Chinese herb medicine in treating 42 patients with diarrhea-predominant IBS. Journal of Fujian University of TCM. 2008; 18(2):38-40.

Xue Y, Tian X. The clinical research of the relationship between radicals and irritable bowel syndrome and the effect of acupuncture. Chinese Archives of Traditional Chinese Medicine. 2009; 27(1): 111-112.

Zeng Y, Bao Y, Chu J, Li H, Zhu G, Zhang W. Effect of moxibustion on diarrhea-dominant irritable bowel syndrome patients in dog days. Chinese Archives of Traditional Chinese Medicine. 2010; 28(8):1774-1776.

Chan J, Carr I, Mayberry JF. The role of acupuncture in the treatment of irritable bowel syndrome: a pilot study. Hepatogastroenterology. 1997; 44(17):1328-1330. [PubMed: 9356848]

Chen, R. Master's thesis of Guangzhou University of Traditional Chinese Medicine. 2005. Clinical study on the electro-acupuncture combined with ear-acupuncture treatment of irritable bowel syndrome.

Chu WCW. Effect of electroacupuncture in patients with irritable bowel syndrome [Official title: A pilot study on the effect of electroacupuncture on functional brain mapping in patients with irritable bowel syndrome]. 2009 ClinicalTrials.gov Identifier: NCT00900965.

Ding S, Li D. Clinical study on acupuncture mainly at BL57 in treating 54 patients of irritable bowel syndrome. Journal of Clinical Acupuncture and Moxibustion. 2004; 20(5):53.

Fireman Z, Segal A, Kopelman Y, Sternberg A, Carasso R. Acupuncture treatment for irritable bowel syndrome. A double-blind controlled study. Digestion. 2001; 64(2):100-103. [PubMed: 11684823]

Fu H, Cai G. Clinical study on acupuncture based upon differentiation of symptoms and signs in treating 40 patients of IBS. Chinese Acupuncture and Moxibustion. 1993; 13(3):1-2.

Gabuzian KS, Sarkisian KA, Grigorian NL, Azatian ZG. Long-term results in the treatment of patients with irritable bowel syndrome. Klinicheskaia Meditsina. 1994; 72(1):47-48. [PubMed: 7910871]

*. Guo G, Bao H, Zhang Y. Clinical observation of warming needle moxibustion for diarrheapredominant irritable bowel syndrome. Modern Journal of Integrated Traditional Chinese and Western Medicine. 2010 Jun; 19(16):1998-1999. 
Guo G, Zhong J, Wang Y, Liu Y. Clinical observation of acupuncture for 50 patients with diarrheapredominant irritable bowel syndrome. Hebei Journal of Traditional Chinese Medicine. 2010; 32(4):564-565.

Hou B, Shi Z. Discussion of the therapeutic effect of western medicine association with Zi-Wu Dao-jiu needling Tianshu and Dachangshu on irritable bowel syndrome. Heibei Medicine. 2011; 17(9): 1169-1172.

Huang Z, He X, Zhang G, Huang J. Clinical observation of single and integrated treatment for 73 patients with irritable bowel syndrome. Academic Journal of Guangzhou Medical College. 1999; 27(4):67-69.

Huang Z, Liang L, Zhang W. Acupuncture combined with massage for treatment of irritable bowel syndrome. Chinese Acupuncture and Moxibustion. 2006; 26(10):717-718. [PubMed: 17117571]

Kang H, Li M. Auricular-plaster therapy for 54 patients with irritable bowel syndrome. Journal of Emergency in Traditional Chinese Medicine. 2006; 15(6):591.

Kunze M, Seidel HJ, Stube G. Comparative studies of the effectiveness of brief psychotherapy, acupuncture and papaverin therapy in patients with irritable bowel syndrome [Vergleichede Untersuchungen zur Effektivitat der kleinen Psychotherapie, der Akupunktur und der Papaverintherapie bei Patienten mit Colon irritabile. Zeitschrift für die gesamte innere Medizin und ihre Grenzgebiete. 1990; 45(20):625-627. [PubMed: 2099583]

Li H, Zhang Z, Chen S. Acupuncture plus ear-acupressure treatment for 30 patients of IBS. Guangxi Journal of Traditional Chinese Medicine. 2005; 28(3):35.

Li B, Yang L, Feng Y. Curative effect of acupuncture on diarrheogenic irritable bowel syndrome. Journal of Beijing University of Traditional Chinese Medicine. 2007; 14(6):19-21.

Liao YC. Acupuncture treatment for 132 cases of irritable bowel syndrome. Clinical Journal of Acupuncture and Moxibustion. 2000; 16(6):13-14.

Liu M, Teng S. Clinical report of ear acupuncture treatment for functional gastric disorder. Shanghai Journal of Acupuncture and Moxibustion. 1995; 14(6):247-248.

Long Z, Yu C, Yu Y, Wang H, Chi X. Clinical observation on acupuncture combined with microorganism pharmaceutical preparations for treatment of 90 irritable bowel syndrome of constipation type. Chinese Acupuncture and Moxibustion. 2006; 26(6):403-405. [PubMed: 16813181]

Ma Y, Yin F. Warming needle moxibustion plus acupoint injection for 61 patients with irritable bowel syndrome. China's Naturopathy. 2009; 17(9):22-23.

Ouyang Q. Clinical observation of ear-acupressure combined with pinaverium bromide in treating 39 patients with irritable bowel syndrome. New Journal of Traditional Chinese Medicine. 2003; 35(9):39-40.

Ouyangm A. Effect of acupuncture on symptoms of diarrhea and pain in IBS [Official Title: Effect of acupuncture on symptoms of diarrhea and pain in diarrhea predominant irritable bowel syndrome (IBS) and effect on plasma beta-endorphin and serotonin levels]. 2006 ClinicalTrials.gov Identifier: NCT00219505.

Qian H, Zhu Y, Meng S, Qi G, Zhao X. Acupuncture treatment of diarrhea-predominant irritable bowel syndrome: a randomized controlled trial. World Chinese Journal of Digestology. 2011; 19(3):257-261.

Shi Z, Lei M, Zhu Y, Wang Q. Curative effect on 20 patients with irritable bowel syndrome by the Son Noon Dao Jiu method of Tianshu and Dachangshu. Hebei Journal of Traditional Chinese Medicine. 2010; 32(10):1527-1528.

Shi Z, Zhu Y, Wang Q, Lei M. Comparative study on irritable bowel syndrome treated with acupuncture and western medicine. Chinese Acupuncture and Moxibustion. 2011; 31(7):607-609. [PubMed: 21823282]

Shi Z, Zhu Y, Wang Q, Lei M. Curative effect on irritable bowel syndrome by the Son Noon Dao Jiu method of Tianshu and Dachangshu. Liaoning Journal of Traditional Chinese Medicine. 2011; 38(4):720-721.

Song, J. Clinical observation of warming needle moxibustion on irritable bowel syndrome; The 3rd Congress of Clinical branch of China Association of Acupuncture-Moxibustion and Symposium of Chinese Clinical Acupuncture-Moxibustion; 2005. 
Song B, Qi H, Ling J. Ear-acupressure combined with otilonium bromide for diarrhea-predominant irritable bowel syndrome. Chinese Journal of Ethnomedicine and Ethnopharmacy. 2011; (12):89.

Sun D. Senlin Baizhu San plus Tongxie Yaofang combined with acupuncture for 57 patients with irritable bowel syndrome. Practical Clinical Journal of Integrated Traditional Chinese and Western Medicine. 2009; 9(3):36-37.

Wang F. Analysis of the treatment efficacy of moxibustion with warming needle combined with TCM rectal irrigation treatment in irritable bowel treatment. TCM Clinical Magazine of An Hui. 2002; 14(3):187.

Wang Y, Li Y. Acupuncture plus moxibustion treatment for 35 patients of IBS. Shanghai Journal of Acupuncture and Moxibustion. 2007; 26(9):30.

Wang W, Bai L, Gao Z, Lv E. Clinical study on acupuncture at ST25 and ST37 in treating diarrheapredominant irritable bowel syndrome. Chinese Journal of Misdiagnostics. 2008; 8(26):63356336.

Wang W. Clinical study on warming acupuncture in treating diarrhea-predominant irritable bowel syndrome. Journal of Emergency in Traditional Chinese Medicine. 2008; 17(10):1377-1407.

Wang, Yuhai. Clinical observation on Xuan Shi silver needle acupuncture for irritable bowel syndrome. Journal of Huaihai Medicine. 2009; 27(3):234.

Wang, Pengqin; Chen, Suning; Liu, Yuedong; Chen, Xiaoyang; Wang, Jian. Randomized controlled study on the eye-acupuncture for diarrhea-predominant irritable bowel syndrome. Journal of Traditional Chinese Medicine. 2011; 52(14):1203-1206.

$\mathrm{Wu}$ X. Clinical observation on combination of warm acupuncture and ear pressing for the treatment of 46 cases of irritable bowel syndrome. Hunan Guiding Journal of TCM. 2004; 10(3):42-43.

Wu H, Liu H, Wang X, Guan Y, Zuo C, Tan L, et al. The research of effectivity and cerebral function change on the treatment of irritable bowel syndrome (D-IBS) with electroacupuncture on Tianshu (ST 25)]. The 20th Anniversary of Foundation of World Federation of Acupuncture-Moxibustion Societies (WFAS) and International Acupuncture Congress. 2008; Vol. March 4:486-487.

Xiao, Futang; Cheng, Jihua; Wang, Manhua; Li, Qingyun. Clinical observation Chinese and Western integrative medicine for irritable bowel syndrome. Chinese Journal of Gastroenterololy. 2003; 8(Suppl 1):A22.

Xiao WB, Liu YL. Rectal hypersensitivity reduced by acupoint TENS in patients with diarrheapredominant irritable bowel syndrome: a pilot study. Digestive Diseases and Sciences. 2004; 49(2):312-319. [PubMed: 15104377]

Xiong J. The treatment of acupuncture combined with Chinese medicine for 30 patients with irritable bowel syndrome. Shaanxi Journal of Traditional Chinese Medicine. 2008; 29(11):1527-1528.

Xu M, Xiao X, Zhu H. Clinical observation of acupuncture plus heat-sensitive moxibustion in treating of irritable bowel syndrome. Research of Integrated Traditional Chinese and Western Medicine. 2009; 1(4):212-213.

Yang XY. Gastrointestinal dysfunction treated by therapy of acupuncture combined tuina. Journal of Chengdu University of TCM. 2000; 23(1):35.

Yu Y, Li G, Liu D. Clinical study on acupuncture plus Chang Ling capsule treatment on IBS. Journal of Experimental Traditional Medical Formulae. 2007; 13(5):48.

Yu B, Peng Y. Ear-acupressure combined with modified Tongxie Yaofang in treating 20 patients with irritable bowel syndrome. Hunan Journal of Traditional Chinese Medicine. 2011; 27(4):21-22.

Zhang W, Liu Y. Tapping acupuncture on paravertebral point in treating 68 patients of irritable bowel syndrome. Journal of Jiamusi Medical College (former name), Heilongjiang Medicine and Pharmacy (present name). 1997; 20(2):87-88.

Zhang W, Meng Q, Yu Y. Tapping acupuncture on paravertebral point in treating 68 patients of irritable bowel syndrome. Chinese Acupuncture and Moxibustion. 1996; 16(7):4.

Zhang L. Clinical study of acupuncture on Jiaji acupoints in treating 86 patients of irritable bowel syndrome. Journal of Practical Traditional Chinese Medicine. 2000; 16(7):31.

Zhang J. Acupuncture treatment for irritable bowel syndrome. Chinese Journal of Ethinomedicine and Ethnopharmacy. 2010; 19(11):117. 
Zhang Y, Sun Z, Yang S. Clinical investigation on Yu Shi scalp acupuncture for diarrhea-predominant IBS plus syndrome of liver depression and spleen deficiency. Chinese Journal of Traditional Medical Science and Technology. 2011; 18(3):231.

Zhang H, Han S, Tang J. Scalp acupuncture for 50 patients with diarrhea-predominant IBS. Chinese Acupuncture and Moxibustion. 2011; 31(7):605-606. [PubMed: 21823281]

Zhao S, Shi Z, Wu H, Liu H, Hua X, Yuan L. Clinical observation of tonifying spleen and stomach by moxibustion for 72 patients with irritable bowel syndrome. The 10th Anniversary of the Establishment of Sisters Association of China Association of Acupuncture-Moxibustion and Korean Acupuncture-Moxibustion Association and Live Demonstration of New Techniques and Therapies of Acupuncture and Symposium of Acupuncture for Incurable Diseases. 2003 Apr. 11:38-42.

Zheng C, Zhang W, Xiao B. Clinical study on Bifidobacterium capsule plus acupuncture in treating irritable bowel syndrome. Chinese Journal of Celiopathy. 2003; 3(3):206-207.

\section{References to ongoing studies}

Anastasi, JK. Acupuncture/Moxibustion for Irritable Bowel Syndrome (IBS). http:// www.clinicaltrials.gov/ct2/show/NCT00945074?term=acupuncture+AND+irritable+bowel + syndrome\&rank=1 ongoing trial

MacPherson H. Acupuncture for irritable bowel syndrome (IBS): a randomised controlled trial to evaluate effectiveness and cost-effectiveness. http://www.controlled-trials.com/ ISRCTN08827905 ongoing trial.

MacPherson H, Bland M, Bloor K, Cox H, Geddes D, Kang'ombe A, et al. Acupuncture for irritable bowel syndrome: a protocol for a pragmatic randomised controlled trial. BMC gastroenterology. 2010; 10:63. [PUBMED: 20565790]. [PubMed: 20565790]

\section{Additional references}

Adetugbo K, Williams H. How well are randomized controlled trials reported in the dermatology literature? Archives of Dermatology. 2000; 136(3):381-385. [PubMed: 10724201]

Bijkerk CJ, de Wit NJ, Muris JW, Jones RH, Knottnerus JA, Hoes AW. Outcome measures in irritable bowel syndrome: comparison of psychometric and methodological characteristics. American Journal of Gastroenterology. 2003; 98(1):122-127. [PUBMED: 12526947]. [PubMed: 12526947]

Brandt LJ, Chey WD, Foxx-Orenstein AE, Schiller LR, Schoenfeld PS, Spiegel BM, et al. An evidence-based position statement on the management of irritable bowel syndrome. American Journal of Gastroenterology. 2009; 104(Suppl 1):S1-S35. [PUBMED: 19521341]. [PubMed: 19521341]

Brenner DM, Moeller MJ, Chey WD, Schoenfeld PS. The utility of probiotics in the treatment of irritable bowel syndrome: a systematic review. American Journal of Gastroenterology. 2009; 104(4):1033-1049. quiz 1050. [PUBMED: 19277023]. [PubMed: 19277023]

Chassany O, Marquis P, Scherrer B, Read NW, Finger T, Bergmann JF, et al. Validation of a specific quality of life questionnaire for functional digestive disorders. Gut. 1999; 44(4):527-533. [PUBMED: 10075960]. [PubMed: 10075960]

Chapter 9: Analysing data and undertaking meta-analyses. In: Deeks, JJ.; Higgins, JPT.; Altman, DG., editors; Higgins, JPT.; Green, S., editors. Cochrane Handbook for Systematic Reviews of Interventions. Chichester (UK): John Wiley \& Sons; 2011.

Drossman, DA.; Richter, JE.; Talley, NJ., editors. The functional gastrointestinal disorders, pathophysiology, and treatment: a multinational consensus. Boston: Little Brown; 1994

El-Serag HB, Olden K, Bjorkman D. Health-related quality of life among persons with irritable bowel syndrome: a systematic review. Alimentary Pharmacology and Therapeutics. 2002; 16(6):11711185. [PubMed: 12030961]

Everhart, JE. The burden of digestive diseases in the United States. NIH Publication No 09-6443. Washington, DC: US Government Printing Office: US Department of Health and Human Services, Public Health Service, National Institutes of Health, National Institute of Diabetes and Digestive and Kidney Diseases; 2008. p. 142 
Ezzo, J.; Lao, L.; Berman, BM. Assessing clinical efficacy of acupuncture: what has been learned from systematic reviews of acupuncture?. In: Stux, G.; Hammerschlag, R., editors. Clinical acupuncture: scientific basis. New York: Springer; 2001. p. 113-130.

Ezzo J, Vickers A, Richardson MA, Allen C, Dibble SL, Issell B, et al. Acupuncture-point stimulation for chemotherapy-induced nausea and vomiting. Journal of Clinical Oncology. 2005; 23(28): 7188-7198. [PUBMED: 16192603]. [PubMed: 16192603]

Flum DR. Interpreting surgical trials with subjective outcomes: avoiding UnSPORTsmanlike conduct. JAMA. 2006; 296(20):2483-2485. [PubMed: 17119146]

Ford AC, Talley NJ, Schoenfeld PS, Quigley EM, Moayyedi P. Efficacy of antidepressants and psychological therapies in irritable bowel syndrome: systematic review and meta-analysis. Gut. 2009; 58(3):367-378. [PubMed: 19001059]

Ford AC, Brandt LJ, Young C, Chey WD, Foxx-Orenstein AE, Moayyedi P. Efficacy of 5-HT3 antagonists and 5-HT4 agonists in irritable bowel syndrome: systematic review and meta-analysis. American Journal of Gastroenterology. 2009; 104(7):1831-1843. quiz 1844. [PubMed: 19471254]

Francis CY, Morris J, Whorwell PJ. The irritable bowel severity scoring system: a simple method of monitoring irritable bowel syndrome and its progress. Alimentary Pharmacology and Therapeutics. 1997; 11(2):395-402. [PUBMED: 9146781]. [PubMed: 9146781]

Furlan AD, van Tulder MW, Cherkin DC, Tsukayama H, Lao L, Koes BW, et al. Acupuncture and dry-needling for low back pain. Cochrane Database of Systematic Reviews. 2005; (Issue 1) [DOI: 10.1002/14651858.CD001351.pub2].

Gaylord SA, Palsson OS, Garland EL, Faurot KR, Coble RS, Mann JD, et al. Mindfulness training reduces the severity of irritable bowel syndrome in women: results of a randomized controlled trial. American Journal of Gastroenterology. 2011; 106(9):1678-1688. [PUBMED: 21691341]. [PubMed: 21691341]

Groll D, Vanner SJ, Depew WT, DaCosta LR, Simon JB, Groll A, et al. The IBS-36: a new quality of life measure for irritable bowel syndrome. American Journal of Gastroenterology. 2002; 97(4): 962-971. [PUBMED: 12003433]. [PubMed: 12003433]

Guyatt GH, Oxman AD, Vist GE, Kunz R, Falck-Ytter Y, Alonso-Coello P, et al. GRADE: an emerging consensus on rating quality of evidence and strength of recommendations. BMJ. 2008; 336(7650):924-926. [PubMed: 18436948]

Heaton KW, Ghosh S, Braddon FE. How bad are the symptoms and bowel dysfunction of patients with the irritable bowel syndrome? A prospective, controlled study with emphasis on stool form. Gut. 1991; 32(1):73-79. [PUBMED: 1991641]. [PubMed: 1991641]

Higgins JPT, Thompson SG, Deeks JJ, Altman DG. Measuring inconsistency in meta-analysis. BMJ. 2003; 327:557-560. [PubMed: 12958120]

Chapter 8: Assessing risk of bias in included studies. In: Higgins, JPT.; Altman, DG., editors; Higgins, JPT.; Green, S., editors. Cochrane Handbook for Systematic Reviews of Interventions. Chichester (UK): John Wiley \& Sons; 2011.

Chapter 16: Special topics in statistics. In: Higgins, JPT.; Deeks, JJ.; Altman, DG., editors; Higgins, JPT.; Green, S., editors. Cochrane Handbook for Systematic Reviews of Interventions. Chichester (UK): John Wiley \& Sons; 2011.

Hrobjartsson A, Gotzsche PC. Placebo interventions for all clinical conditions. Cochrane Database of Systematic Reviews. 2010; (Issue 1) [DOI: 10.1002/ 14651858.CD003974.pub3].

Irvine EJ, Whitehead WE, Chey WD, Matsueda K, Shaw M, Talley NJ, et al. Design of treatment trials for functional gastrointestinal disorders. Gastroenterology. 2006; 130(5):1538-1551. [PUBMED: 16678567]. [PubMed: 16678567]

Jailwala J, Imperiale TF, Kroenke K. Pharmacologic treatment of the irritable bowel syndrome: a systematic review of randomized, controlled trials. Annals of Internal Medicine. 2000; 133(2): 136-147. [PubMed: 10896640]

Johnson JA, Coons SJ. Comparison of the EQ-5D and SF-12 in an adult US sample. Quality of Life Research. 1998; 7(2):155-166. [PUBMED: 9523497]. [PubMed: 9523497]

Kalauokalani D, Cherkin DC, Sherman KJ, Koepsell TD, Deyo RA. Lessons from a trial of acupuncture and massage for low back pain: patient expectations and treatment effects. Spine. 2001; 26(13):1418-1424. [PubMed: 11458142] 
Kaptchuk TJ, Stason WB, Davis RB, Legedza AR, Schnyer RN, Kerr CE, et al. Sham device v inert pill: randomised controlled trial of two placebo treatments. BMJ. 2006; 332(7538):391-397. [PubMed: 16452103]

Kleinhenz J, Streitberger K, Windeler J, Güssbacher A, Mavridis G, Martin E. Randomised clinical trial comparing the effects of acupuncture and a newly designed placebo needle in rotator cuff tendinitis. Pain. 1999; 83(2):235-241. [PUBMED: 10534595]. [PubMed: 10534595]

Lim B, Manheimer E, Lao L, Ziea E, Wisniewski J, Liu J, et al. Acupuncture for treatment of irritable bowel syndrome. Cochrane Database of Systematic Reviews. 2006; (Issue 4) [DOI: 10.1002/14651858.CD005111.pub2].

Linde K, Witt CM, Streng A, Weidenhammer W, Wagenpfeil S, Brinkhaus B, et al. The impact of patient expectations on outcomes in four randomized controlled trials of acupuncture in patients with chronic pain. Pain. 2007; 128(3):264-271. [PubMed: 17257756]

Lindfors P, Unge P, Arvidsson P, Nyhlin H, Bjornsson E, Abrahamsson H, et al. Effects of gutdirected hypnotherapy on IBS in different clinical settings-results from two randomized, controlled trials. American Journal of Gastroenterology. 2012; 107(2):276-285. [PubMed: 21971535]

Longstreth GF, Wilson A, Knight K, Wong J, Chiou CF, Barghout V, et al. Irritable bowel syndrome, health care use costs: a U.S. managed care perspective. American Journal of Gastroenterology. 2003; 98(3):600-607. [PUBMED: 12650794]. [PubMed: 12650794]

Longstreth GF, Thompson WG, Chey WD, Houghton LA, Mearin F, Spiller RC. Functional bowel disorders. Gastroenterology. 2006; 130(5):1480-1491. [PUBMED: 16678561]. [PubMed: 16678561]

MacPherson H, White A, Cummings M, Jobst K, Rose K, Niemtzow R. Standards for reporting interventions in controlled trials of acupuncture: the STRICTA recommendations. Complementary Therapies in Medicine. 2001; 9(4):246-249. [PubMed: 12184354]

MacPherson H, Altman DG, Hammerschlag R, Youping L, Taixiang W, White A, et al. Revised STandards for Reporting Interventions in Clinical Trials of Acupuncture (STRICTA): extending the CONSORT statement. PLoS Medicine. 2010; 7(6):e1000261. [PubMed: 20543992]

Mangel AW, Hahn BA, Heath AT, Northcutt AR, Kong S, Dukes GE, et al. Adequate relief as an endpoint in clinical trials in irritable bowel syndrome. Journal of International Medical Research. 1998; 26(2):76-81. [PUBMED: 9602985]. [PubMed: 9602985]

Manheimer E, Linde K, Lao L, Bouter LM, Berman BM. Meta-analysis: acupuncture for osteoarthritis of the knee. Annals of Internal Medicine. 2007; 146(12):868-877. [PUBMED: 17577006]. [PubMed: 17577006]

Manheimer E, Cheng K, Linde K, Lao L, Yoo J, Wieland S, et al. Acupuncture for peripheral joint osteoarthritis. Cochrane Database of Systematic Reviews. 2010; (Issue 1) [DOI: 10.1002/14651858.CD001977.pub2].

Manheimer E. Selecting a control for in vitro fertilization and acupuncture randomized controlled trials (RCTs): how sham controls may unnecessarily complicate the RCT evidence base. Fertility and Sterility. 2011; 95(8):2456-2461. [PubMed: 21570069]

Manning AP, Thompson WG, Heaton KW, Morris AF. Towards positive diagnosis of the irritable bowel. BMJ. 1978; 2(6138):653-654. [PubMed: 698649]

Maxion-Bergemann S, Thielecke F, Abel F, Bergemann R. Costs of irritable bowel syndrome in the UK and US. Pharmacoeconomics. 2006; 24(1):21-37. [PubMed: 16445300]

Melchart D, Weidenhammer W, Streng A, Reitmayr S, Hoppe A, Ernst E, et al. Prospective investigation of adverse effects of acupuncture in 97733 patients. Archives of Internal Medicine. 2004; 164(1):104-105. [PubMed: 14718331]

O'Connell NE, Wand BM, Goldacre B. Interpretive bias in acupuncture research?: A case study. Evaluation and the Health Professions. 2009; 32(4):393-409. [PubMed: 19942631]

Pasricha PJ. Desperately seeking serotonin... A commentary on the withdrawal of tegaserod and the state of drug development for functional and motility disorders. Gastroenterology. 2007; 132(7): 2287-2290. [PubMed: 17570201] 
Patrick DL, Drossman DA, Frederick IO, DiCesare J, Puder KL. Quality of life in persons with irritable bowel syndrome: development and validation of a new measure. Digestive Diseases and Sciences. 1998; 43(2):400-411. [PUBMED: 9512138]. [PubMed: 9512138]

Ruepert L, Quartero AO, de Wit NJ, van der Heijden GJ, Rubin G, Muris JW. Bulking agents, antispasmodics and antidepressants for the treatment of irritable bowel syndrome. Cochrane Database of Systematic Reviews. 2011; (Issue 8) [DOI: 10.1002/14651858.CD003460.pub3].

Saito YA, Locke GR, Talley NJ, Zinsmeister AR, Fett SL, Melton LJ 3rd. A comparison of the Rome and Manning criteria for case identification in epidemiological investigations of irritable bowel syndrome. American Journal of Gastroenterology. 2000; 95(10):2816-2824. [PubMed: 11051354]

Saito YA, Schoenfeld P, Locke GR 3rd. The epidemiology of irritable bowel syndrome in North America: a systematic review. American Journal of Gastroenterology. 2002; 97(8):1910-1915. [PUBMED: 12190153]. [PubMed: 12190153]

Schulz KF, Grimes DA. Unequal group sizes in randomised trials: guarding against guessing. Lancet. 2002; 359(9310):966-970. [PubMed: 11918933]

Schünemann, HJ.; Oxman, AD.; Vist, GE.; Higgins, JPT.; Deeks, JJ.; Glasziou, P., et al. Higgins, JPT.; Green, S., editors. Chapter 12: Interpreting results and drawing conclusions. Cochrane Handbook for Systematic Reviews of Interventions Version 5.1.0 (updated March 2011). The Cochrane Collaboration. 2011. Available from www.cochrane-handbook.org

Spiller RC. Problems and challenges in the design of irritable bowel syndrome clinical trials: experience from published trials. American Journal of Medicine. 1999; 107(5A):91S-97S. [PubMed: 10588179]

Streitberger K, Kleinhenz J. Introducing a placebo needle into acupuncture research. Lancet. 1998; 352(9125):364-365. [PubMed: 9717924]

Streitberger K, Diefenbacher M, Bauer A, Conradi R, Bardenheuer H, Martin E, et al. Acupuncture compared to placebo-acupuncture for postoperative nausea and vomiting prophylaxis: a randomised placebo-controlled patient and observer blind trial. Anaesthesia. 2004; 59(2):142149. [PUBMED: 14725517]. [PubMed: 14725517]

Talley NJ, Gabriel SE, Harmsen WS, Zinsmeister AR, Evans RW. Medical costs in community subjects with irritable bowel syndrome. Gastroenterology. 1995; 109(6):1736-1741. [PUBMED: 7498636]. [PubMed: 7498636]

Thompson, WG.; Longstreth, D.; Drossman, DA., et al. Functional bowel disorders. In: Drossman, DA.; Corazziari, E.; Talley, NJ.; Thompson, WG.; Whitehead, WE., editors. Rome II: The Functional Gastrointestinal Disorders. 2nd Edition. McLean, VA: Degnon Associates Inc; 2000. p. 355

Thompson CA. Alosetron withdrawn from market. American Journal of Health-System Pharmacy. 2001; 58(1):13. [PubMed: 11194127]

Vanner SJ, Depew WT, Paterson WG, DaCosta LR, Groll AG, Simon JB, et al. Predictive value of the Rome criteria for diagnosing the irritable bowel syndrome. American Journal of Gastroenterology. 1999; 94(10):2912-2917. [PubMed: 10520844]

Wechsler ME, Kelley JM, Boyd IO, Dutile S, Marigowda G, Kirsch I, et al. Active albuterol or placebo, sham acupuncture, or no intervention in asthma. New England Journal of Medicine. 2011; 365(2):119-126. [PubMed: 21751905]

White A, Hayhoe S, Hart A, Ernst E. Adverse events following acupuncture: prospective survey of 32 000 consultations with doctors and physiotherapists. BMJ. 2001; 323(7311):485-486. [PubMed: 11532840]

Whitehead, WE.; Corazziari, E.; Prizont, R., et al. Definition of a responder in clinical trials for functional gastrointestinal disorders: Report on a symposium. In: Drossman, DA., editor. ROME II: The functional gastrointestinal disorders. 2nd Edition. McLean, VA: Degnon Associates; 2000.

Wood L, Egger M, Gluud LL, Schulz KF, Juni P, Altman DG, et al. Empirical evidence of bias in treatment effect estimates in controlled trials with different interventions and outcomes: metaepidemiological study. BMJ. 2008; 336(7644):601-605. [PubMed: 18316340] 
Wu T, Li Y, Bian Z, Liu G, Moher D. Randomized trials published in some Chinese journals: how many are randomized? Trials. 2009; 10:46. [PubMed: 19573242]

\section{APPENDICES}

Appendix 1

Search strategies

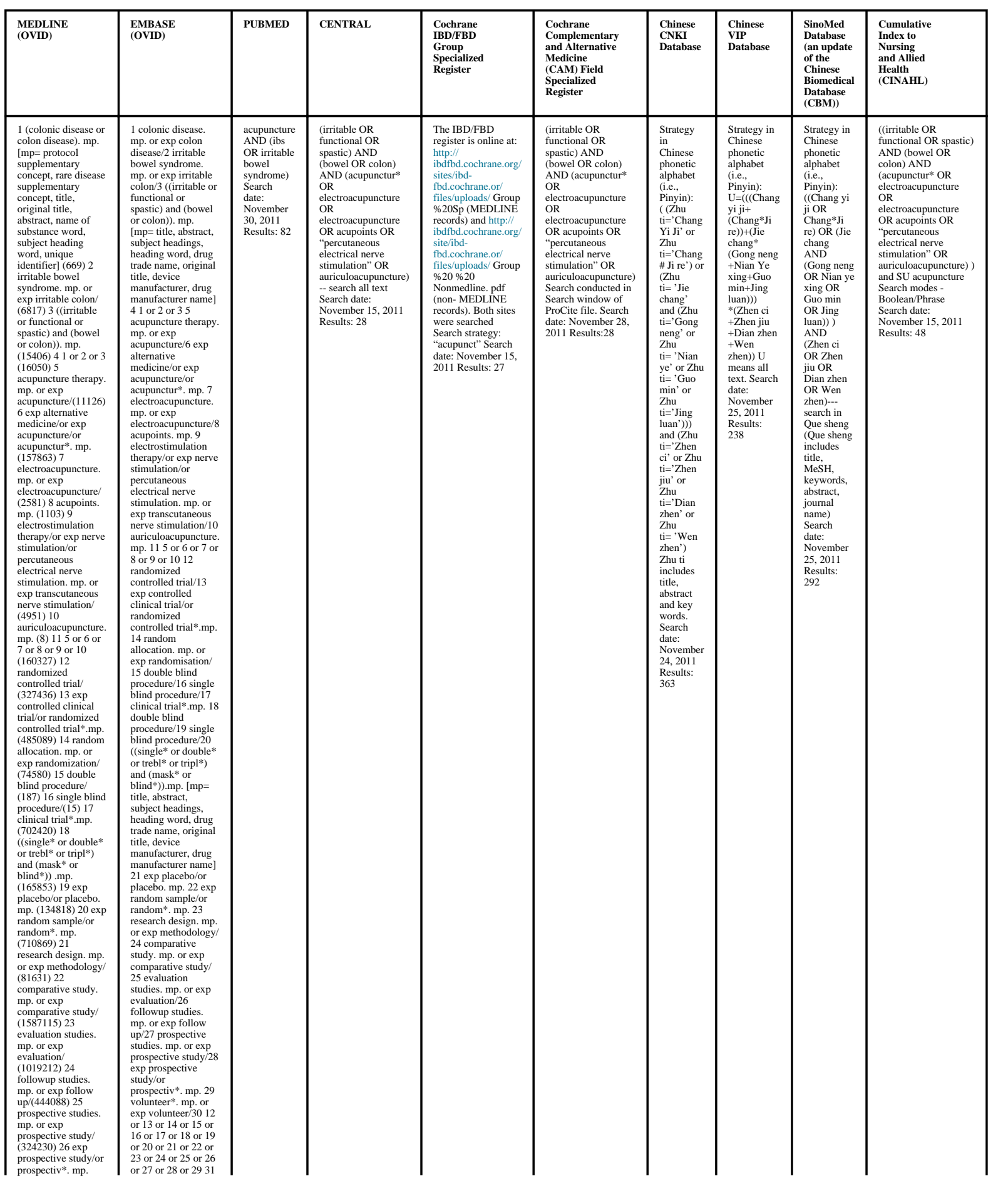

Cochrane Database Syst Rev. Author manuscript; available in PMC 2013 July 22. 


\begin{tabular}{|c|c|c|c|c|c|c|c|c|c|}
\hline $\begin{array}{l}\text { MEDLINE } \\
\text { (OVII) }\end{array}$ & $\begin{array}{l}\text { EMBASE } \\
\text { (OVID) }\end{array}$ & PUBMED & CENTRAL & $\begin{array}{l}\text { Cochrane } \\
\text { IIID/FBD } \\
\text { Group } \\
\text { Specialized } \\
\text { Register }\end{array}$ & $\begin{array}{l}\text { Cochrane } \\
\text { Complementary } \\
\text { and Alternative } \\
\text { Medicine } \\
\text { (CAM) Field } \\
\text { Specialized } \\
\text { Register }\end{array}$ & $\begin{array}{l}\text { Chinese } \\
\text { CNKL } \\
\text { Database }\end{array}$ & $\begin{array}{l}\text { Chinese } \\
\text { VIP } \\
\text { Database }\end{array}$ & $\begin{array}{l}\text { SinoMed } \\
\text { Database } \\
\text { (an update } \\
\text { of the } \\
\text { Chinese } \\
\text { Biomedical } \\
\text { Database } \\
\text { (CBM) }\end{array}$ & $\begin{array}{l}\text { Cumulative } \\
\text { Index to } \\
\text { Nursing } \\
\text { and Allied } \\
\text { Health } \\
\text { (CINAHL) }\end{array}$ \\
\hline 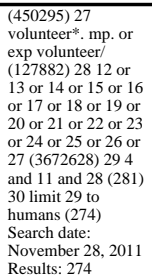 & $\begin{array}{l}4 \text { and } 11 \text { and } 3032 \\
\text { limitit to thuman } \\
\text { Search date: } \\
\text { Noventere } 22,22011 \\
\text { Results: } 6333\end{array}$ & & & & & & & & \\
\hline
\end{tabular}

\section{Appendix 2}

Characteristics of randomized controlled trials in acupuncture for irritable bowel syndrome (IBS)

\begin{tabular}{|c|c|c|c|c|c|c|c|c|}
\hline Study & ${ }_{\mathrm{N}} a$ & Country & $\begin{array}{l}\text { Diagnostic } \\
\text { criteria used } \\
\text { for IBS }\end{array}$ & $\begin{array}{l}\text { Criteria } \\
\text { for improvement } \\
\text { in overall } \\
\text { IBS symptoms }\end{array}$ & $\begin{array}{l}\text { Criteria } \\
\text { for } \\
\text { improvement } \\
\text { in ISS-related } \\
\text { quality of life }\end{array}$ & $\begin{array}{l}\text { Time } \\
\text { point for outcome } \\
\text { assessment } b\end{array}$ & $\begin{array}{l}\text { Acupuncture } \\
\text { treatment }\end{array}$ & $\begin{array}{l}\text { Control } \\
\text { treatment(s) }\end{array}$ \\
\hline An 2010 & ${ }_{81} \mathrm{C}$ & China & Rome II & Categorical $d$ & $e$ & 4 wks (EoT) & $\begin{array}{l}\text { Fixed formula } \\
\text { with moxibustion } \\
\text { at } 2 \text { fixed points; } \\
24 \text { sessions over } \\
4 \text { wks }\end{array}$ & $\begin{array}{l}\text { Combined } \\
\text { Bifidobacterium, } \\
\text { lactobacillus and } \\
\text { Enterococcus } \\
\text { faecium capsules } \\
\text { (2 pills, 3x/d) }\end{array}$ \\
\hline Anastasi 2009 & 29 & USA & Rome II/III & CGI & - & 4 wks (EoT) & $\begin{array}{l}\text { Flexible formula } \\
\text { with moxixubstion } \\
\text { at all points; } 8 \\
\text { sessions over } 4 \\
\text { wks }\end{array}$ & $\begin{array}{l}\text { Sham acupuncture } \\
\text {-superficial } \\
\text { needling 2-3 } \mathrm{cm} \\
\text { from true } \\
\text { acupoints }\end{array}$ \\
\hline Chen 2009 & ${ }_{60} \mathrm{c}$ & China & Rome II & Categorical & FDG QoL scale & 4 wks (EoT) & $\begin{array}{l}\text { Flexible formula } \\
\text { with moxibustion } \\
\text { at } 4 \text { fixed pts; } 12 \\
\text { sessions over } 4 \\
\text { wks + Chinese } \\
\text { herbal formula }\end{array}$ & $\begin{array}{l}\text { Chinese herbal } \\
\text { formula alone (3 } \\
\text { pills, 3x/d) }\end{array}$ \\
\hline Chen 2011 & 60 & China & $\begin{array}{l}\text { Rome III - } \\
\text { IBS-D }\end{array}$ & Categorical & - & 3 wks (EoT) & $\begin{array}{l}\text { Flexible formula } \\
\text { with moxibustion } \\
\text { at } 3-5 \text { pts; } 15 \\
\text { sessions over } 3 \\
\text { wks }\end{array}$ & $\begin{array}{l}\text { Montmorillonite (1 } \\
\text { bag, 2x/day) + } \\
\text { loperamide (4mg, } \\
\text { 3x/day) } \\
\text { pinaverium } \\
\text { bromide ( } \\
\text { 3x/d) } f \text { f }\end{array}$ \\
\hline Forbes 2005 & 59 & UK & $\begin{array}{l}\text { Rome I and } \\
\text { Manning }\end{array}$ & $\begin{array}{l}\text { Global symptom } \\
\text { score based on patient } \\
\text { diary } g\end{array}$ & EuroQol & 13 wks (EoT) & $\begin{array}{l}\text { Individualized; } \\
10 \text { sessions over } \\
10 \mathrm{wks}\end{array}$ & $\begin{array}{l}\text { Sham acupuncture } \\
\text { - penentrating } \\
\text { needles at } \\
\text { nonacupoints }\end{array}$ \\
\hline Lembo $2009 h$ & 230 & USA & Rome II & IBS-AR and IBS-SSS & IBS-QoL & 3 wks (EoT) & $\begin{array}{l}\text { Flexible formula; } \\
6 \text { sessions over } 3 \\
\text { wks }\end{array}$ & $\begin{array}{l}\text { 1) Sham } \\
\text { acupuncture - } \\
\text { validated } \\
\text { Streitberger } \\
\text { placebo needles } \\
\text { placed at non- } \\
\text { acupoints in } \\
\text { general vicinity of } \\
\text { the true acupoints } \\
\text { 2) Wait list with } \\
\text { continuation of } \\
\text { usual care }\end{array}$ \\
\hline Li 2009 & 186 & China & Rome III & Categorical & - & 10 wks (EoT) & $\begin{array}{l}\text { Flexible formula } \\
\text { with moxibustion } \\
\text { at all points; } 60 \\
\text { sessions over } 10 \\
\text { wks + Tuina } \\
\text { spinal massage }\end{array}$ & $\begin{array}{l}\text { Tuina spinal } \\
\text { massage alone ( } 60 \\
\text { sessions over } 10 \\
\text { wks) }\end{array}$ \\
\hline Liu 1997 & 150 & China & Not specified & Categorical & - & 3-21 wks (EoT) & $\begin{array}{l}\text { Flexible formula } \\
\text { with moxibustion } \\
\text { at acupoint } \\
10-60 \text { sessions } \\
\text { over } 20-120 \\
\text { days } \\
\text { psychotherapy }\end{array}$ & $\begin{array}{l}\text { 1) Acupuncture } \\
\text { alone } \\
\text { 2) Psychotherapy } \\
\text { alone }\end{array}$ \\
\hline Liu 2010 & 300 & China & $\begin{array}{l}\text { Rome III - } \\
\text { IBS-D }\end{array}$ & Categorical & - & 4 wks (EoT) & $\begin{array}{l}\text { Fixed formula } \\
\text { EA } 288 \text { sessions } \\
\text { over } 4 \text { wks }+\end{array}$ & $\begin{array}{l}\text { 1) EA alone } \\
\text { 2) Chinese herbal } \\
\text { formula alone } \\
\text { (150ml, 2x/d) }\end{array}$ \\
\hline
\end{tabular}




\begin{tabular}{|c|c|c|c|c|c|c|c|c|}
\hline Study & ${ }_{\mathrm{N}} a$ & Country & $\begin{array}{l}\text { Diagnostic } \\
\text { criteria used } \\
\text { for IBS }\end{array}$ & $\begin{array}{l}\text { Criteria } \\
\text { for improvement } \\
\text { in overall } \\
\text { IBS symptoms }\end{array}$ & $\begin{array}{l}\text { Criteria } \\
\text { for } \\
\text { improvement } \\
\text { in IBS-related } \\
\text { quality of life }\end{array}$ & $\begin{array}{l}\text { Time } \\
\text { point for outcome } \\
\text { assessment } b\end{array}$ & $\begin{array}{l}\text { Acupuncture } \\
\text { treatment }\end{array}$ & $\begin{array}{l}\text { Control } \\
\text { treatment(s) }\end{array}$ \\
\hline & & & & & & & $\begin{array}{l}\text { Chinese herbal } \\
\text { formula }\end{array}$ & $\begin{array}{l}\text { 3) Bifidobacterim } \\
\text { longum alone (1 } \\
\text { pill, 2x/d) }\end{array}$ \\
\hline Lowe 2000 & 50 & Canada & $\begin{array}{l}\text { Rome } \\
\text { (version not } \\
\text { stated) }\end{array}$ & $\begin{array}{l}\text { Dichotomous measure } \\
\text { of symptom relief }\end{array}$ & IBS-36 & 4 wks (Eot) & $\begin{array}{l}\text { Fixed formula; } 8 \\
\text { sessions over } 4 \\
\text { wks }\end{array}$ & $\begin{array}{l}\text { Sham acupuncture } \\
\text {-- tapping blunt } \\
\text { needle on the skin } \\
\text { and then taping the } \\
\text { needle in place }\end{array}$ \\
\hline Reynolds 2008 & 30 & UK & Rome II & IBS-SSS & - & $3 \operatorname{mos}(\mathrm{EoT})$ & $\begin{array}{l}\text { Flexible formula; } \\
8 \text { sessions over } 3 \\
\text { mos }\end{array}$ & Usual care \\
\hline Schneider 2006 & 43 & Germ-any & Rome II & Not measured & FDDQL & 5 wks (EoT) & $\begin{array}{l}\text { Fixed formula; } \\
10 \text { sessions over } \\
5 \text { wks }\end{array}$ & $\begin{array}{l}\text { Sham acupuncture } \\
- \text { validated } \\
\text { Streitberger } \\
\text { placebo needles } \\
\text { placed } 2 \mathrm{~cm} \text { from } \\
\text { true acupoints }\end{array}$ \\
\hline Shi 2010 & 70 & China & $\begin{array}{l}\text { Rome III - } \\
\text { IBS-D }\end{array}$ & Categorical & - & $\begin{array}{l}5 \text { wks }(1 \text { wk after } \\
(\mathrm{EoT})\end{array}$ & $\begin{array}{l}\text { Flexible formula } \\
\text { EA; } 28 \text { sessions } \\
\text { over } 4 \text { wks }\end{array}$ & $\begin{array}{l}\text { Pinaverium } \\
\text { bromide (50mg, } \\
3 \mathrm{x} / \mathrm{d})\end{array}$ \\
\hline Sun 2011 & 63 & China & $\begin{array}{l}\text { Rome III - } \\
\text { IBS-D }\end{array}$ & Categorical & - & 4 wks (EoT) & $\begin{array}{l}\text { Fixed formula; } \\
20 \text { sessions over } \\
4 \text { wks }\end{array}$ & $\begin{array}{l}\text { Pinaverium } \\
\text { bromide (50mg, } \\
3 \mathrm{x} / \mathrm{d})\end{array}$ \\
\hline Xiong 2008a & 120 & China & Rome II & Categorical & - & 4 wks (EoT) & $\begin{array}{l}\text { Fixed formula } \\
\text { with moxibustion } \\
\text { at } 2 \text { pts; } 28 \\
\text { sessions over } 4 \\
\text { ws + Chinese } \\
\text { herbal formula }\end{array}$ & $\begin{array}{l}\text { Chinese herbal } \\
\text { formula alone }\end{array}$ \\
\hline Xue 2009 & 210 & China & Rome II & Categorical & - & 3-7 weeks (EoT) & $\begin{array}{l}\text { Fixed formula } \\
\text { with moxibustion } \\
\text { at } 1 \text { point; } 20-40 \\
\text { sessions over 3-7 } \\
\text { wks }\end{array}$ & $\begin{array}{l}\text { Sulfasalazine (10 } \\
\mathrm{mg}, 1 \mathrm{x} / \mathrm{d})\end{array}$ \\
\hline Zeng 2010 & 65 & China & $\begin{array}{l}\text { Rome III - } \\
\text { IBS-D }\end{array}$ & Categorical & - & $30 \mathrm{~d}(\mathrm{E} O \mathrm{~T})$ & $\begin{array}{l}\text { Flexible formula } \\
\text { with moxibustion } \\
\text { at } 6 \text { points; } 30 \\
\text { sessions over } 30 \\
\text { d }\end{array}$ & $\begin{array}{l}\text { Trimebutine } \\
\text { maleate }(100 \mathrm{mg} \text {, } \\
3 \mathrm{x} / \mathrm{d})\end{array}$ \\
\hline
\end{tabular}

IBS, irritable bowel syndrome; EoT, end of treatment; wks, weeks; d, day; CGI, Clinical Global Impression Scale (Whitehead 2000) ; acupoints, acupuncture points; FDG QoL, Functional Digestive Diseases Quality of Life Scale, an IBS quality of life questionnaire which had been used in previous Chinese studies but that has not been validated; IBS-D, study restricted eligibility to IBS-D (IBS with diarrhea) subtype patients; EuroQol, EuroQol Group's rating scale (Johnson 1998); IBS-AR, IBS-Adequate Relief question (Mangel 1998); IBS-SSS, IBS Severity Scoring System (Francis 1997); IBS-QoL, IBS Quality of Life Measure (Bijkerk 2003); EA, electroacupuncture; IBS-36 (Groll 2002); FDDQL, Functional Digestive Diseases Quality of Life Questionnaire (Chassany 1999).

a Number randomized.

$b$ The time point listed is the number of weeks after randomization

$c_{\text {For these }} 2$ trials, the author did not record nor recall the numbers randomized, nor the numbers of dropouts, and the numbers analyzed are reported here

${ }^{d}$ For all 11 trials conducted in China, a symptom scale was used to assess the severity of the patients' overall IBS-related symptoms (e.g., abdominal pain, defecation difficulties, diarrhea) both at baseline and after treatment. For 8 of these trials (Xiong 2008a; Chen 2009; An 2010; Liu 2010; Shi 2010; Zeng 2010; Chen 2011; Sun 2011), a percentage improvement from baseline scores was then calculated (i.e., (baseline symptom score - symptom score after treatment)/baseline symptom score), and this percentage change from baseline was then grouped into 2 (Shi 2010), 3 (An 2010; Zeng 2010), or 4 (Xiong 2008a; Chen 2009; Liu 2010; Chen 2011; Sun 2011) categories, which were then converted into 2 categories for the metaanalysis, as described in the Methods section. For the other 3 trials (Liu 1997; Xue 2009; Liu 2010), it was not clear how the symptom scale scores were converted into the categorical data. For these 11 trials, the criteria for improvement is listed as "Categorical" in this table

e A dash (-) indicates that the outcome not measured.

$f$ The Montmorillonite was given to all patients and the loperamide and pinaverium bromide was added if the diarrhea did not stop

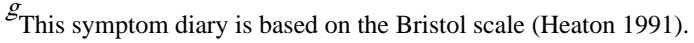

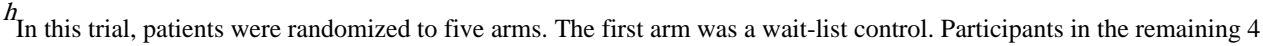
arms were randomized to sham or true acupuncture, with or without an augmented practitioner-patient interaction. There was no main effect of practitioner-patient interaction; therefore we combined the two acupuncture groups (augmented and 
limited encounter) and the two sham acupuncture groups (augmented and limited encounter) in order to compare the effects of acupuncture and sham acupuncture

${ }^{1}$ This trial also included an EoT measurement point, for which the results were very similar to the 1 wk post EoT measurement point

\section{Appendix 3}

Acupuncture adequacy assessments of included studies*

\begin{tabular}{|c|c|c|c|c|c|c|c|c|}
\hline Study & $\begin{array}{l}\text { Choice of } \\
\text { acupoints }\end{array}$ & $\begin{array}{l}\text { Total number } \\
\text { of sessions }\end{array}$ & $\begin{array}{l}\text { Treatment } \\
\text { duration }\end{array}$ & $\begin{array}{l}\text { Treatment } \\
\text { frequency }\end{array}$ & $\begin{array}{l}\text { Needling } \\
\text { technique }\end{array}$ & Experience & $\begin{array}{l}\text { Assessment of } \\
\text { likelihood } \\
\text { of physiological } \\
\text { activity of sham } \\
\text { control }\end{array}$ & $\begin{array}{l}\text { Guess of } \\
\text { study }\end{array}$ \\
\hline An 2010 & Adequate & Adequate & Adequate & Adequate & Adequate & Don't know & No sham/placebo intervention & Don't know \\
\hline Anastasi 2009 & Adequate & Adequate & Adequate & Adequate & Adequate & Adequate & 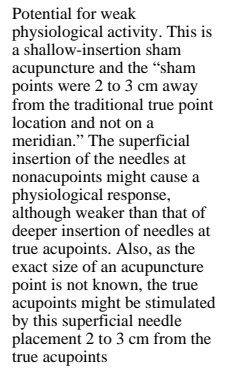 & Don't know \\
\hline Chen 2009 & Adequate & Adequate & Adequate & Adequate & Adequate & Don't know & No sham/placebo intervention & Don't know \\
\hline Chen 2011 & Adequate & Adequate & Adequate & Adequate & Adequate & Don't know & No sham/placebo controls & Don't know \\
\hline Forbes 2005 & Adequate & Adequate $^{\dagger}$ & Adequate & $\begin{array}{l}\text { Inadequate } \\
\text { (Once per } \\
\text { week } \\
\text { treatment } \\
\text { seems not } \\
\text { frequent } \\
\text { enough.) }\end{array}$ & Adequate & Adequate & $\begin{array}{l}\text { Potential for weak } \\
\text { physiological activity. From } \\
\text { the description, it sounds like } \\
\text { a needle insertion sham at } \\
\text { non-acupoints, which might } \\
\text { cause a physiological } \\
\text { response, although weaker } \\
\text { than that of insertion of } \\
\text { needles at true acupoints }\end{array}$ & $\begin{array}{l}\text { One } \\
\text { acupuncturist } \\
\text { (XS) is } \\
\text { unawara of } \\
\text { this study or } \\
\text { its results. } \\
\text { The other } \\
\text { acupuncturist } \\
\text { (LL) guesses } \\
\text { this must be } \\
\text { conducted in } \\
\text { England, but } \\
\text { doesn't but } \\
\text { know who } \\
\text { the authors } \\
\text { are }\end{array}$ \\
\hline Lembo 2009 & Adequate & Adequate & Adequate & Adequate & Adequate & Adequate & $\begin{array}{l}\text { Unlikely to have } \\
\text { physiological activity. Use of } \\
\text { non-insertion Strititerger } \\
\text { sham device in the relative } \\
\text { vicinity of the genuine } \\
\text { acupoints is an adequate } \\
\text { control. While perhaps } \\
\text { unlikely, it is possible that the } \\
\text { true acupoints may be } \\
\text { stimulated by the sham } \\
\text { needle placement in the } \\
\text { vicinity of the true acupoints }\end{array}$ & Don't know \\
\hline Li 2009 & Adequate & Adequate & Adequate & Adequate & Adequate & Don't know & No sham/placebo intervention & Don't know \\
\hline Liu 1997 & Adequate & Adequate & Adequate & Adequate & Adequate & Don't know & No sham/placebo intervention & Don't know \\
\hline Liu 2010 & Adequate & Adequate & Adequate & Adequate & Adequate & Don't know & No sham/placebo intervention & Don't know \\
\hline Lowe 2000 & Don't know $t$ & Adequate & Adequate & Adequate & Don't know & Inadequate $\mathcal{S}$ & $\begin{array}{l}\text { Unlikely to have } \\
\text { physiological activity: It } \\
\text { seems adequate as this sham } \\
\text { only involved "tapping a } \\
\text { blunt needle o the skin and } \\
\text { taping in place at the same } \\
\text { point". Although the shams } \\
\text { were placed at the same true } \\
\text { acupoints, the blunt needdes } \\
\text { were only briefly tapped, so } \\
\text { would be unlikely to have a } \\
\text { therapeutic effect }\end{array}$ & Don't know \\
\hline Reynolds 2008 & Adequate & Adequate & Adequate & Inadequate $f \dagger$ & Adequate $t \%$ & Adequate & $\begin{array}{l}\text { No sham/placebo intervention } \\
\text { group }\end{array}$ & Don't know \\
\hline Schneider 2006 & Adequate & Adequate & Adequate & Adequate & Adequate & Adequate & $\begin{array}{l}\text { Unlikely to have } \\
\text { physiological activity: This is } \\
\text { a non-insertion sham using a } \\
\text { placebo acupuncture device. } \\
\text { It seems an andequate control. } \\
\text { While entilikely it is possible } \\
\text { that the true acupoints may be } \\
\text { stimulated by the sham } \\
\text { needle placement } 2-3 \mathrm{~cm} \\
\text { from the true acupoints }\end{array}$ & Don't know \\
\hline
\end{tabular}




\begin{tabular}{|l|l|l|l|l|l|l|l|l|}
\hline Study & $\begin{array}{l}\text { Choice of } \\
\text { acupoints }\end{array}$ & $\begin{array}{l}\text { Total number } \\
\text { of sessions }\end{array}$ & $\begin{array}{l}\text { Treatment } \\
\text { duration }\end{array}$ & $\begin{array}{l}\text { Treatment } \\
\text { frequency }\end{array}$ & $\begin{array}{l}\text { Needling } \\
\text { technique }\end{array}$ & Experience & $\begin{array}{l}\text { Assessment of } \\
\text { likelihood } \\
\text { of physiological } \\
\text { activity of sham } \\
\text { control }\end{array}$ & $\begin{array}{l}\text { Guess of } \\
\text { study }\end{array}$ \\
\hline Shi 2010 & Adequate & Adequate & Adequate & Adequate & Adequate & Adequate & No sham/placebo intervention & Don't know \\
\hline Sun 2011 & Adequate & Adequate & Adequate & Adequate & Adequate & Don't know & No sham/placebo controls & Don't know \\
\hline Xiong 2008a & Adequate & Adequate & Adequate & Adequate & Adequate & Don't know & $\begin{array}{l}\text { No sham/placebo intervention } \\
\text { group. }\end{array}$ & Don't know \\
\hline Xue 2009 & Adequate & Adequate & Adequate & Adequate & Adequate & Don't know & No sham/placebo intervention & Don't know \\
\hline Zeng 2010 & Adequate & Adequate & Adequate & Adequate & Adequate & Don't know & No sham/placebo intervention & Don't know \\
\hline
\end{tabular}

Two independent acupuncturists assessed acupuncture as adequate in terms of the choice of acupuncture points, number of sessions, needling technique and experience of acupuncturists for all trials.

${ }^{\dagger} 10$ sessions of treatment may be ok. However, treatment once per week does not seem frequent enough.

* Names of acupoints were not provided.

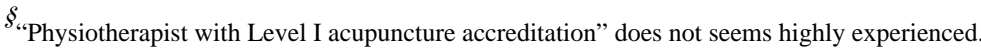

${ }^{t \dagger}$ Although the total number of treatments (10 treatments) is adequate, the frequency of the treatment is probably not adequate (over 3 months).

${ }^{t+}$ Use of two different styles of acupuncture treatment is problematic. It is a weakness of the study design.

\section{Appendix 4}

Adverse events in the acupuncture and control groups *

\begin{tabular}{|c|c|c|c|c|c|}
\hline \multirow[t]{2}{*}{ Study } & \multirow[t]{2}{*}{$\begin{array}{l}\text { Assessment } \\
\text { Methods for } \\
\text { Adverse Events }\end{array}$} & \multicolumn{2}{|c|}{$\begin{array}{l}\text { Minor Adverse Events per } \\
\text { Group, } \mathbf{n} / \mathbf{n}^{\dagger}\end{array}$} & \multirow{2}{*}{$\begin{array}{l}\text { Assessment } \\
\text { Methods } \\
\text { for Side Effects } \\
\text { of Acupuncture }\end{array}$} & \multirow[t]{2}{*}{ Comments $t$} \\
\hline & & Acupuncture & Control & & \\
\hline An 2010 & NR & 0 & NR & NR & "No adverse events were found during the treatment" \\
\hline Anastasi 2009 & $\begin{array}{l}\text { The study facilitator (SF) was } \\
\text { trained and responsible for } \\
\text { structured elicitation of adverse } \\
\text { events }\end{array}$ & 0 & 0 & NR & "No adverse events were reported" \\
\hline Chen 2009 & NR & 0 & 0 & NR & "No adverse effects appeared in all participants" \\
\hline Chen 2011 & NR & $\mathrm{NR}$ & NR & $\mathrm{NR}$ & $\mathrm{NR}$ \\
\hline Forbes 2005 & NR & 0 & 0 & $\mathrm{NR}$ & "No direct adverse events were elicited" \\
\hline Lembo 2009 & NR & $1 / 78$ & $\begin{array}{l}\text { Sham, 2/75; } \\
\text { Waitlist, 0/77 }\end{array}$ & NR & $\begin{array}{l}\text { "Three adverse events were reported during the } \\
\text { acupuncture vs. sham acupuncture phase of the } \\
\text { study... All of these events were considered to be } \\
\text { unrelated to the study procedure" }\end{array}$ \\
\hline Li 2009 & NR & $\mathrm{NR}$ & NR & $\mathrm{NR}$ & $\mathrm{NR}$ \\
\hline Liu 1997 & NR & NR & NR & NR & NR \\
\hline Liu 2010 & $\begin{array}{l}\text { "The results of routine blood, urine } \\
\text { and stool test did not significantly } \\
\text { change before and after treatment, } \\
\text { which suggested there's no obvious } \\
\text { toxic side effect in treatment group } \\
\text { and control groups" }\end{array}$ & 0 & 0 & NR & $\begin{array}{l}\text { "The results of routine blood, urine and stool test did } \\
\text { not significantly change before and after treatment, } \\
\text { which suggested there's no obvious toxic side effect in } \\
\text { treatment group and control groups." }\end{array}$ \\
\hline Lowe 2000 & NR & $\mathrm{NR}$ & NR & NR & NR \\
\hline Reynolds 2008 & $\begin{array}{l}\text { "An open text question at one and } \\
\text { three months gathered adverse } \\
\text { events. We also collected data on } \\
\text { safety and treatment process from } \\
\text { logs completed by the } \\
\text { acupuncturists" }\end{array}$ & NR & NR & NR & $\begin{array}{l}\text { "No serious adverse events were reported. The } \\
\text { acupuncturists reported some mild adverse effects of } \\
\text { the acupuncture treatment (mild dizziness during } \\
\text { treatment and temporary worsening of symptoms } \\
\text { followed by improvement). Some patients also } \\
\text { reported mild adverse effects, but they all continued to } \\
\text { attend for treatment" }\end{array}$ \\
\hline Schneider 2006 & NR & $\mathrm{NR}$ & NR & NR & $\mathrm{NR}$ \\
\hline Shi 2010 & NR & $1 / 32$ & $1 / 38$ & NR & $\begin{array}{l}\text { "One participant in electro-acupuncture group } \\
\text { withdrew due to acupuncture syncope and one } \\
\text { participant in pinaverium bromide group withdrew } \\
\text { due to o thch and skin rash caused by allergic reaction. } \\
\text { There's no obvious adverse effect in other } \\
\text { participants" }\end{array}$ \\
\hline Sun 2011 & NR & 0 & 0 & NR & "No any adverse reaction occurred" \\
\hline Xiong 2008a & NR & $\mathrm{NR}$ & NR & $\mathrm{NR}$ & $\mathrm{NR}$ \\
\hline Xue 2009 & NR & NR & NR & $\mathrm{NR}$ & NR \\
\hline
\end{tabular}

Cochrane Database Syst Rev. Author manuscript; available in PMC 2013 July 22. 


\begin{tabular}{|c|c|c|c|c|c|}
\hline \multirow[t]{2}{*}{ Study } & \multirow{2}{*}{$\begin{array}{l}\text { Assessment } \\
\text { Methods for } \\
\text { Adverse Events }\end{array}$} & \multicolumn{2}{|c|}{$\begin{array}{l}\text { Minor Adverse Events per } \\
\text { Group, } \mathbf{n} / \mathbf{n} \dagger\end{array}$} & \multirow{2}{*}{$\begin{array}{l}\text { Assessment } \\
\text { Methods } \\
\text { for Side Effects } \\
\text { of Acupuncture }\end{array}$} & \multirow[t]{2}{*}{ Commentst } \\
\hline & & Acupuncture & Control & & \\
\hline Zeng 2010 & NR & NR & NR & NR & NR \\
\hline
\end{tabular}

Definition of adverse events and side effects of acupuncture and methods of assessments varied among trials. NR = not reported; RCT $=$ randomized controlled trial.

${ }^{\prime}$ For the only two RCTs (Lembo 2009; Shi 2010) that reported number of adverse events per group, numbers reported in this table are the numbers of patients in each group who had adverse events. The one serious adverse event observed in the acupuncture groups in Lembo 2009 was not interpreted as treatment-related. The one adverse event observed in the acupuncture group in Shi 2010 was syncope due to acupuncture.

The frequency, severity or duration of the minor side effects associated with the needling was not systematically reported in any RCT. 


\section{WHAT'S NEW}

Last assessed as up-to-date: 15 November 2011.

Date Event Description

11 January $2012 \quad$ New citation required and

Substantively updated review with new conclusions have changed conclusions and authors

11 January $2012 \quad$ New search has been performed

New literature searches conducted between November 15 and November 28, 2011. New studies added 


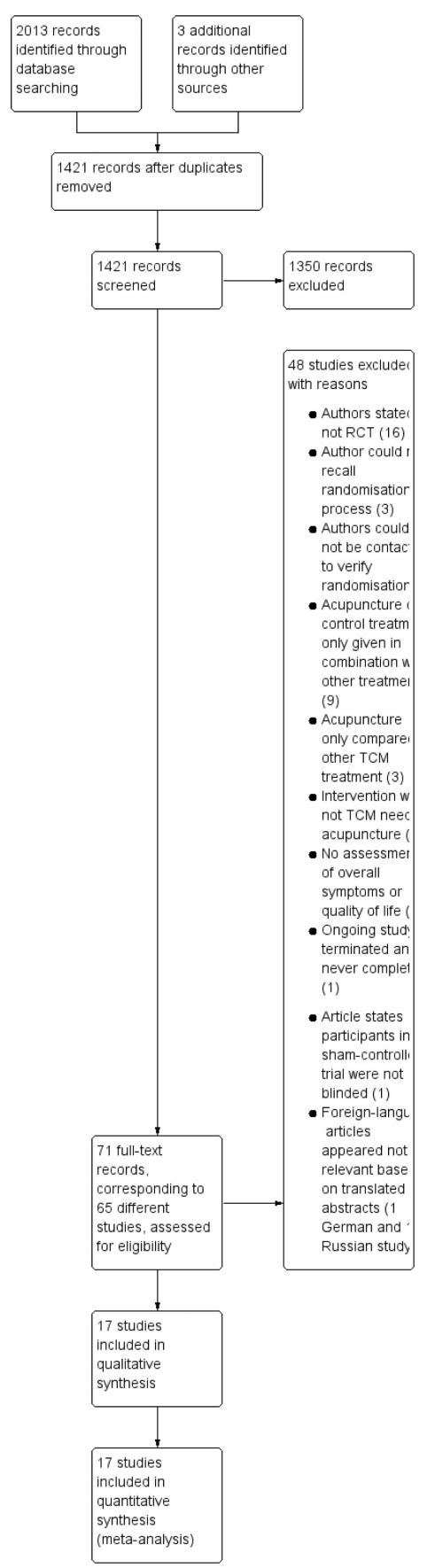

Figure 1.

Flow of studies through selection process. 


\begin{tabular}{|c|c|c|c|c|c|c|}
\hline & 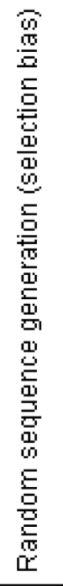 & 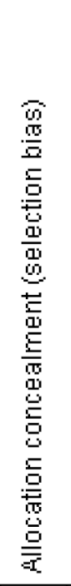 & 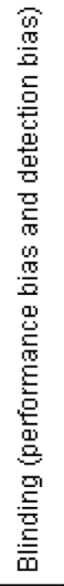 & 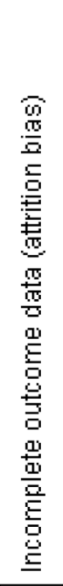 & 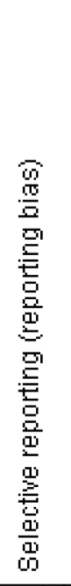 & 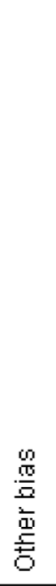 \\
\hline An 2010 & $\odot$ & $\odot$ & $\odot$ & $?$ & $\oplus$ & $?$ \\
\hline Anastasi 2009 & $\odot$ & $\odot$ & $\odot$ & $\odot$ & $\oplus$ & $\odot$ \\
\hline Chen 2009 & - & 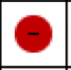 & 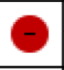 & $?$ & + & $?$ \\
\hline Chen 2011 & $\odot$ & $\odot$ & $\ominus$ & + & $\oplus$ & + \\
\hline Forbes 2005 & $\odot$ & + & $\odot$ & + & + & $\odot$ \\
\hline Lembo 2009 & $\odot$ & + & $\odot$ & $\odot$ & $\odot$ & $\odot$ \\
\hline Li 2009 & 7 & $O$ & ○ & $?$ & + & $?$ \\
\hline Liu 1997 & $\odot$ & $?$ & $\Theta$ & 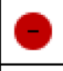 & + & $\odot$ \\
\hline Liu 2010 & $?$ & 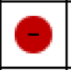 & ○ & $?$ & + & $?$ \\
\hline Lowe 2000 & $\odot$ & $\odot$ & $?$ & $?$ & $\odot$ & $?$ \\
\hline Reynolds 2008 & + & + & 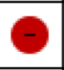 & + & $\Theta$ & + \\
\hline Schneider 2006 & + & + & + & + & + & + \\
\hline Shi 2010 & + & + & $\Theta$ & + & + & + \\
\hline Sun 2011 & + & - & ○ & + & + & $?$ \\
\hline Xiong 2008a & + & 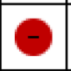 & C & $\theta$ & + & - \\
\hline Xue 2009 & $?$ & $?$ & $\odot$ & + & + & $?$ \\
\hline Zeng 2010 & + & 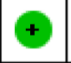 & $\odot$ & + & $\odot$ & $?$ \\
\hline
\end{tabular}

Figure 2.

Risk of bias summary: review authors' judgements about each risk of bias item for each included study. 


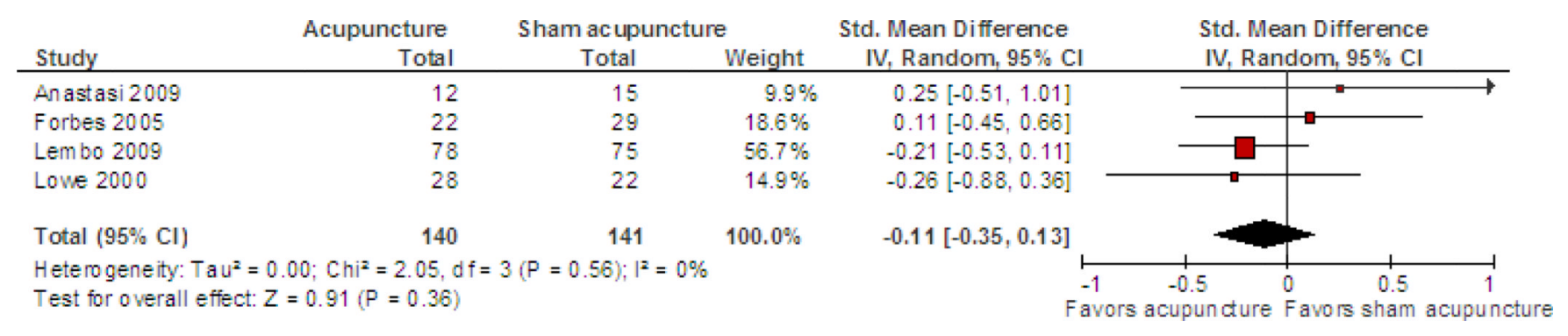

Figure 3.

Acupuncture versus sham acupuncture: Symptom severity 


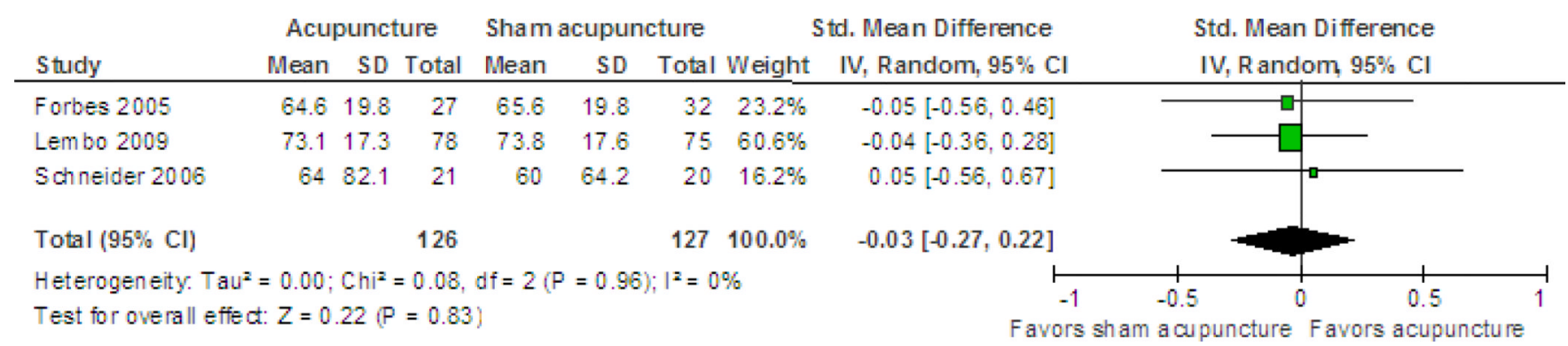

Figure 4.

Acupuncture versus sham acupuncture: Quality of life 


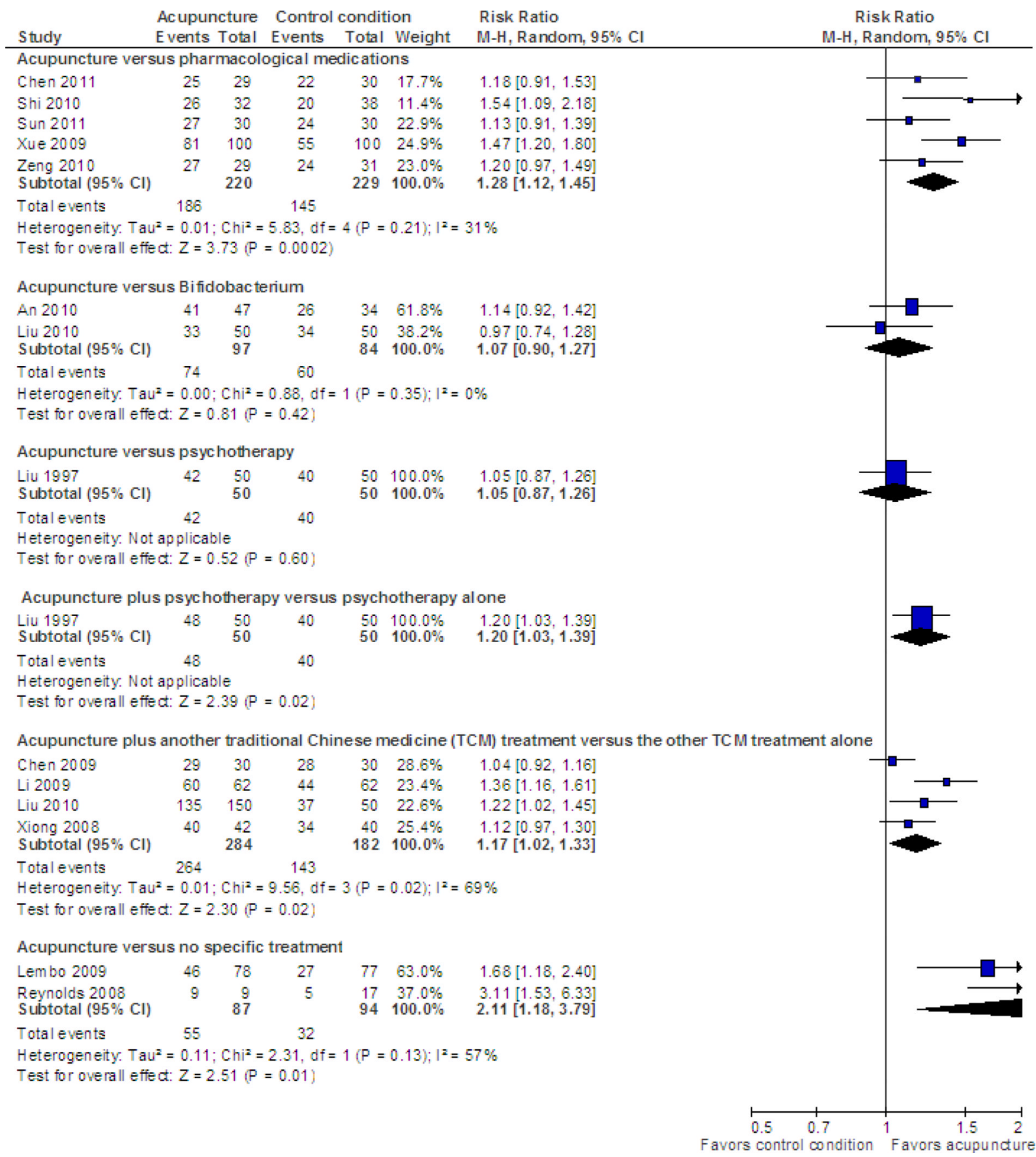

Figure 5.

Acupuncture versus another active treatment, as adjuvant to another active treatment, or compared to no specific treatment: Symptom severity 


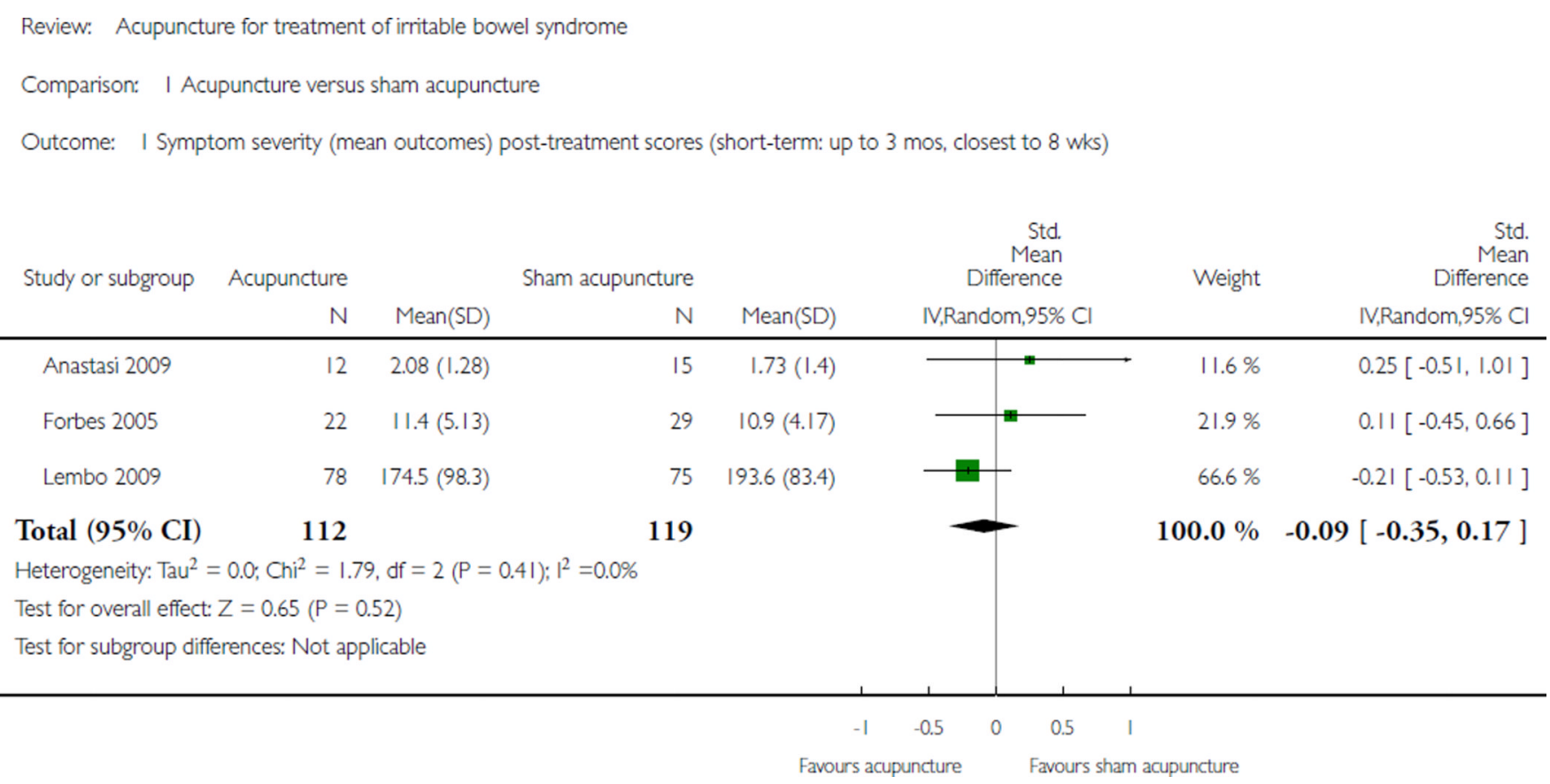

Analysis 1.1.

Comparison 1 Acupuncture versus sham acupuncture, Outcome 1 Symptom severity (mean outcomes) post-treatment scores (short-term: up to $3 \mathrm{mos}$, closest to $8 \mathrm{wks}$ ). 


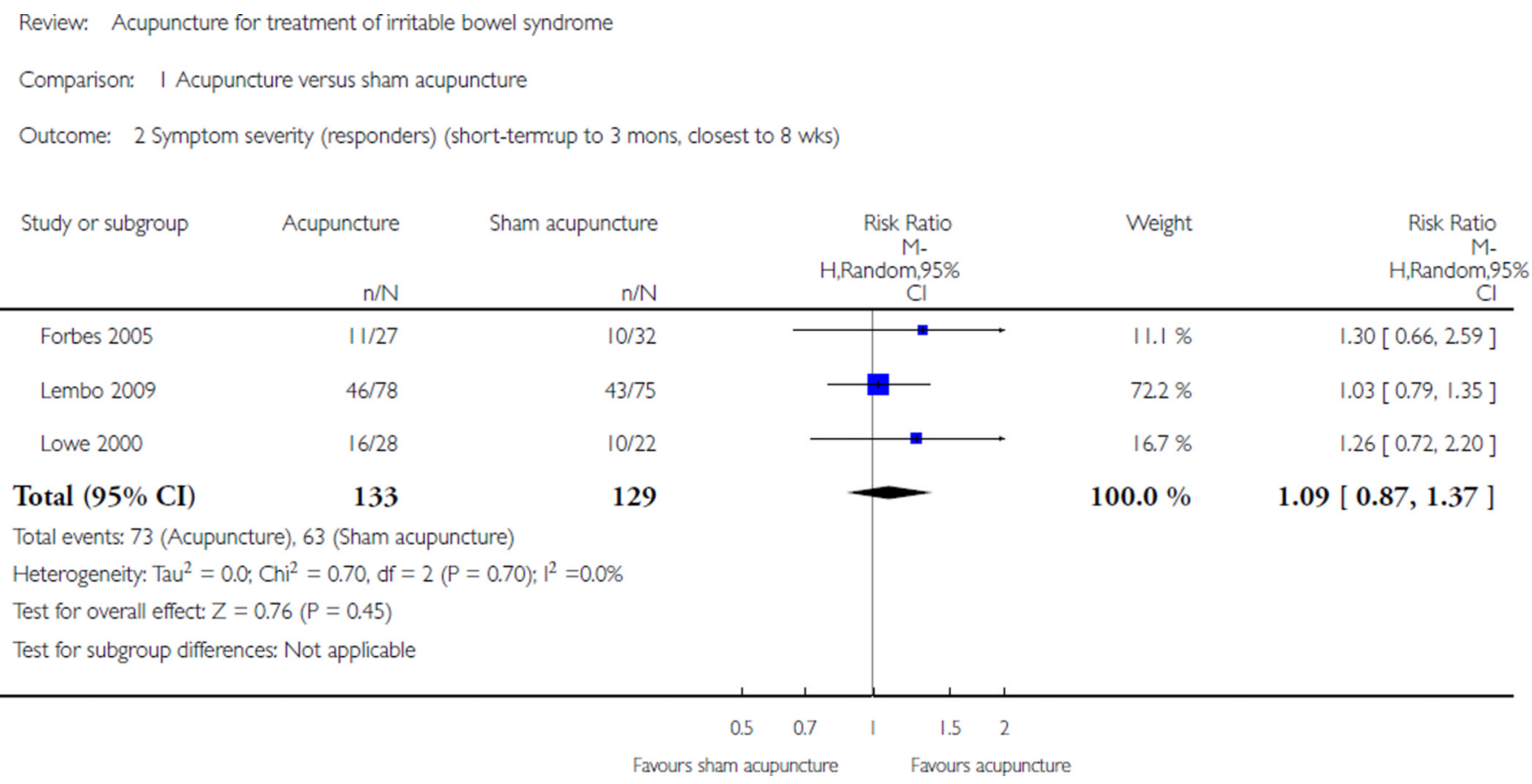

Analysis 1.2.

Comparison 1 Acupuncture versus sham acupuncture, Outcome 2 Symptom severity (responders) (short-term:up to 3 mons, closest to $8 \mathrm{wks}$ ). 
Review: Acupuncture for treatment of irritable bowel syndrome
Comparison: I Acupuncture versus sham acupuncture
Outcome: 3 Symptom severity (generic inverse variance) post-treatment scores (short-term: up to 3 mos, closest to 8 wks)

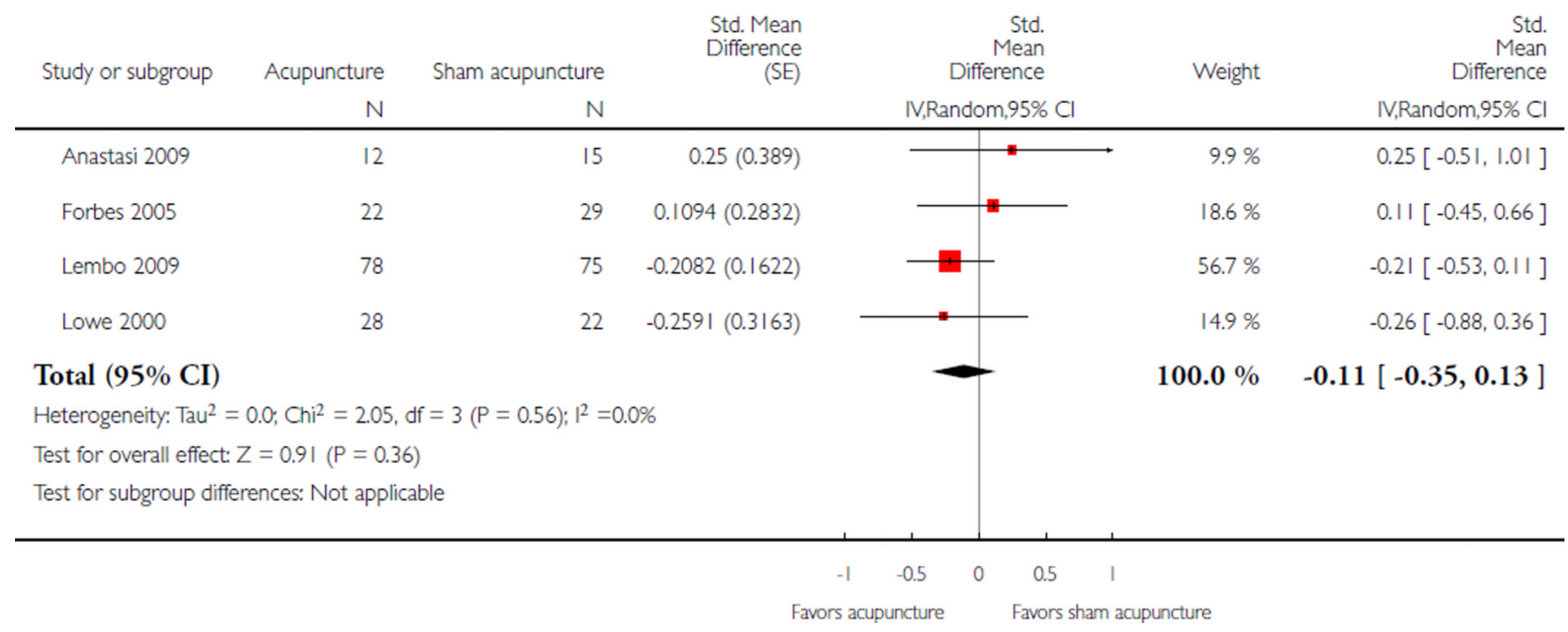

Analysis 1.3.

Comparison 1 Acupuncture versus sham acupuncture, Outcome 3 Symptom severity (generic inverse variance) post-treatment scores (short-term: up to 3 mos, closest to $8 \mathrm{wks}$ ). 
Review: Acupuncture for treatment of irritable bowel syndrome
Comparison: I Acupuncture versus sham acupuncture
Outcome: 4 Quality of life (mean outcomes) post-treatment scores (short-term: up to 3 mos, closest to 8 wks)

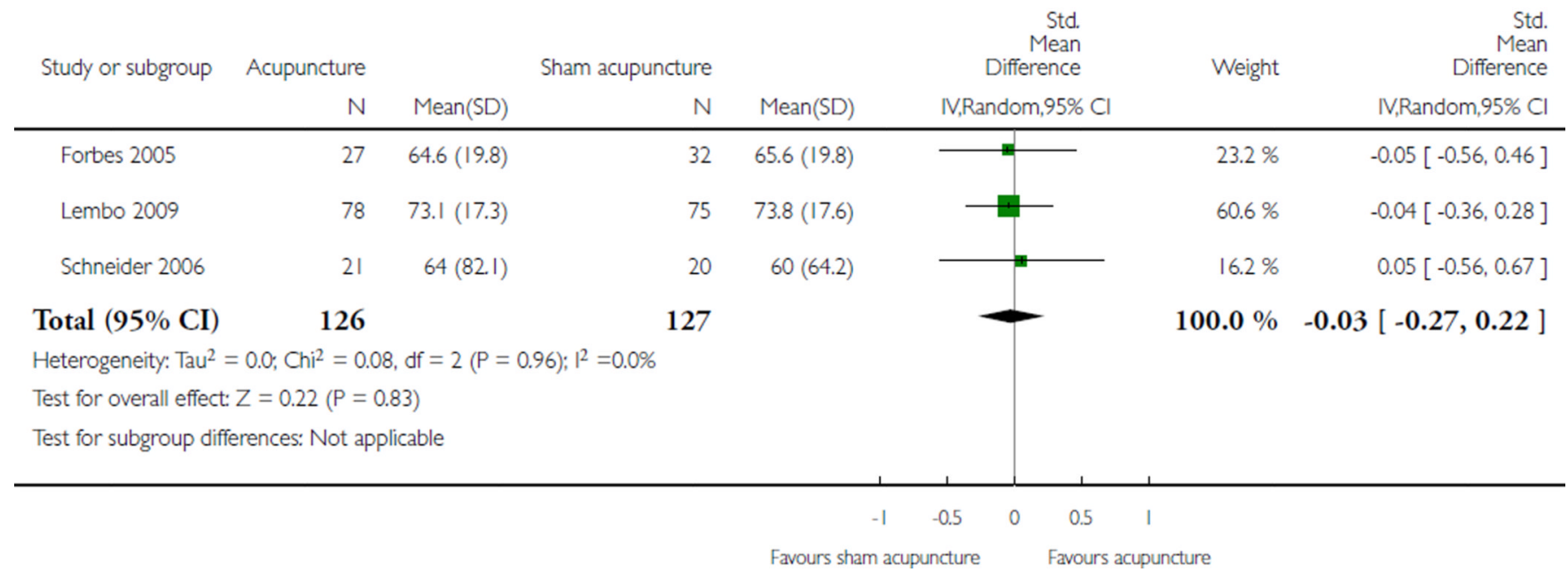

Analysis 1.4.

Comparison 1 Acupuncture versus sham acupuncture, Outcome 4 Quality of life (mean outcomes) post-treatment scores (short-term: up to 3 mos, closest to $8 \mathrm{wks}$ ). 


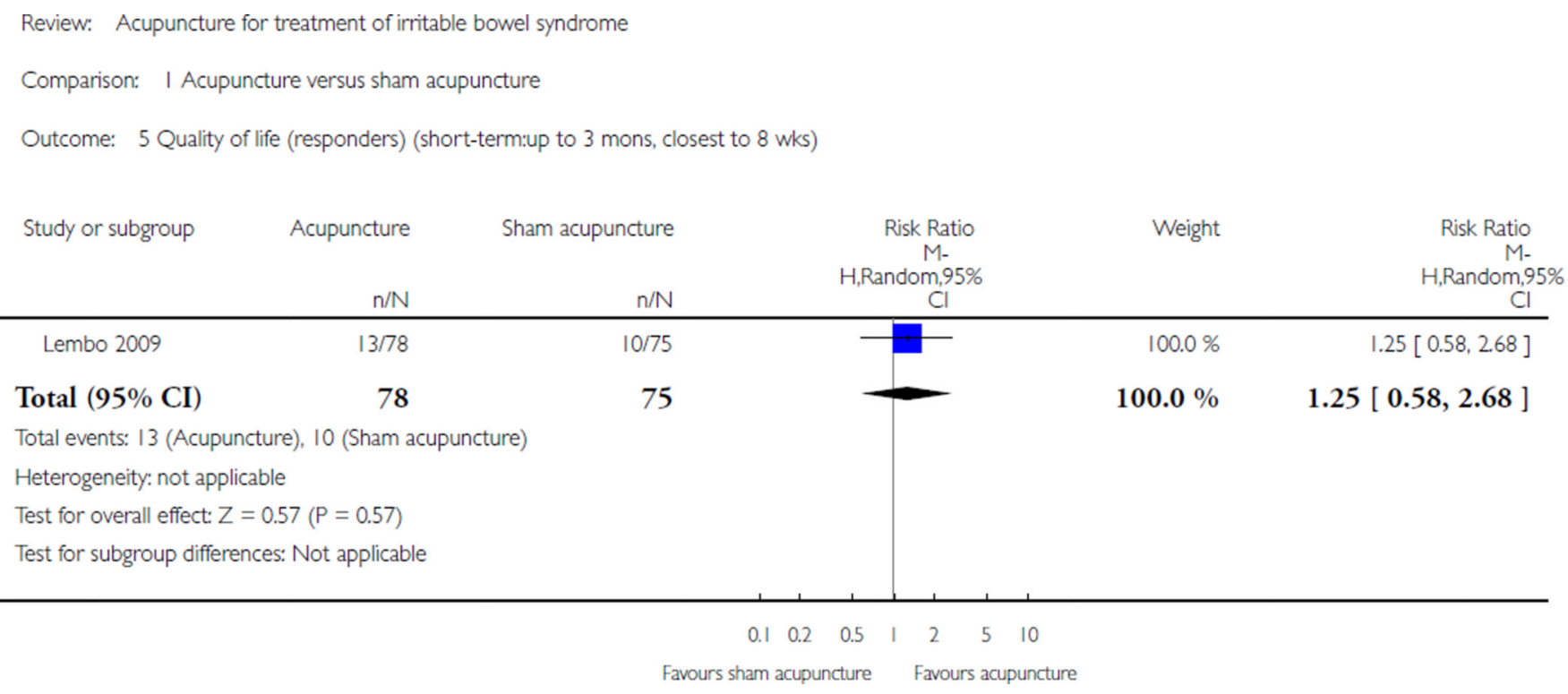

\section{Analysis 1.5.}

Comparison 1 Acupuncture versus sham acupuncture, Outcome 5 Quality of life (responders) (short-term:up to 3 mons, closest to $8 \mathrm{wks}$ ). 
Review: Acupuncture for treatment of irritable bowel syndrome
Comparison: I Acupuncture versus sham acupuncture
Outcome: 6 Quality of life (mean outcomes) post-treatment scores (long-term: $>3$ mos, closest to 6 mos)

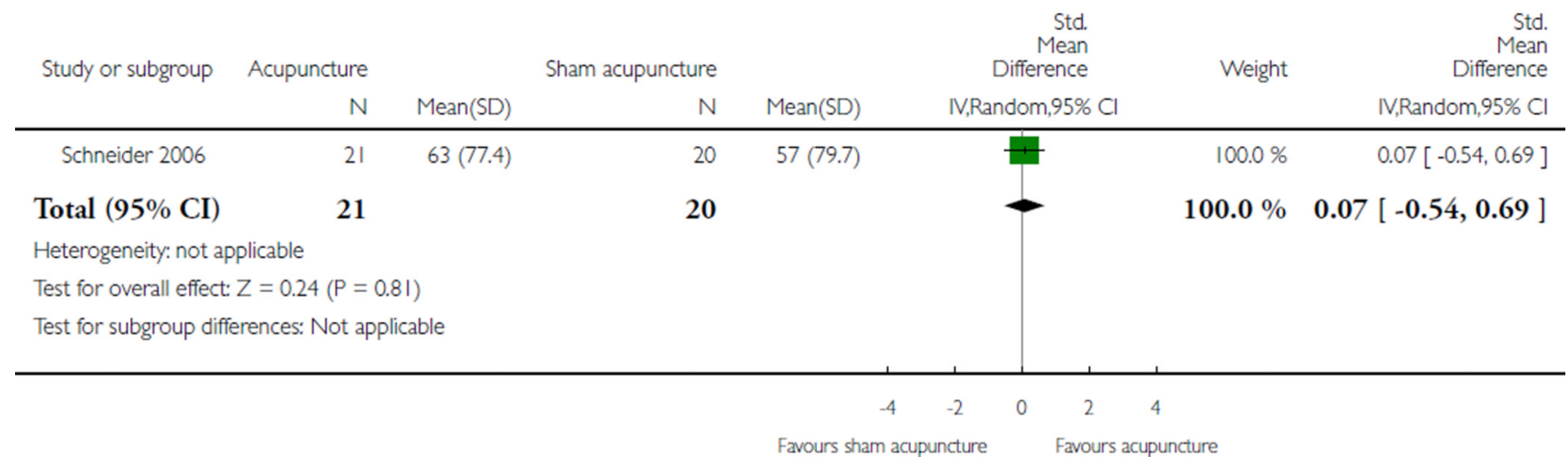

Analysis 1.6.

Comparison 1 Acupuncture versus sham acupuncture, Outcome 6 Quality of life (mean outcomes) post-treatment scores (long-term: >3 mos, closest to 6 mos). 
Review: Acupuncture for treatment of irritable bowel syndrome
Comparison: 2 Acupuncture versus pharmacological medication
Outcome: I Symptom severity (responders) (short-term: up to 3 mons, closest to 8 wks)

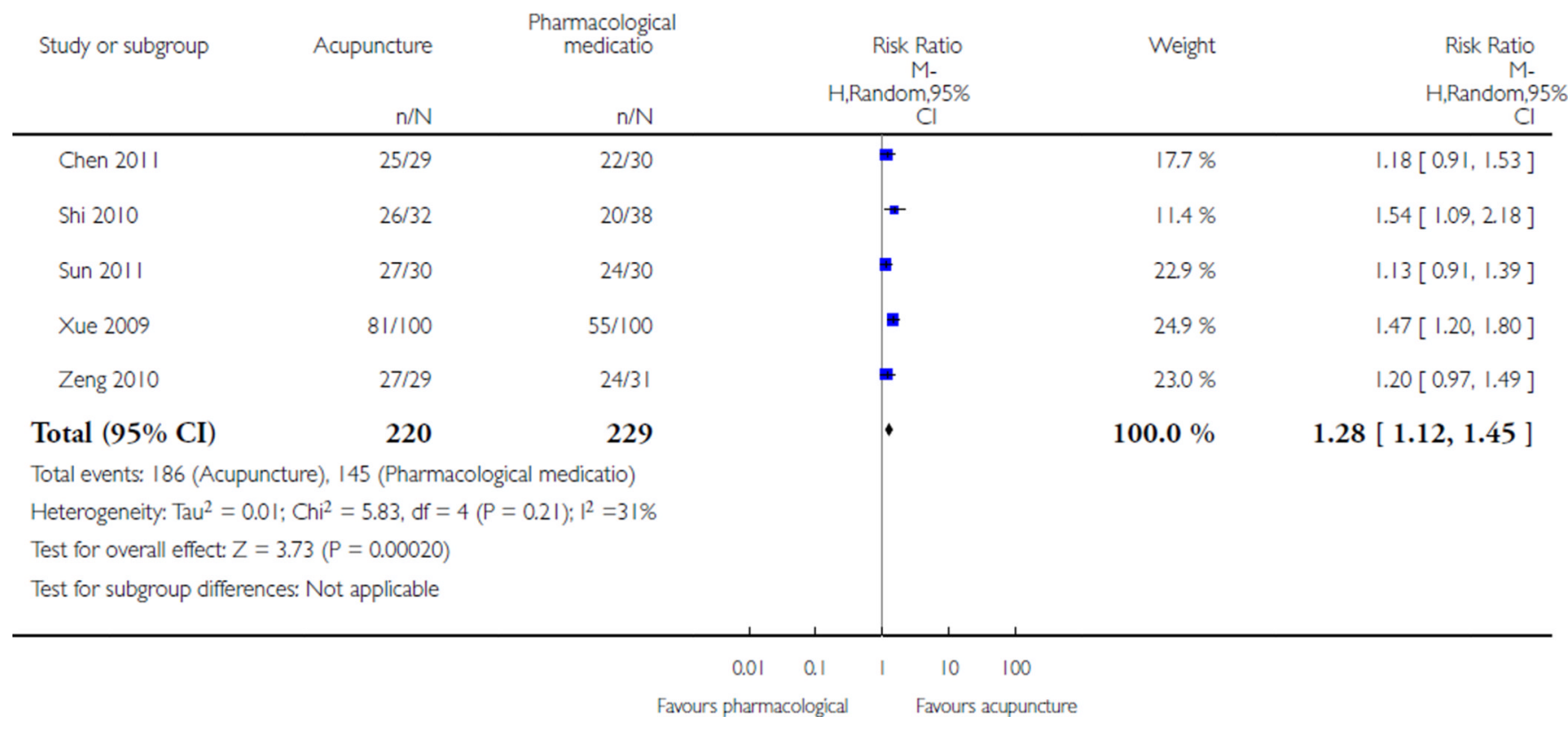

\section{Analysis 2.1.}

Comparison 2 Acupuncture versus pharmacological medication, Outcome 1 Symptom severity (responders) (short-term: up to 3 mons, closest to $8 \mathrm{wks}$ ). 


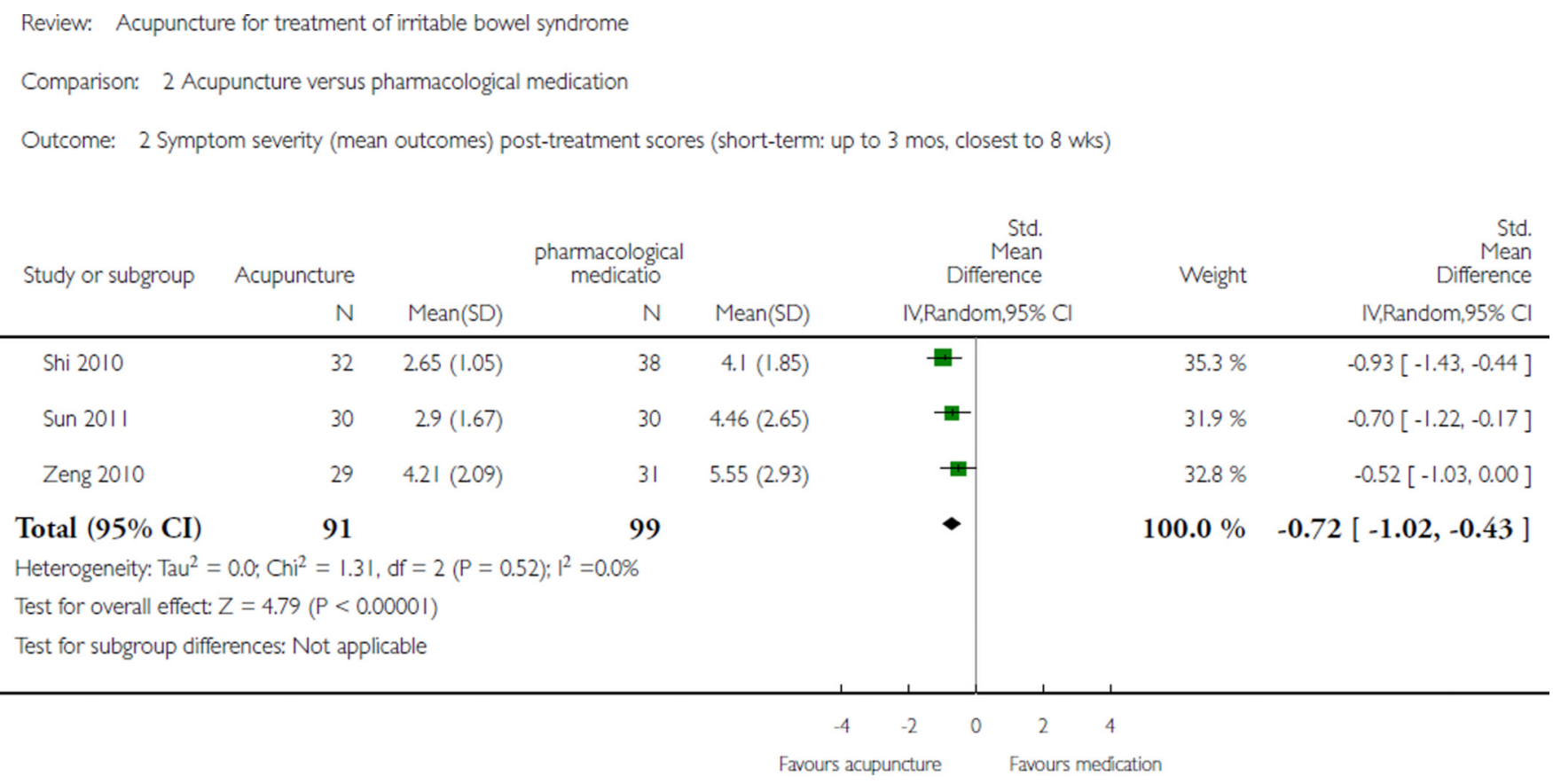

Analysis 2.2.

Comparison 2 Acupuncture versus pharmacological medication, Outcome 2 Symptom severity (mean outcomes) post-treatment scores (short-term: up to 3 mos, closest to 8 wks). 


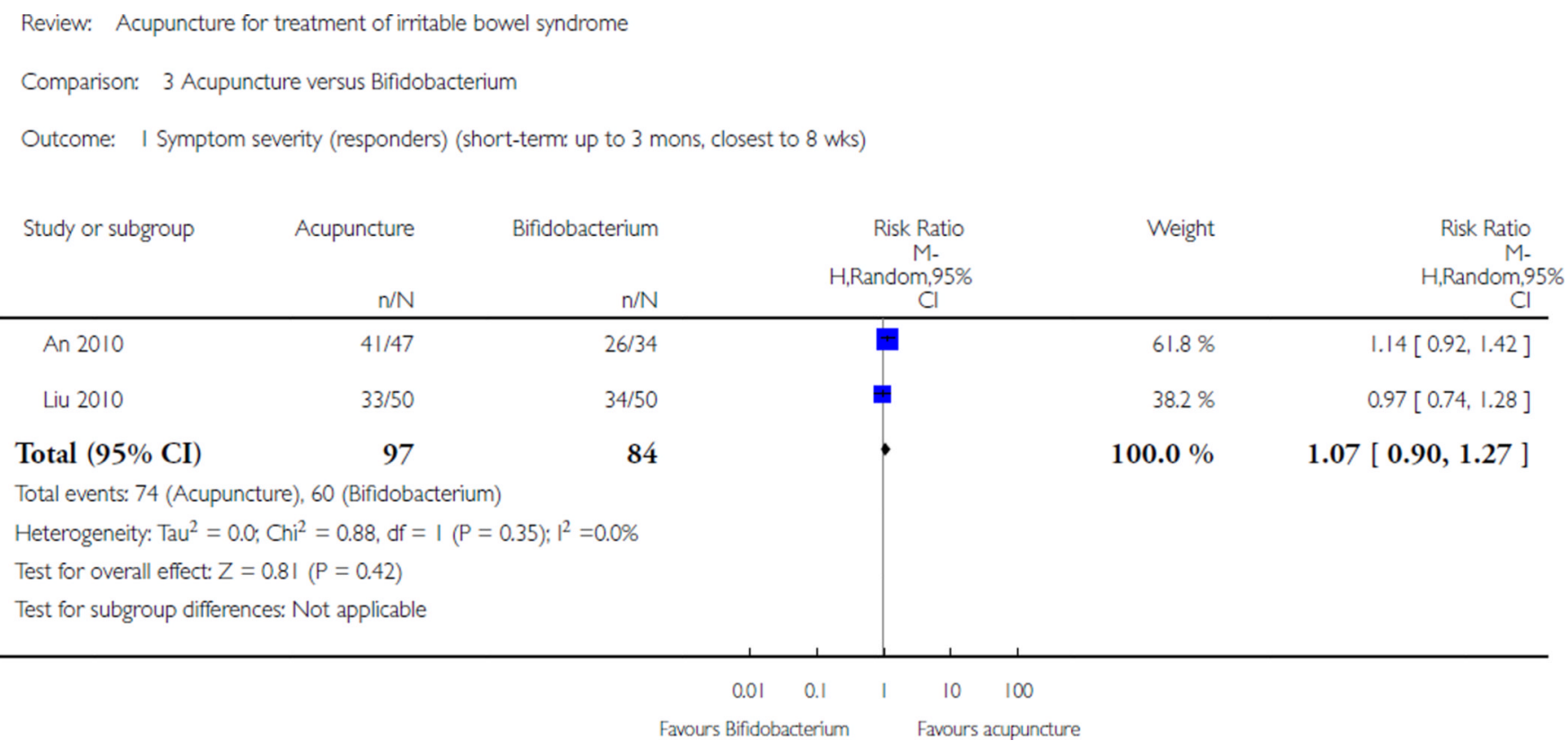

\section{Analysis 3.1.}

Comparison 3 Acupuncture versus Bifidobacterium, Outcome 1 Symptom severity (responders) (short-term: up to 3 mons, closest to 8 wks). 


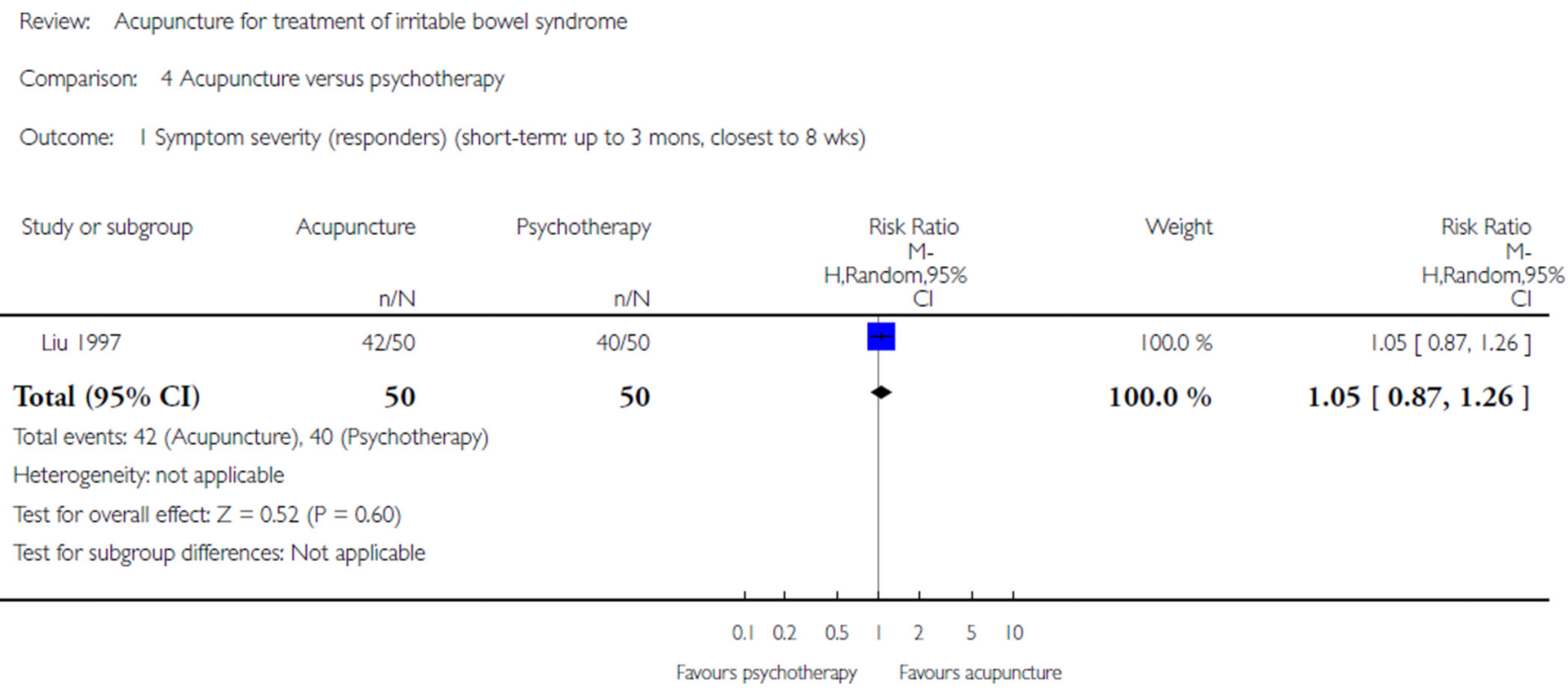

\section{Analysis 4.1.}

Comparison 4 Acupuncture versus psychotherapy, Outcome 1 Symptom severity (responders) (short-term: up to 3 mons, closest to 8 wks). 


\begin{tabular}{|c|c|c|c|c|c|}
\hline \multicolumn{6}{|c|}{ Comparison: 5 Acupuncture plus psychotherapy versus psychotherapy alone } \\
\hline \multicolumn{6}{|c|}{ Outcome: I Symptom severity (responders) (short-term: up to 3 mons, closest to 8 wks) } \\
\hline Study or subgroup & $\begin{array}{c}\text { Acupuncture } \\
\text { as adjunct } \\
n / N\end{array}$ & $\begin{array}{r}\text { No acupuncture } \\
n / N\end{array}$ & $\begin{array}{c}\text { Risk Ratio } \\
\text { M- } \\
\text { H,Random,95\% } \\
\mathrm{Cl} \\
\end{array}$ & Weight & $\begin{array}{c}\text { Risk Ratio } \\
\mathrm{M}- \\
\mathrm{H}, \text { Random,95\% } \\
\mathrm{Cl} \\
\end{array}$ \\
\hline Liu 1997 & $48 / 50$ & $40 / 50$ & 田 & $49.0 \%$ & $1.20[1.03,1.39]$ \\
\hline Xiong 2008a & $40 / 42$ & $34 / 40$ & 巴 & $51.0 \%$ & $1.12[0.97,1.30]$ \\
\hline Total $(95 \% \mathrm{CI})$ & 92 & 90 & $\bullet$ & $100.0 \%$ & $1.16[1.04,1.29]$ \\
\hline \multicolumn{6}{|c|}{ Total events: 88 (Acupuncture as adjunct), 74 (No acupuncture) } \\
\hline \multicolumn{6}{|c|}{ Heterogeneity: $\operatorname{Ta}^{2}=0.0 ; \mathrm{Ch}^{2}=0.42, \mathrm{df}=1(P=0.52) ; 1^{2}=0.0 \%$} \\
\hline \multicolumn{6}{|c|}{ Test for overall effect: $Z=2.76(P=0.0059)$} \\
\hline \multicolumn{6}{|c|}{ Test for subgroup differences: Not applicable } \\
\hline
\end{tabular}

Analysis 5.1.

Comparison 5 Acupuncture plus psychotherapy versus psychotherapy alone, Outcome 1 Symptom severity (responders) (short-term: up to 3 mons, closest to $8 \mathrm{wks}$ ). 


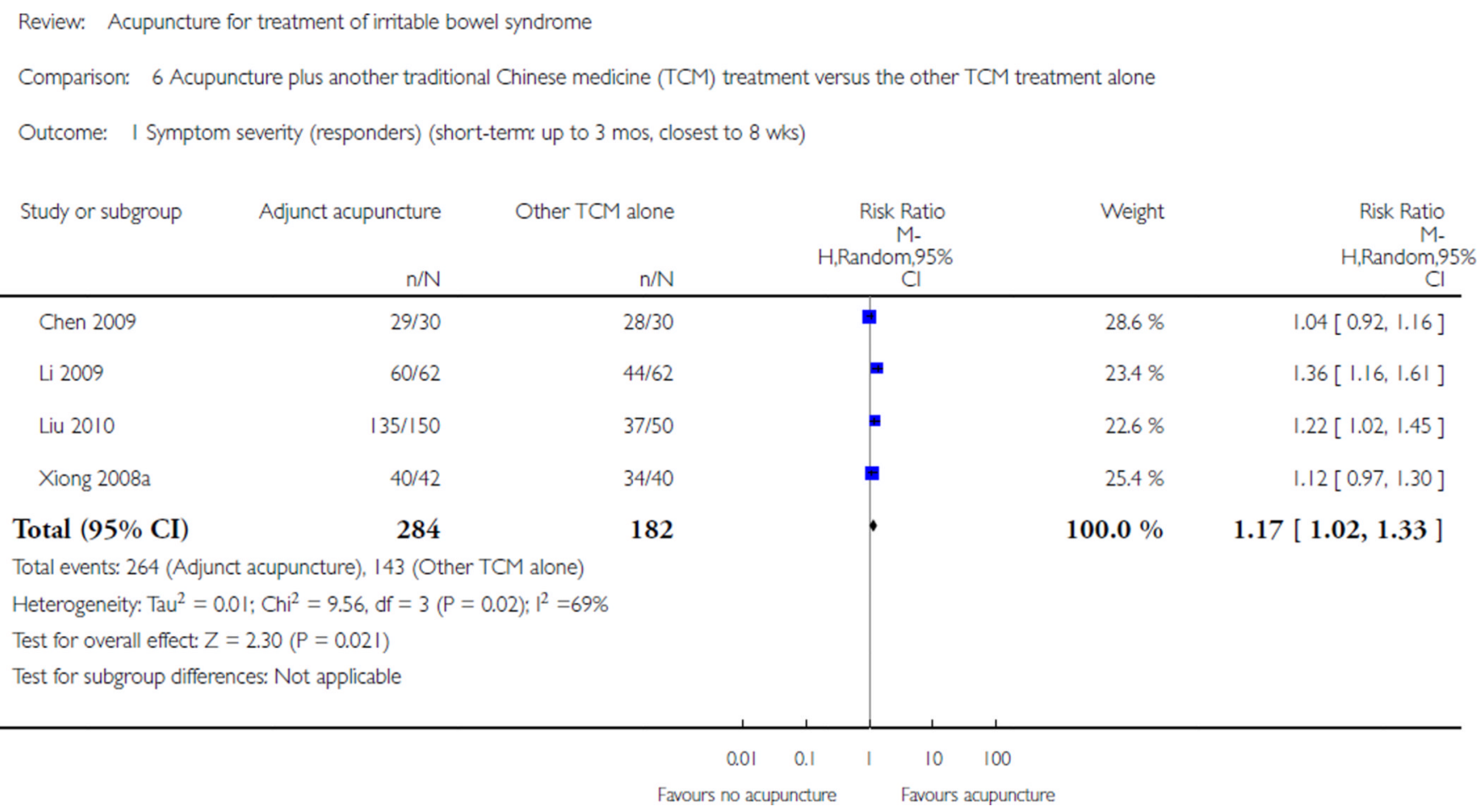

\section{Analysis 6.1.}

Comparison 6 Acupuncture plus another traditional Chinese medicine (TCM) treatment versus the other TCM treatment alone, Outcome 1 Symptom severity (responders) (shortterm: up to 3 mos, closest to $8 \mathrm{wks}$ ). 


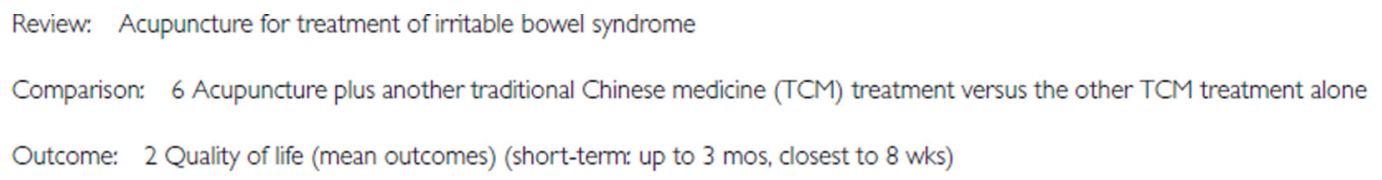

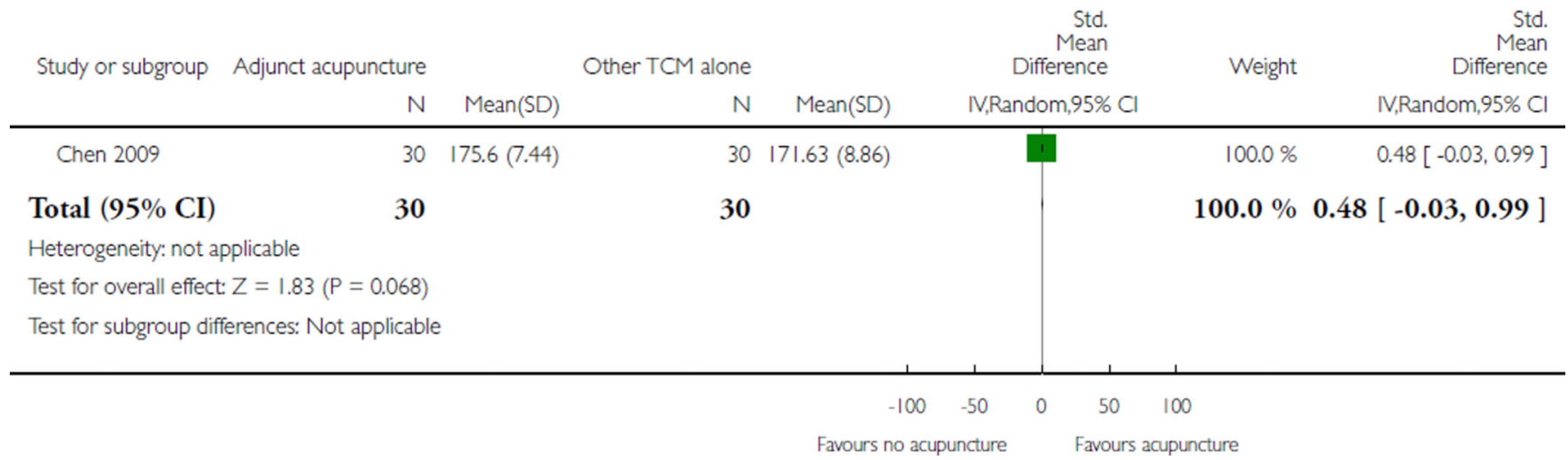

Analysis 6.2.

Comparison 6 Acupuncture plus another traditional Chinese medicine (TCM) treatment versus the other TCM treatment alone, Outcome 2 Quality of life (mean outcomes) (shortterm: up to 3 mos, closest to 8 wks). 


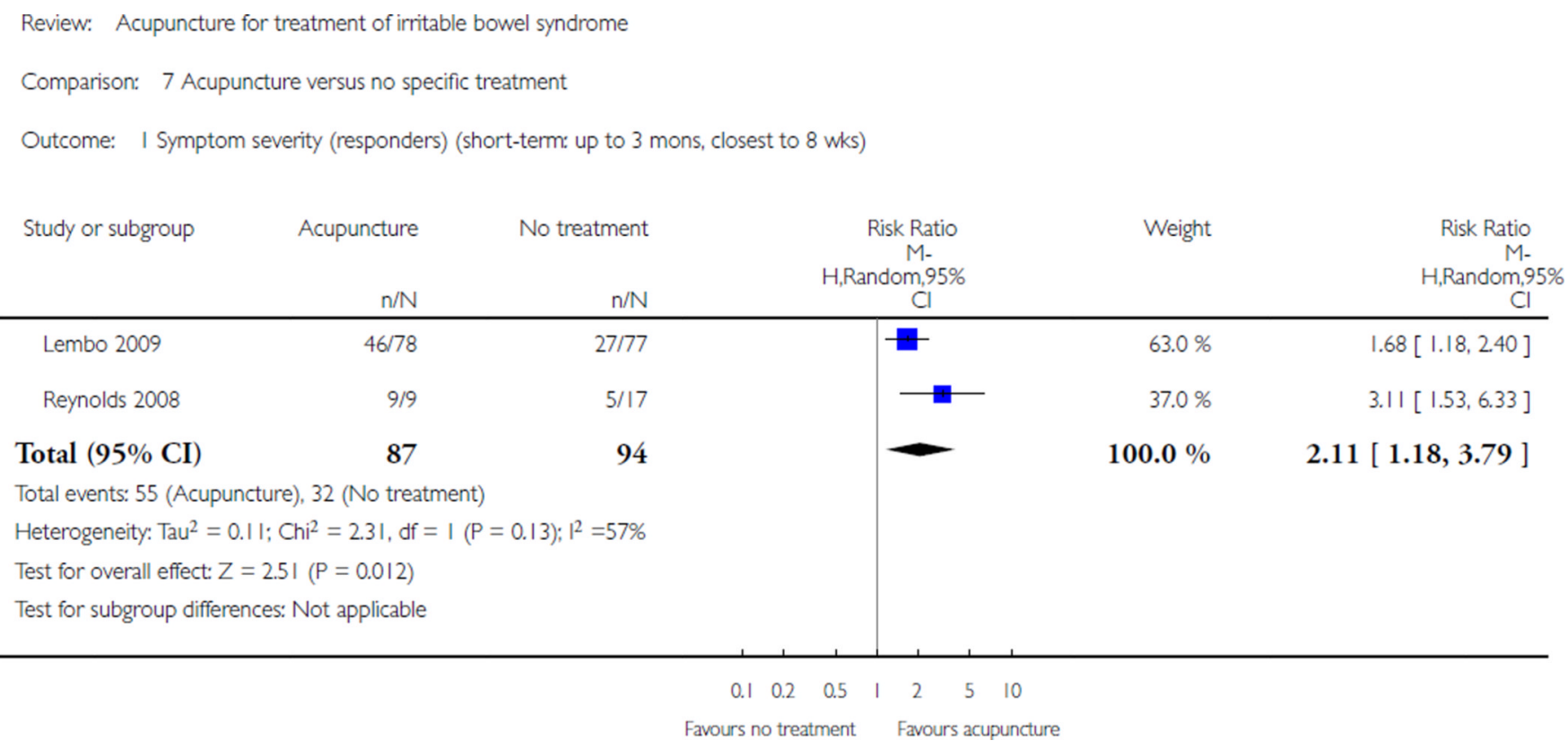

\section{Analysis 7.1.}

Comparison 7 Acupuncture versus no specific treatment, Outcome 1 Symptom severity (responders) (short-term: up to 3 mons, closest to 8 wks). 
Review: Acupuncture for treatment of irritable bowel syndrome

Comparison: 7 Acupuncture versus no specific treatment

Outcome: 2 Symptom severity (mean outcomes) post-treatment scores (short-term: up to 3 mos, closest to 8 wks)

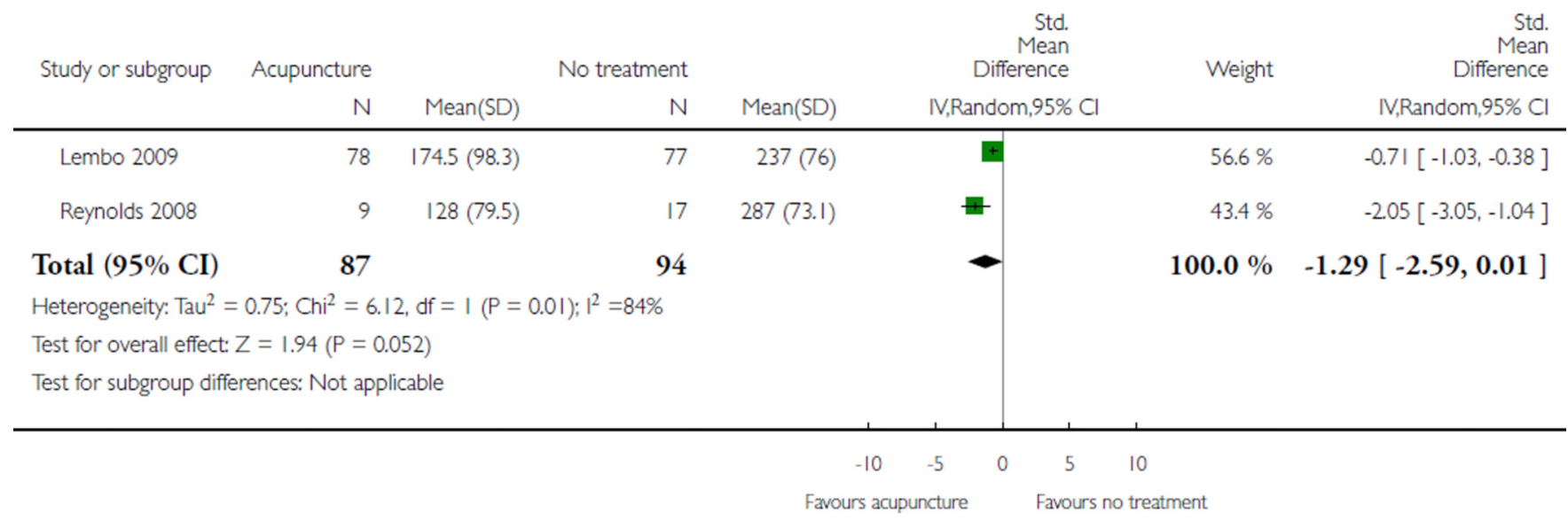

\section{Analysis 7.2.}

Comparison 7 Acupuncture versus no specific treatment, Outcome 2 Symptom severity (mean outcomes) post-treatment scores (short-term: up to 3 mos, closest to $8 \mathrm{wks}$ ). 
Review: Acupuncture for treatment of irritable bowel syndrome
Comparison: 7 Acupuncture versus no specific treatment
Outcome: 3 Quality of life (mean outcomes) post-treatment scores (short-term: up to 3 mos, closest to 8 wks)

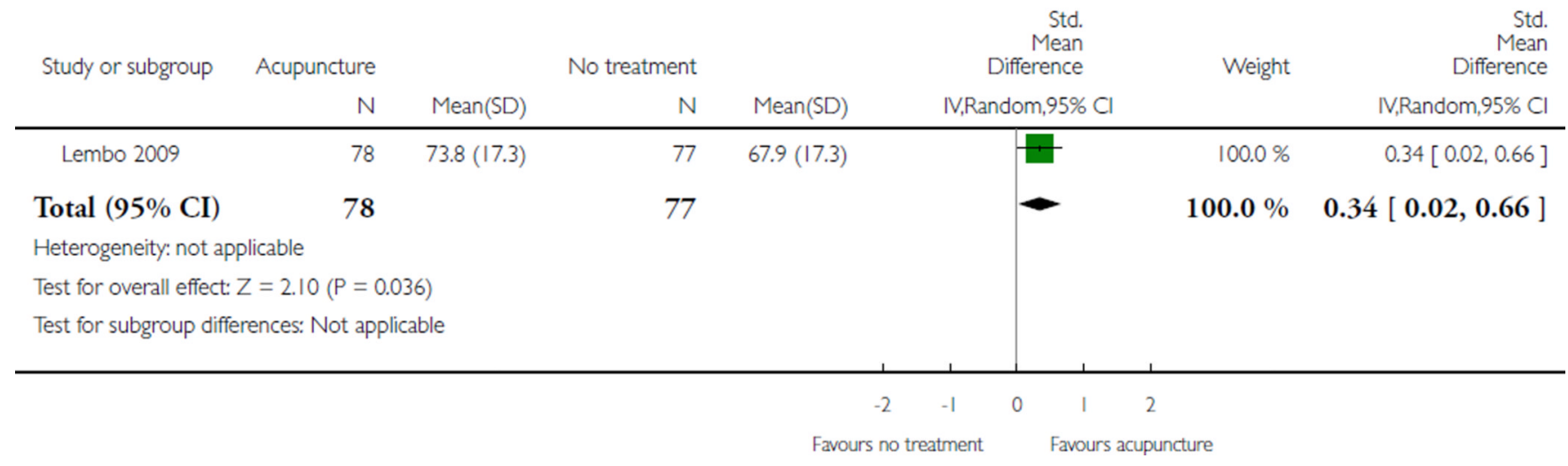

Analysis 7.3.

Comparison 7 Acupuncture versus no specific treatment, Outcome 3 Quality of life (mean outcomes) post-treatment scores (short-term: up to 3 mos, closest to $8 \mathrm{wks}$ ). 


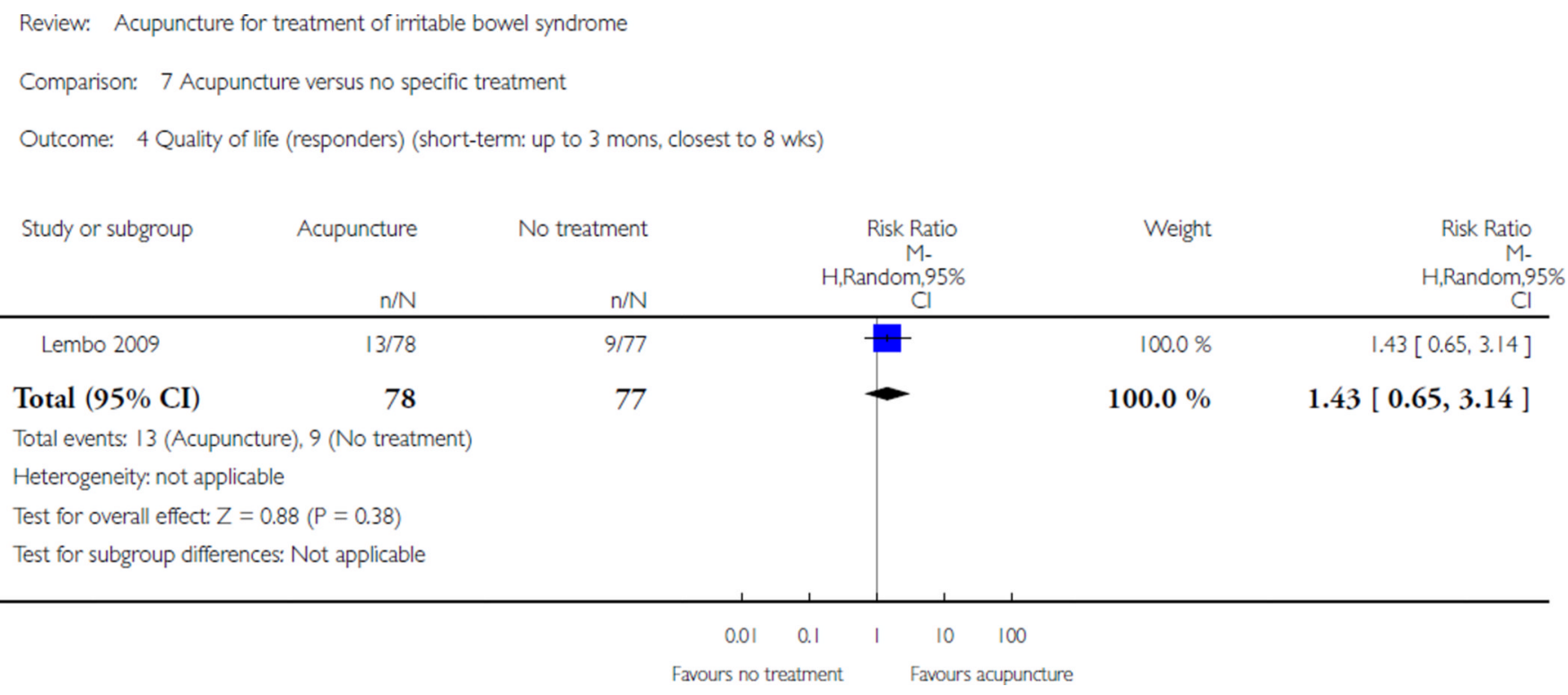

\section{Analysis 7.4.}

Comparison 7 Acupuncture versus no specific treatment, Outcome 4 Quality of life (responders) (short-term: up to 3 mons, closest to $8 \mathrm{wks}$ ). 


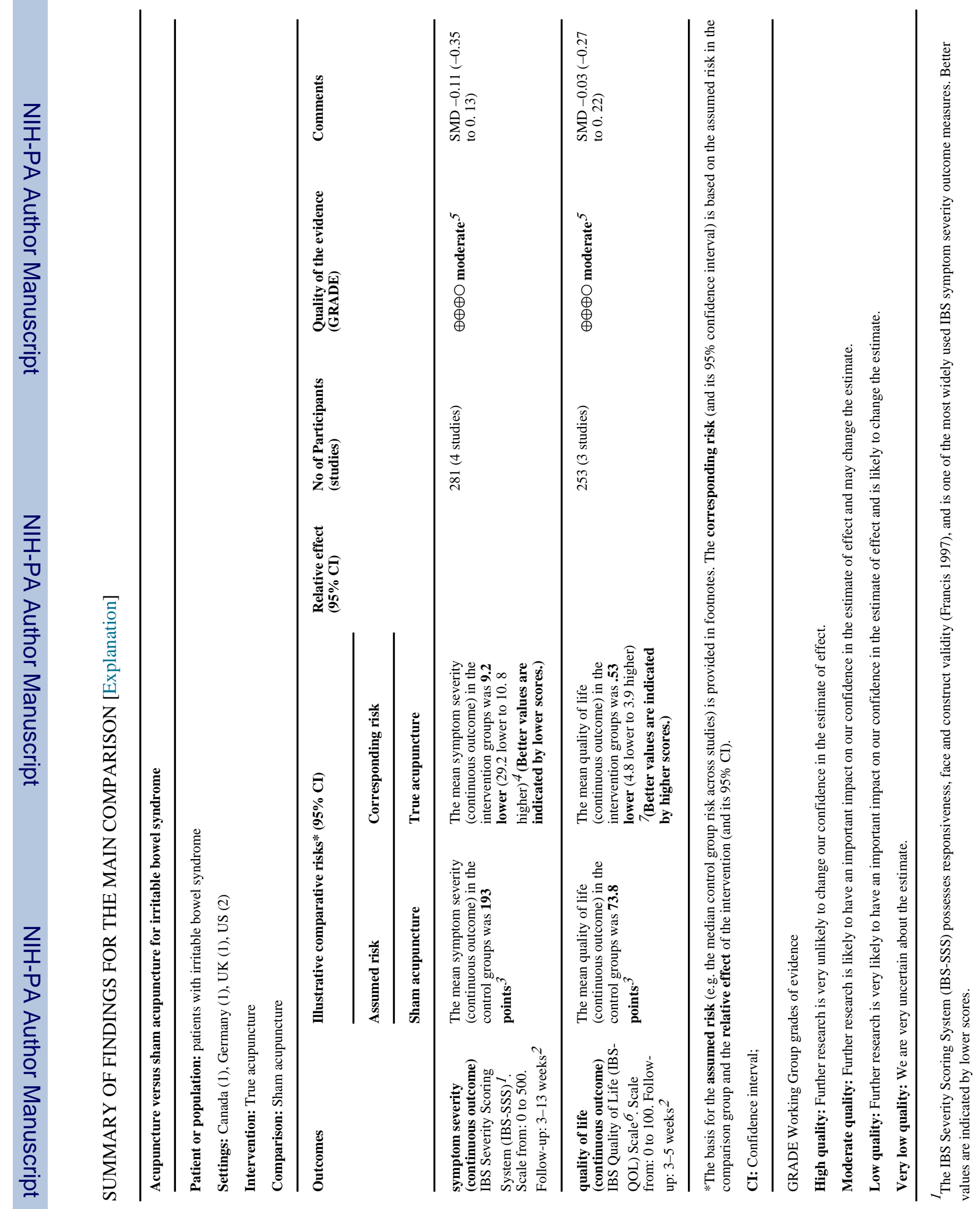




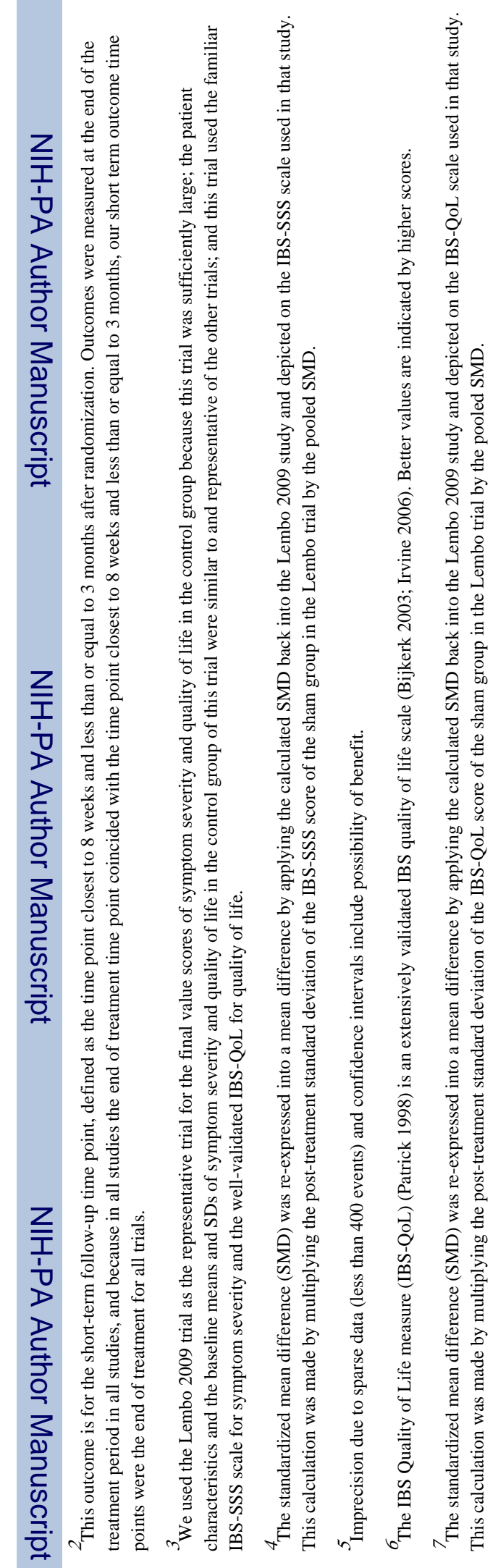

Cochrane Database Syst Rev. Author manuscript; available in PMC 2013 July 22. 


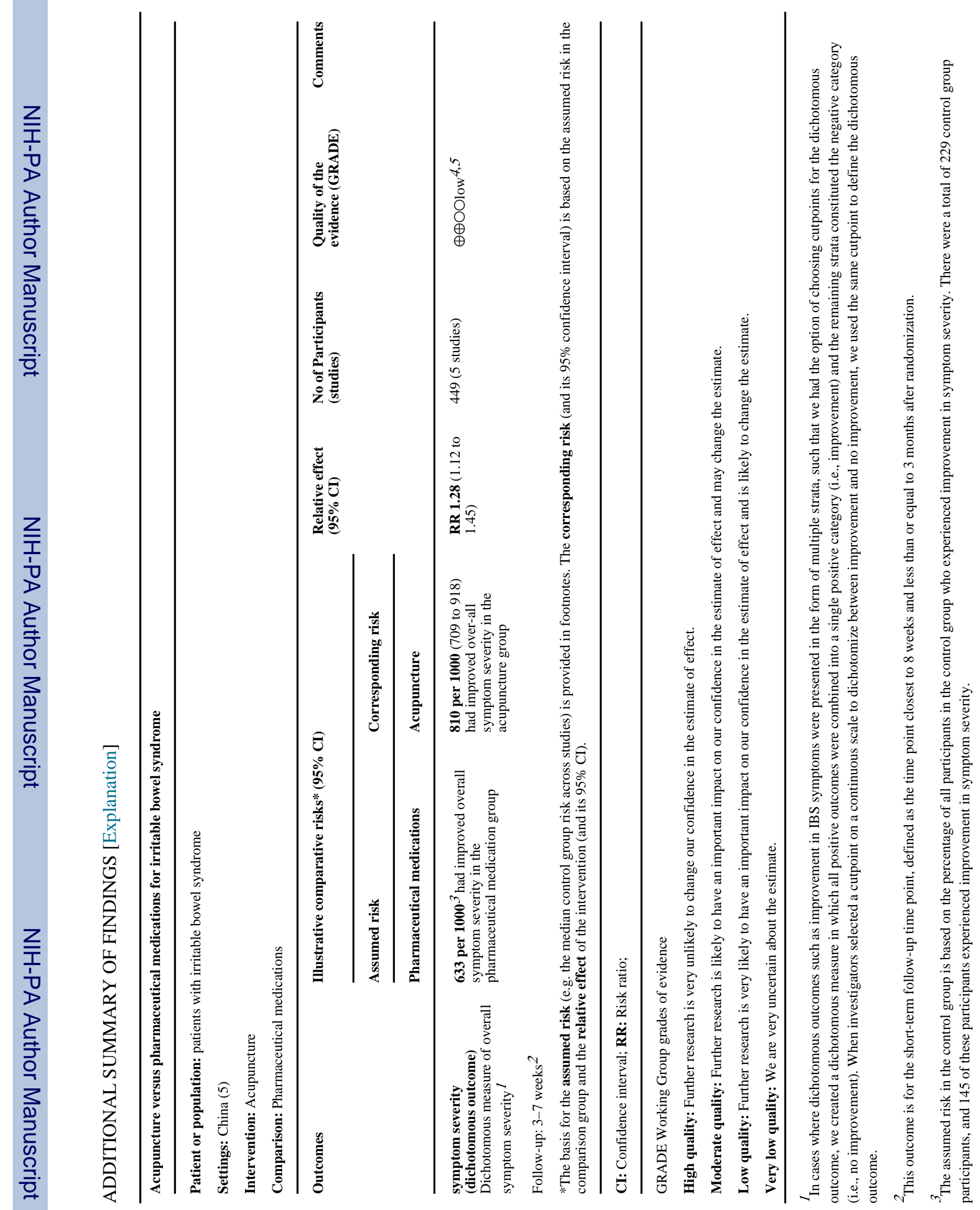




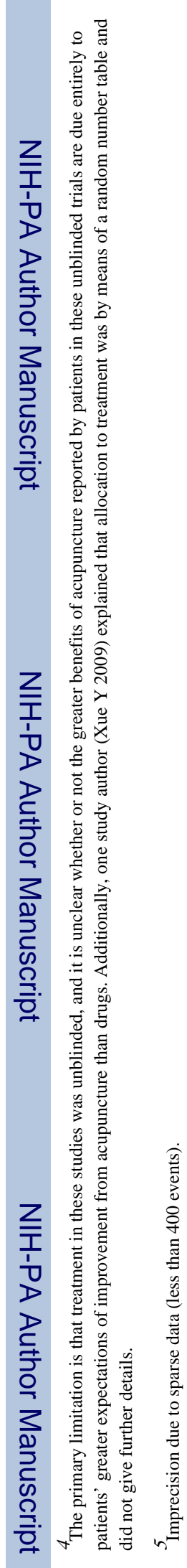

Cochrane Database Syst Rev. Author manuscript; available in PMC 2013 July 22. 


\title{
CHARACTERISTICS OF STUDIES
}

\author{
Characteristics of included studies [ordered by study ID]
}

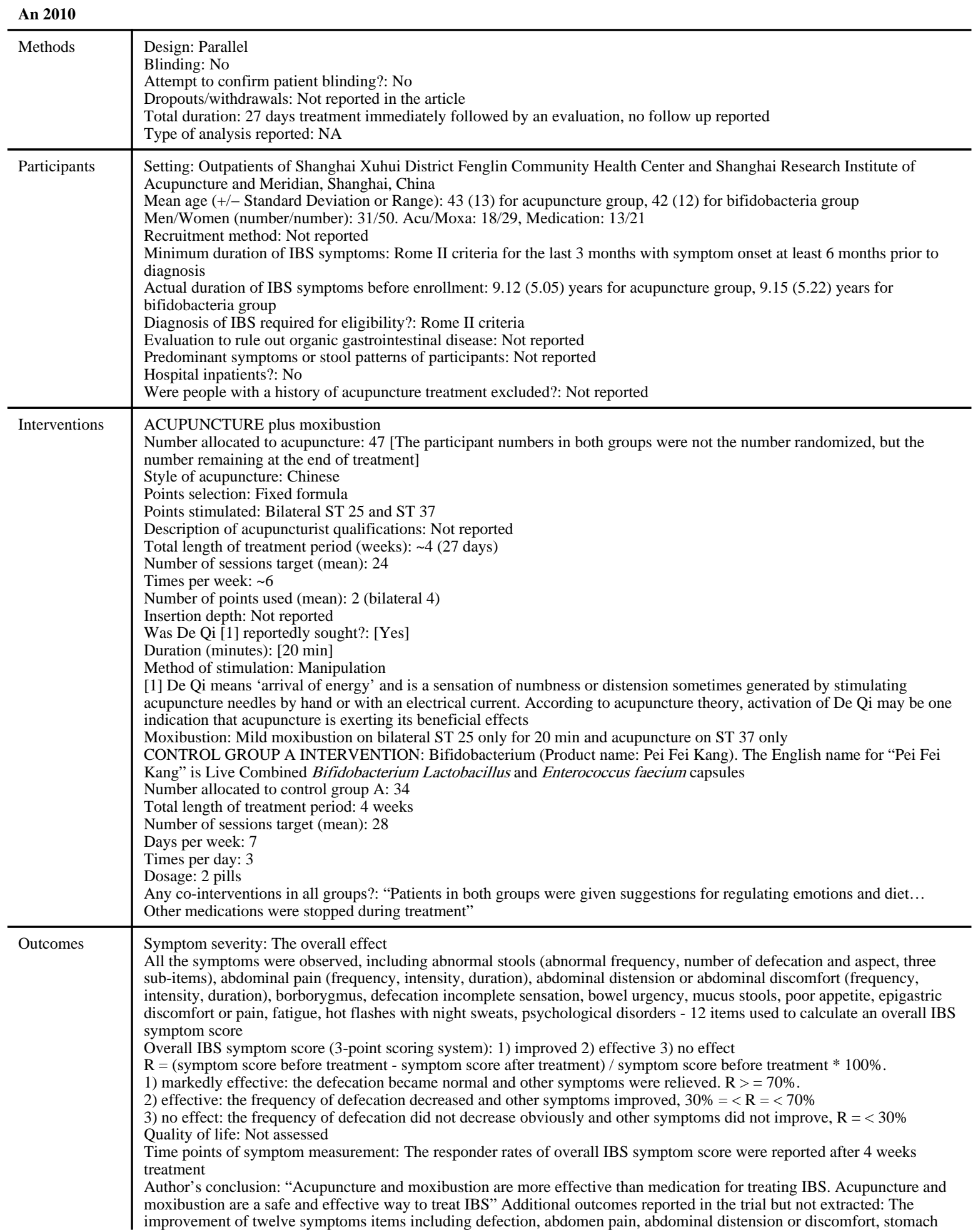

Cochrane Database Syst Rev. Author manuscript; available in PMC 2013 July 22. 


\begin{tabular}{|c|c|c|}
\hline & \multicolumn{2}{|c|}{$\begin{array}{l}\text { rumbling, feeling of unfinished defection, feeling of urgent need to defect, mucus stool, indigestion and loss of appetite, } \\
\text { stomach discomfort or distending pain, asthenia, hot flushes and night sweats and mental aberration were reported after } 4 \\
\text { weeks treatment| "No adverse events were observed" } \\
\text { Adverse effects: "No }\end{array}$} \\
\hline Notes & \multicolumn{2}{|c|}{$\begin{array}{l}\text { Comments: } \\
\text { Funding sources: Project of Xuhui District Health Bureau of Shanghai (SHXH20070402) } \\
\text { randomization: Referring to a random number table } \\
\text { Allocation: [Sequentially numbered, opaque, sealed envelopes] } \\
\text { Additional information in square brackets was provided by the first author An GQ, in a telephone survey on September 1, } \\
2011 \\
\text { We dichotomized improved, effective and no effect into the } 2 \text { categories of improved or not improved according to the } \\
\text { methods section of the review }\end{array}$} \\
\hline \multicolumn{3}{|l|}{ Risk of bias } \\
\hline Bias & Authors' judgement & Support for judgement \\
\hline $\begin{array}{l}\text { Random } \\
\text { sequence } \\
\text { generation } \\
\text { (selection bias) }\end{array}$ & Low risk & $\begin{array}{l}\text { "Referring to a random number table, we assigned } 47 \text { participants } \\
\text { into acupuncture-moxibustion group and } 34 \text { participants into } \\
\text { bifidobacteria group" }\end{array}$ \\
\hline $\begin{array}{l}\text { Allocation } \\
\text { concealment } \\
\text { (selection bias) }\end{array}$ & Low risk & [Sequentially numbered, opaque, sealed envelopes] \\
\hline $\begin{array}{l}\text { Blinding } \\
\text { (performance } \\
\text { bias and } \\
\text { detection bias) } \\
\text { All outcomes }\end{array}$ & High risk & $\begin{array}{l}\text { Single blind: The evaluators were blind to the participant } \\
\text { assignment }\end{array}$ \\
\hline $\begin{array}{l}\text { Incomplete } \\
\text { outcome data } \\
\text { (attrition bias) } \\
\text { Short term }\end{array}$ & Unclear risk & $\begin{array}{l}\text { Dropouts were not reported in the article. [There were dropouts } \\
\text { during the } 4 \text { weeks of treatment, but the author could not recall the } \\
\text { number of the dropouts in both groups] }\end{array}$ \\
\hline $\begin{array}{l}\text { Selective } \\
\text { reporting } \\
\text { (reporting bias) }\end{array}$ & Low risk & $\begin{array}{l}\text { This trial reported outcomes for overall IBS symptom score at the } \\
\text { completion of the } 4 \text { week treatment period, together with results } \\
\text { for each outcome measured }\end{array}$ \\
\hline Other bias & Unclear risk & $\begin{array}{l}\text { ITT analysis was not reported and the author also could not recall } \\
\text { the number of dropouts, so we could not estimate whether the } \\
\text { "missingness" would affect the treatment effect in this trial } \\
\text { "The two groups were comparable at baseline in terms of sex }(\mathrm{P}= \\
0.084) \text {, age }(\mathrm{P}=0.389) \text { and disease duration }(\mathrm{P}=0.708) \text {." There } \\
\text { was no description or } \mathrm{P} \text { value reported for the comparison of } \\
\text { symptom score between two groups at baseline }\end{array}$ \\
\hline
\end{tabular}

\section{Anastasi 2009}

\begin{tabular}{|c|c|}
\hline Methods & $\begin{array}{l}\text { Design: Parallel } \\
\text { Blinding: Yes. "The SF monitored and recorded Acu/Moxa point sequencing and duration and maintained blinding. The PI, } \\
\text { data manager, statistician, DA, and study coordinator were all blinded to study assignment until the final statistical analysis." } \\
\text { Also, "all subjects were blindfolded during treatment..."Attempt to confirm patient blinding? : No } \\
\text { Dropouts/withdrawals: During the } 4 \text { weeks, } 2 / 14 \text { drop-outs in acupuncture/moxibustion group and } 0 / 15 \text { drop-outs in the } \\
\text { sham group. An additional } 1 / 14 \text { participants in the acupuncture/moxibustion group and } 3 / 15 \text { in sham acupuncture/ } \\
\text { moxibustion group did not complete the symptom diary at end of follow-up, however the symptom diary was not an } \\
\text { outcome for this review } \\
\text { Total duration: } 4 \text { weeks of treatment, evaluation at } 3 \text { weeks and } 4 \text { weeks after baseline (symptom diary) } \\
\text { Type of analysis reported: Not specified }\end{array}$ \\
\hline Participants & $\begin{array}{l}\text { Setting: outpatient research lab, USA } \\
\text { Mean age (+/-SD or Range): } 40.4 \text { ( } 34.6 \text { to } 46.2) \\
\text { Men/Women (n/n): } 10 / 19 \\
\text { Recruitment method: "Subjects were recruited by the study team by informing GI practitioners, internists, and nurse } \\
\text { practitioners in the New York City area about the study. Advertisements were also posted in select New York newspapers } \\
\text { and community boards. Potential subjects responding to advertisements or practitioner referrals were screened by the } \\
\text { primary investigator (PI) and research staff for eligibility" } \\
\text { Minimum duration of IBS symptoms: } 6 \text { months } \\
\text { Actual duration of IBS symptoms before enrollment: Not stated } \\
\text { Diagnosis of IBS required to be eligible? (if yes, describe how patients were verified to have IBS): Rome III criteria } \\
\text { Evaluation to rule out organic gastrointestinal disease: "Subjects had to have verification from their medical provider } \\
\text { confirming their IBS diagnosis and absence of pathology confirmed by diagnostic workup" }\end{array}$ \\
\hline
\end{tabular}




\begin{tabular}{|c|c|c|}
\hline & \multicolumn{2}{|c|}{$\begin{array}{l}\text { Predominant symptoms or stool patterns of participants: Not reported } \\
\text { Hospital inpatients? (Y/N; if Y list number inpatients): No } \\
\text { Were people with a history of acupuncture treatment excluded?: Yes, if they had received acupuncture during the past } 6 \\
\text { months }\end{array}$} \\
\hline Interventions & \multicolumn{2}{|c|}{ 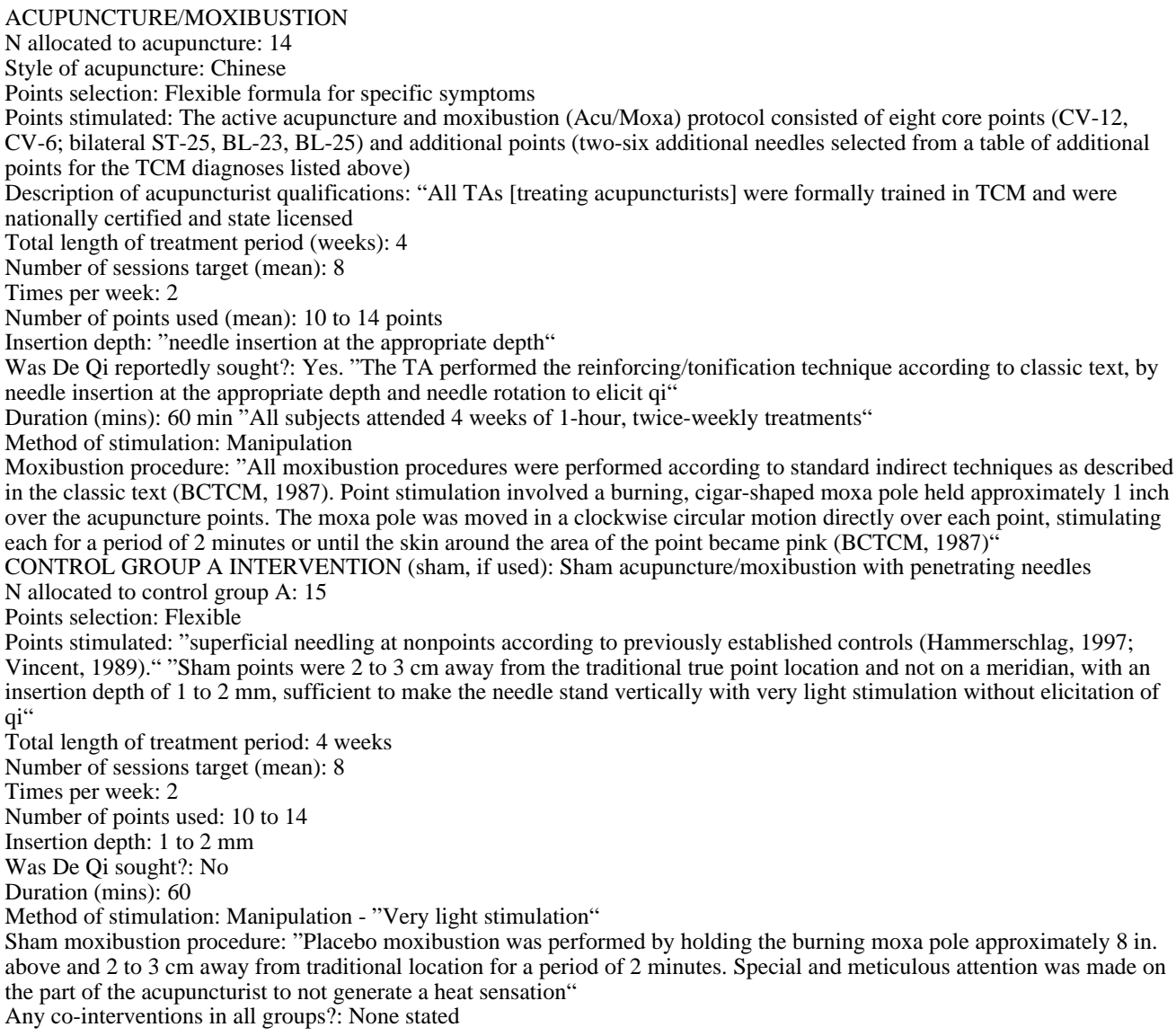 } \\
\hline Outc & \multicolumn{2}{|c|}{$\begin{array}{l}\text { Symptom severity: "The Clinical Global Impression Scale (CGIS) measures the patient-perceived severity of symptoms with } \\
\text { a 7-point Likert-type scale ranging from } 0 \text { (no discomfort) to } 6 \text { (very severe discomfort) } \\
\text { Quality of life: Not assessed } \\
\text { Time points of symptom measurement: "The CGIS was administered at baseline before the intervention and again at } \\
\text { completion of the 4-week treatment period" } \\
\text { Author's conclusion: "The findings indicate that Acu/Moxa treatment shows promise in the area of symptom management } \\
\text { for IBS" } \\
\text { Additional outcomes reported in the trial but not extracted: Symptoms of 1) Abdominal pain/discomfort, and 2) intestinal } \\
\text { gas, bloating, and stool consistency } \\
\text { Adverse effects: "Among the } 29 \text { subjects in this eight-session study, no adverse events were reported" }\end{array}$} \\
\hline Notes & \multicolumn{2}{|c|}{$\begin{array}{l}\text { Comments: Carefully worked, especially for the blinding of subjects } \\
\text { Weak points: Small sample size } \\
\text { Standard deviations for CGIS at pretreatment and post-treatment were not reported. We used the confidence interval for the } \\
\text { mean difference to calculate post-treatment standard deviations } \\
\text { The first author Joyce Anastasi was contacted by e-mail to request information about randomization, allocation concealment } \\
\text { and CGIS. She replied with detailed information on February } 10,2010 \\
\text { Funding sources: Not stated }\end{array}$} \\
\hline \multicolumn{3}{|l|}{ Risk of bias } \\
\hline Bias & Authors' judgement & \\
\hline & Low risk & \\
\hline
\end{tabular}


Anastasi 2009

\begin{tabular}{|c|c|c|}
\hline $\begin{array}{l}\text { Allocation } \\
\text { concealment } \\
\text { (selection bias) }\end{array}$ & Low risk & $\begin{array}{l}\text { [We assured that blinded and masked allocation of intervention was preserved during the study. } \\
\text { These codes were delivered in a masked log sheet, consecutively numbered, again with only codes } \\
\# 1 \text { or \# } 2 \text { (not the meaning of the code). The log sheet was kept in a binder (in a locked cabinet) for } \\
\text { a blinded study coordinator with no involvement with the facilitation of the treatments. Once it was } \\
\text { determined that the subject was eligible, the study facilitator contacted a blinded study coordinator } \\
\text { to receive the code. The study facilitator did not have access to the randomization sequence log } \\
\text { sheet. Upon receiving the code (\#1 or \#2), the study facilitator would translate the code into the } \\
\text { actual treatment condition for the treating acupuncturist. The principal investigator, data manager, } \\
\text { statistician, diagnostic acupuncturist and the study coordinator were blinded to the treatment } \\
\text { condition code. It was only after, the completion of the last study subject and all data were entered } \\
\text { and analyzed, the treatment condition was revealed (that is the corresponding treatment associated } \\
\text { with codes \#1 and \#2)] }\end{array}$ \\
\hline $\begin{array}{l}\text { Blinding } \\
\text { (performance } \\
\text { bias and } \\
\text { detection bias) } \\
\text { All outcomes }\end{array}$ & Low risk & $\begin{array}{l}\text { "The SF monitored and recorded Acu/Moxa point sequencing and duration and maintained } \\
\text { blinding. The PI, data manager, statistician, DA, and study coordinator were all blinded to study } \\
\text { assignment until the final statistical analysis" } \\
\text { "All subjects were blindfolded during treatment....." } \\
\text { "Subjects received sham acupuncture by superficial needling at nonpoints according to previously } \\
\text { established controls (Hammerschlag, 1997; Vincent, 1989). The sham points were as anatomically } \\
\text { precise as an active treatment protocol so that they were reproducible and consistent. Sham points } \\
\text { were } 2 \text { to } 3 \mathrm{~cm} \text { away from the traditional true point location and not on a meridian, with an } \\
\text { insertion depth of } 1 \text { to } 2 \mathrm{~mm} \text {, sufficient to make the needle stand vertically with very light } \\
\text { stimulation without elicitation of qi. This procedure" minimizes the specific effects of the needling } \\
\text { while maintaining its psychological impact" (Vincent \& Lewith, 1995) and has been assessed as a } \\
\text { credible and effective control procedure (Birch, Hammerschlag, Trinh, \& Zaslawski, 2002; Stux \& } \\
\text { Hammerschlag, } 2001 \text {; Vincent } 1989 \text {; Vincent \& Lewith } 1995) \text {." } \\
\text { "Placebo moxibustion was performed by holding the burning moxa pole approximately } 8 \text { inches } \\
\text { above and } 2 \text { to } 3 \text { cm away from traditional location for a period of } 2 \text { minutes. Special and } \\
\text { meticulous attention was made on the part of the acupuncturist to not generate a heat sensation. } \\
\text { Both true treatment and sham/placebo sessions were identical in duration" } \\
\text { Although one of the exclusion criteria in this trial was no use of acupuncture in the past } 6 \text { months, } \\
\text { the patients in this trial were not required to have never used acupuncture (i.e. to be acupuncture } \\
\text { naive) (i.e. "Anyone receiving acupuncture over the past } 6 \text { months with a history of receiving } \\
\text { moxibustion... was not enrolled.") Also, there were no tests for checking the success of the } \\
\text { blinding. However, because a needle insertion sham was used and the needles were inserted close } \\
\text { to the genuine acupuncture points, and because this procedure has reportedly been assessed as a } \\
\text { credible and effective control procedure, we judged that this sham was likely to be } \\
\text { indistinguishable from the true acupuncture }\end{array}$ \\
\hline $\begin{array}{l}\text { Incomplete } \\
\text { outcome data } \\
\text { (attrition bias) } \\
\text { Short term }\end{array}$ & Low risk & $\begin{array}{l}\text { "One withdrew, one lost to follow-up, and four did not submit final symptom diary" At } 4 \text { weeks, } \\
2 / 14(14 \%) \text { participants in the true acupuncture/moxibustion group did not complete the Clinical } \\
\text { Global Impression Scale. All }(15 / 15) \text { participants in the sham control group completed the } 4 \text { week } \\
\text { Clinical Global Impression Scale }\end{array}$ \\
\hline $\begin{array}{l}\text { Selective } \\
\text { reporting } \\
\text { (reporting bias) }\end{array}$ & Low risk & $\begin{array}{l}\text { This trial reported outcomes for overall IBS symptom severity at the completion of the } 4 \text { week } \\
\text { treatment period, together with results for each outcome measured }\end{array}$ \\
\hline Other bias & Low risk & $\begin{array}{l}\text { Although ITT analysis was not reported, there were few drop-outs, so the degree of "missingness" } \\
\text { would be unlikely to affect the estimate of the treatment effect in this trial. The two treatment } \\
\text { groups were comparable at baseline in terms of the variables "abdominal pain/discomfort", } \\
\text { "intestinal gas, bloating, and stool consistency" and "Clinical Global Impression Scale." The two } \\
\text { treatment groups also appeared comparable at baseline in terms of demographic characteristics. } \\
\text { However, there were no statistical tests or P values reported for these comparisons }\end{array}$ \\
\hline
\end{tabular}

Chen 2009

\begin{tabular}{l|l}
\hline Methods & $\begin{array}{l}\text { Design: Parallel } \\
\text { Blinding: No } \\
\text { Attempt to confirm patient blinding?: No } \\
\text { Dropouts/withdrawals: Not reported in the article [In order to ensure the number of } 30 \text { participants for both groups, the } \\
\text { participants who withdrew during the } 4 \text { weeks treatment were eliminated from the trial and new participants were recruited. } \\
\text { The author could not recall the number of the dropouts] } \\
\text { Total duration: } 4 \text { weeks treatment followed by an evaluation, no follow up reported } \\
\text { Type of analysis reported: Not reported }\end{array}$ \\
\hline Participants & $\begin{array}{l}\text { Setting: Outpatient and inpatient of the First Affiliated Hospital of Guangzhou University of Traditional Chinese Medicine } \\
\text { from Jan } 2005 \text { to May } 2006, \text { Guangzhou, China Mean age }(+/- \text { Standard Deviation or Range): Not reported. The age range } \\
\text { for acupuncture plus patented Chinese medicine group was } 18 \text { to } 63 \text { years; the age range for patented Chinese medicine alone } \\
\text { group was } 18 \text { to } 65 \text { years } \\
\text { Men/Women (number/number): } 27 / 33 \\
\text { Recruitment method: Not reported } \\
\text { Minimum duration of IBS symptoms: Rome II criteria for the last } 3 \text { months with symptom onset at least } 6 \text { months prior to } \\
\text { diagnosis }\end{array}$
\end{tabular}

Cochrane Database Syst Rev. Author manuscript; available in PMC 2013 July 22. 
Chen 2009

\begin{tabular}{|c|c|}
\hline & $\begin{array}{l}\text { Actual duration of IBS symptoms before enrollment: Not reported. The duration range for acupuncture plus patented Chinese } \\
\text { medicine group was } 14 \text { months to } 12 \text { years; the duration range for patented Chinese medicine alone group was } 12 \text { months to } \\
15 \text { years } \\
\text { Diagnosis of IBS required for eligibility?: Rome II criteria and diagnostic criteria for liver-qi stagnation with spleen } \\
\text { deficiency according to the Guiding Principles for Clinical Study of New Chinese Medicine } \\
\text { Evaluation to rule out organic gastrointestinal disease: Yes } \\
\text { Predominant symptoms or stool patterns of participants: Not reported } \\
\text { Hospital inpatients?: Yes, the number inpatients was not reported } \\
\text { Were people with a history of acupuncture treatment excluded?: Not reported }\end{array}$ \\
\hline Interventions & $\begin{array}{l}\text { ACUPUNCTURE (Warming needle moxibustion) plus patented Chinese medicine } \\
\text { Number allocated to acupuncture: } 30 \\
\text { Style of acupuncture: Chinese warming needle } \\
\text { Points selection: Flexible formula } \\
\text { Points stimulated: } 2 \text { main fixed acupoints and } 2 \text { to } 5 \text { optional points. The fixed points were bilateral ST } 25 \text { and BL 25. The } \\
\text { optional points were HT 7, PC 6, LR } 3 \text { and SP6 for restlessness, insomnia, anxiety and suspiciousness; ST 37, GV 20, GV } 1 \\
\text { and BL } 57 \text { for a sense of incomplete emptying and down-bearing sensation in the anus; CV 12, ST 36, SP 6, LR 3, SP } 9 \text { for } \\
\text { abdominal pain or distension, bowel sounds and severe diarrhea; ST } 37 \text { and SJ } 6 \text { for constipation } \\
\text { Description of acupuncturist qualifications: Not reported } \\
\text { Total length of treatment period (weeks): } 4 \\
\text { Number of sessions target (mean): } 12 \\
\text { Times per week: } 3 \\
\text { Number of points used (mean): } 2 \text { fixed acupoints plus } 2 \text { to } 5 \text { optional points } \\
\text { Insertion depth: Not reported } \\
\text { Was De Qi reportedly sought?: Yes } \\
\text { Duration (minutes): } 30 \text { min } \\
\text { Method of stimulation: Manipulation, even reinforcing - reducing. Warming needle moxibustion only on bilateral ST25 and } \\
\text { BL } 25 \text {, acupuncture on other optional acupoints Warming needle moxibustion means using needles to puncture in the } \\
\text { acupoint first, then put a moxa cone on the needle handle and burn it. Co-intervention: Patented Chinese medicine: Kang Tai } \\
\text { Capsule (previously known as Shun } J i \text { Decoction), } 3 \text { capsules, } 3 \text { times a day } \\
\text { CONTROLGROUP A INTERVENTION: Patented Chinese medicine alone (Product name: Kang Tai Capsule (previously } \\
\text { known as Shun } J i \text { Decoction)) } \\
\text { Number allocated to control group A: } 30 \\
\text { Total length of treatment period: } 4 \text { weeks } \\
\text { Number of sessions target (mean): } 28 \\
\text { Days per week: } 7 \\
\text { Times per day: } 3 \\
\text { Dosage: } 3 \text { capsules / time } \\
\text { Any co-interventions in all groups?: Both groups were administered patented Chinese Medicine }\end{array}$ \\
\hline Outcomes & $\begin{array}{l}\text { Symptom severity: } \\
\text { IBS symptom score for TCM symptom (4-point scoring system): 1) cured 2) improved 4) effective 4) no effect } \\
\mathrm{N} \text { (Efficacy index) }=\text { (symptom score before treatment - symptom score after treatment) / symptom score before treatment * } \\
100 \% \\
\text { 1) Recovery: } \mathrm{N}>=90 \% \\
\text { 2) Markedly effective: } 70 \%=<\mathrm{N}=<90 \% \\
\text { 3) Improvement: } 30 \%=<\mathrm{N}=<70 \% \\
\text { 4) Failure: } \mathrm{N}=<30 \% \\
\text { Quality of life: Functional gastrointestinal disease and quality of life scale created by Prof. Zhou FS, et al included } \\
\text { assessment of field of disease, field of physiology, field of psychology, field of society and total score. There are } 44 \text { items in } \\
\text { the QOL questionnaire. } \\
\text { This does not appear to be a validated scale } \\
\text { Time points of symptom measurement: The responder rates of IBS symptom score for TCM symptom were reported after } 4 \\
\text { weeks treatment. The quality of life score in total and for each field were reported before and after treatment } \\
\text { Author's conclusion: "Both treatment methods could improve the clinical symptoms and increase the patient's quality of life. } \\
\text { The total effective rate in the treatment group was slightly higher than the control group" } \\
\text { Additional outcomes reported in the trial but not extracted: Symptom scales for } 9 \text { items including abdominal paindegree, } \\
\text { frequency of abdominal pain, abdominal distension, upset and insomnia, anxiety and suspicion, loose stool, feeling of } \\
\text { unfinished defection, asthenia and loss of appetite before treatment, } 2 \text { weeks and } 4 \text { weeks } \\
\text { Adverse effects: "No adverse effects appeared in all participants" }\end{array}$ \\
\hline Notes & $\begin{array}{l}\text { Comments: } \\
\text { Funding sources: [No funding] } \\
\text { randomization: [Drawing of lots] } \\
\text { Allocation: [No specific method was used to conceal the allocation] } \\
\text { Reason for identical numbers assigned to the two groups: [The author said if the patient number of one group started to } \\
\text { exceed 30, they assigned the additional patients into the other group. The number of patients assigned in this non-random } \\
\text { manner was not available from the author] } \\
\text { Information in square brackets was provided by the first author Chen YQ, in a telephone survey on July } 23,2011 \\
\text { We dichotomized cured, improved, effective and no effect into the } 2 \text { categories of improved or not improved according to the } \\
\text { methods section of the review }\end{array}$ \\
\hline \multicolumn{2}{|l|}{ Risk of bias } \\
\hline Bias & Support for judgement \\
\hline
\end{tabular}


Chen 2009

\begin{tabular}{|c|c|c|}
\hline $\begin{array}{l}\text { Random } \\
\text { sequence } \\
\text { generation } \\
\text { (selection } \\
\text { bias) }\end{array}$ & High risk & $\begin{array}{l}\text { "Sixty IBS cases of liver-qi stagnation with spleen deficiency were } \\
\text { randomized into a treatment and control group by single-blind } \\
\text { method" } \\
\text { [We used drawing of lots. If the number of patient of one group } \\
\text { started to exceed 30, they assigned the additional patients into the } \\
\text { other group] }\end{array}$ \\
\hline $\begin{array}{l}\text { Allocation } \\
\text { concealment } \\
\text { (selection } \\
\text { bias) }\end{array}$ & High risk & [No specific method was used to conceal the allocation] \\
\hline $\begin{array}{l}\text { Blinding } \\
\text { (performance } \\
\text { bias and } \\
\text { detection bias) } \\
\text { All outcomes }\end{array}$ & High risk & $\begin{array}{l}\text { [Quality of life scales were evaluated by participants themselves. } \\
\text { The IBS symptom score for TCM symptom were evaluated by the } \\
\text { first author who knew the group assignment of the participants] }\end{array}$ \\
\hline $\begin{array}{l}\text { Incomplete } \\
\text { outcome data } \\
\text { (attrition bias) } \\
\text { Short term }\end{array}$ & Unclear risk & $\begin{array}{l}\text { The dropouts were not reported in the article } \\
\text { [In order to ensure the number of } 30 \text { participants for both groups, the } \\
\text { participants who withdrew during the } 4 \text { weeks treatment were } \\
\text { eliminated from the trial and new participants were recruited. The } \\
\text { first author could not recall the number of the dropouts }\end{array}$ \\
\hline $\begin{array}{l}\text { Selective } \\
\text { reporting } \\
\text { (reporting } \\
\text { bias) }\end{array}$ & Low risk & $\begin{array}{l}\text { This trial reported outcomes for IBS symptom score for TCM } \\
\text { symptom at the completion of the } 4 \text { week treatment period and } \\
\text { quality of life scale before and after treatment }\end{array}$ \\
\hline Other bias & Unclear risk & $\begin{array}{l}\text { ITT analysis was not reported and the author also could not recall } \\
\text { the number of dropouts, so we could not estimate whether the } \\
\text { "missingness" would affect the treatment effect in this trial } \\
\text { "There was no significant difference in gender, age and duration } \\
\text { between the two groups." The P values were } 0.417 \text { for gender, } 1.0 \\
\text { for age and } 0.919 \text { for duration between the two groups } \\
\text { There were no P values reported for the comparison of quality of life } \\
\text { scale and each symptom score between two groups at baseline, but } \\
\text { according to the mean(SD) of quality of life scale in Table } 8 \text { and } \\
\text { symptom score for each item in Table } 4 \text { in Chen YQ } 2006 \text { Master's } \\
\text { thesis, the } 2 \text { groups appeared comparable at baseline }\end{array}$ \\
\hline
\end{tabular}

Chen 2011

\begin{tabular}{|c|c|}
\hline Methods & $\begin{array}{l}\text { Design: Parallel } \\
\text { Blinding: No } \\
\text { Attempt to confirm patient blinding?: No } \\
\text { Dropouts/withdrawals: Not reported in the article [one withdrew from acupuncture group] } \\
\text { Total duration: } 3 \text { weeks treatment followed by an evaluation, no follow up reported } \\
\text { Type of analysis reported: NA }\end{array}$ \\
\hline Participants & $\begin{array}{l}\text { Setting: Acupuncture outpatients of the First Affiliated Hospital of Guangzhou University of Traditional Chinese Medicine } \\
\text { and digestion medicine outpatient of the Second Hospital of TCM, Guangzhou, China } \\
\text { Mean age (+/- Standard Deviation or Range): Not reported. } 14 \text { patients in the acupuncture group and } 14 \text { patients in the } \\
\text { Western medication control group were aged } 18 \text { to } 35 \text { years; } 10 \text { patients in the acupuncture group and } 12 \text { patients in the } \\
\text { Western medication group were aged } 36 \text { to } 50 \text { years; and } 5 \text { patients in the acupuncture group and } 4 \text { patients in the Western } \\
\text { medication control group were aged } 56 \text { to } 70 \text { years } \\
\text { Men/Women (number/number): } 27 / 3214 / 15 \text {, Medication: } 13 / 17 \\
\text { Recruitment method: Not reported } \\
\text { Minimum duration of IBS symptoms: Rome III criteria for the last } 3 \text { months with symptom onset at least } 6 \text { months prior to } \\
\text { diagnosis } \\
\text { Actual duration of IBS symptoms before enrollment: The duration for acupuncture group was } 13.44 \text { (7.63) months; the } \\
\text { duration for western medication group was } 13.36 \text { (7.79) months } \\
\text { Diagnosis of IBS required for eligibility?: Rome III criteria and diagnostic criteria for } 4 \text { different TCM syndrome } \\
\text { differentiations according to the Traditional Chinese Internal Medicine (Version } 7 \text { ) and Integrated Traditional Chinese and } \\
\text { Western Internal Medicine } \\
\text { Evaluation to rule out organic gastrointestinal disease: Yes } \\
\text { Predominant symptoms or stool patterns of participants: Diarrhea-predominant IBS } \\
\text { Hospital inpatients?: No } \\
\text { Were people with a history of acupuncture treatment excluded?: Not reported }\end{array}$ \\
\hline Interventions & $\begin{array}{l}\text { ACUPUNCTURE (plus mild moxibustion) } \\
\text { Number allocated to acupuncture: } 29 \text { [ } 30 \text { participants were assigned to each treatment group, one patient withdrew from the } \\
\text { acupuncture group during treatment] } \\
\text { Style of acupuncture: Chinese } \\
\text { Points selection: Flexible formula }\end{array}$ \\
\hline
\end{tabular}


Chen 2011

Points stimulated: 4 main fixed acupoints and 1 to 2 optional points. The fixed points were bilateral ST 25 and ST 37, single

GV 20 and CV 4. The optional points were ST 36 for deficiency of the spleen and stomach; BL 23 and GV 4 for Yang

deficiency of spleen and kidney; LR 4 and ST 36 for stagnation of the Liver-Qi attacking the spleen; SP 9 for wetness-heat stagnated in the middle energizer

Description of acupuncturist qualifications: Not reported

Total length of treatment period (weeks): 3

Number of sessions target (mean): 15

Times per week: 5

Number of points used (mean): 4 fixed acupoints plus 1 to 2 optional points

Insertion depth: Not reported

Was De Qi reportedly sought? Yes

Duration (minutes): $30 \mathrm{~min}$

Method of stimulation: Manipulation, reinforcing and reducing. Mild moxibustion on GV 20, CV 4 and ST 25. Mild

moxibustion on BL 23 and GV 4 for Yang deficiency of spleen and kidney

CONTROL GROUP A INTERVENTION: Montmorillonite was given to all patients and the loperamide and pinaverium

bromide was added if the diarrhea did not stop

Number allocated to control group A: 30

Total length of treatment period: [ 3 weeks]

Number of sessions target (mean): 21

Days per week: 7

Times per day: smecta: 2 times/day, loperamide and pinaverium bromide: 3 times/day Dosage: 1 bag/time for smecta, $4 \mathrm{mg} /$

time for loperamide and $50 \mathrm{mg} / \mathrm{time}$ for pinaverium bromide

Any co-interventions in all groups? Not reported

\begin{tabular}{|c|c|c|}
\hline Outcomes & \multicolumn{2}{|c|}{$\begin{array}{l}\text { Symptom severity: } \\
\text { Overall IBS symptom score (4-point scoring system) referring to the guide for clinical trials of new drugs of Chinese } \\
\text { medicine at end of treatment: 1) cured 2) improved 3) effective 4) no effect. } \\
\text { 1) cured: the symptom disappeared. Effect index }=100 \% \text {. } \\
\text { 2) improved: the symptom obviously improved. } 100 \%>\text { Effect index }>=75 \% \text {. } \\
\text { 3) effective: the symptom improved. } 75 \%>\text { Effect index }>=30 \% \text {. } \\
\text { 4) no effect: the symptom did not improved. Effect index }=<30 \% \text {. } \\
\text { Computation formula: Effect index = (symptom score before treatment - symptom score after treatment) / symptom score } \\
\text { before treatment } * 100 \% \\
\text { Quality of life: Not assessed } \\
\text { Time points of symptom measurement: The responders for overall IBS symptom were reported after } 3 \text { weeks treatment } \\
\text { Author's conclusion: Although acupuncture is slightly better than conventional western medication for overall IBS symptom, } \\
\text { there was no statistically significant difference }(\mathrm{P}>0.05) \\
\text { Additional outcomes reported in the trial but not extracted: Symptom score for abdominal pain and abdominal distension, } \\
\text { score for defecation frequency, score for stool characteristics before and after treatment were reported respectively in Table } \\
5,6 \text { and 7; responder rates based on TCM syndrome differentiation, responder rates based on age, responder rates based on } \\
\text { disease duration } \\
\text { Adverse effects: Not reported }\end{array}$} \\
\hline Notes & \multicolumn{2}{|c|}{$\begin{array}{l}\text { Funding sources: [The research was supported partly by my advisor, myself and the university.] } \\
\text { randomization: "We used simple randomization method. The sample size was entered into the JMTJFX statistical software } \\
\text { then the random number table was obtained." Reason for identical numbers assigned to the two groups: [The participants } \\
\text { number assigned to both group were } 30 \text { respectively. I entered the sample size into the randomization program in JMTJFX, it } \\
\text { automatically generated the randomized group assignment] Evaluation blinding: "All outcome data came from the daily } \\
\text { record card filled by participants" } \\
\text { Information in square brackets was provided by the author Chen QM, in a telephone survey on December } 4,2011 \\
\text { We dichotomized cured, improved, effective and no effect into the } 2 \text { categories of improved or not improved according to the } \\
\text { methods section of the review }\end{array}$} \\
\hline \multicolumn{3}{|l|}{ Risk of bias } \\
\hline Bias & Authors' judgement & Support for judgement \\
\hline $\begin{array}{l}\text { Random } \\
\text { sequence } \\
\text { generation } \\
\text { (selection bias) }\end{array}$ & Low risk & $\begin{array}{l}\text { "We used simple randomization method. } \\
\text { The sample size was entered into the JMTJFX statistical software } \\
\text { then the random number table was obtained." } \\
\text { [The participants number assigned to both group were } 30 \\
\text { respectively originally. I entered the sample size into the } \\
\text { randomization program in JMTJFX, it automatically generated the } \\
\text { randomized group assignment] }\end{array}$ \\
\hline $\begin{array}{l}\text { Allocation } \\
\text { concealment } \\
\text { (selection bias) }\end{array}$ & Low risk & $\begin{array}{l}\text { [We used envelope method. The envelopes were sequentially } \\
\text { numbered, opaque, sealed] }\end{array}$ \\
\hline $\begin{array}{l}\text { Blinding } \\
\text { (performance } \\
\text { bias and } \\
\text { detection bias) } \\
\text { All outcomes }\end{array}$ & High risk & "All data came from the daily record card filled by participants" \\
\hline
\end{tabular}


Chen 2011

\begin{tabular}{|c|c|c|}
\hline $\begin{array}{l}\text { Incomplete } \\
\text { outcome data } \\
\text { (attrition bias) } \\
\text { Short term }\end{array}$ & Low risk & [One withdrew from the acupuncture group during the treatment] \\
\hline $\begin{array}{l}\text { Selective } \\
\text { reporting } \\
\text { (reporting } \\
\text { bias) }\end{array}$ & Low risk & $\begin{array}{l}\text { This trial reported outcomes for overall IBS symptom responders at } \\
\text { the completion of the } 3 \text { week treatment period, together with results } \\
\text { for each outcome measured as described in the methods section }\end{array}$ \\
\hline Other bias & Low risk & $\begin{array}{l}\text { Although ITT analysis was not reported, there were few drop-outs, } \\
\text { so the degree of "missingness" would be unlikely to affect the } \\
\text { estimate of the treatment effect in this trial. The two groups were } \\
\text { comparable at baseline in terms of sex, age and disease duration (P } \\
>0.05) \text {. The two treatment groups were not significantly different at } \\
\text { baseline in terms of abdominal pain, abdominal distention, } \\
\text { defecation frequency and stool characteristics }\end{array}$ \\
\hline
\end{tabular}

Forbes 2005

\begin{tabular}{|c|c|}
\hline Methods & $\begin{array}{l}\text { Design: Parallel } \\
\text { Blinding: Yes } \\
\text { Attempt to confirm patient blinding?: Not reported } \\
\text { Dropouts/withdrawals: } 1 / 60 \text { before randomization, } 8 / 59 \text { after randomization. Total of } 59 \text { participants randomized and } \\
\text { followed } \\
\text { Total duration: } 10 \text { weeks of treatment with a weekly evaluation (symptom diaries), follow-up evaluation at } 13 \text { weeks after } \\
\text { baseline (or prior exit) } \\
\text { Type of analysis reported: Intention to treat analysis }\end{array}$ \\
\hline Participants & $\begin{array}{l}\text { Setting: Hospital outpatient, UK } \\
\text { Mean age (+/- SD or Range): } 43.0 \text { (range: } 19 \text { to } 67) \text { for acupuncture group, } 44.4 \text { (range: } 17 \text { to } 79 \text { ) for control group } \\
\text { Men/Women (n/n): } 20 / 39 \\
\text { Recruitment method: Personal approach in the hospital clinics } \\
\text { Minimum duration of IBS symptoms: } 3 \text { months } \\
\text { Actual duration of IBS symptoms before enrollment: Not stated } \\
\text { Diagnosis of IBS required to be eligible? (if yes, describe how patients were verified to have IBS): Manning and Rome II } \\
\text { criteria } \\
\text { Evaluation to rule out organic gastrointestinal disease: Reported } \\
\text { Predominant symptoms or stool patterns of participants: Pain was the predominant symptom (21/59); diarrhea (16/59) was } \\
\text { more common than constipation (4/59) } \\
\text { Hospital inpatients? (Y/N; if Y list number inpatients): No } \\
\text { Were people with a history of acupuncture treatment excluded?: Not reported }\end{array}$ \\
\hline Interventions & $\begin{array}{l}\text { ACUPUNCTURE } \\
\text { N allocated to acupuncture: } 27 \\
\text { Style of acupuncture: Chinese } \\
\text { Points selection: Flexible formula for specific symptoms } \\
\text { Points stimulated: Names of points were not stated } \\
\text { Description of acupuncturist qualifications: "fully trained in traditional Chinese acupuncture and accredited to the British } \\
\text { Acupuncture Council" } \\
\text { Total length of treatment period (weeks): } 10 \\
\text { Number of sessions target (mean): } 10 \\
\text { Times per week: } 1 \\
\text { Number of points used (mean): } 4 \text { to } 8 \text { points ( } 8 \text { to } 16 \text { needles for both sides) } \\
\text { Insertion depth: Not stated } \\
\text { Was De Qi reportedly sought?: Yes } \\
\text { Duration (mins): } 25 \text { min } \\
\text { Method of stimulation: Manipulation } \\
\text { CONTROL GROUP A INTERVENTION (sham, if used): Sham acupuncture with penetrating needles } \\
\text { N allocated to control group A: } 32 \\
\text { Points selection: formula } \\
\text { Points stimulated: Nonacupuncture points in three different areas on the body } \\
\text { Total length of treatment period: } 13 \text { weeks } \\
\text { Number of sessions target (mean): } 10 \\
\text { Times per week: } 1 \\
\text { Number of points used: Not reported } \\
\text { Insertion depth: Not reported } \\
\text { Was De Qi sought?: No } \\
\text { Duration (mins): } 25 \\
\text { Method of stimulation: Manipulation } \\
\text { Any co-interventions in all groups?: Specific dietary and lifestyle advice }\end{array}$ \\
\hline Outcomes & $\begin{array}{l}\text { Symptom severity: "Patients completed weekly symptom diaries... The symptom diary is based on the Bristol scale[15] and } \\
\text { has been previously validated[16]. It employs eight Likert scales relating to abdominal symptomatology and their } \\
\text { interference with activities (Appendix), and permits the compilation of a numerical (non-linear) global"symptom }\end{array}$ \\
\hline
\end{tabular}

Cochrane Database Syst Rev. Author manuscript; available in PMC 2013 July 22. 
Forbes 2005

\begin{tabular}{|c|c|c|}
\hline & \multicolumn{2}{|c|}{$\begin{array}{l}\text { score" between } 0 \text { and } 30 \ldots \text { The principal outcome measure was a change in the symptom score. A reduction of four is } \\
\text { considered indicative of a clinically useful response" } \\
\text { Quality of life: EuroQol instrument, measured as change in score from baseline for each group } \\
\text { Time points of symptom measurement: } \\
\text { Global symptom score at baseline (Table 1) and } 13 \text { weeks after baseline (Results section); } \\
\text { Number of patients with symptoms score reduction at } 13 \text { weeks after baseline (Results section); } \\
\text { Number of patients with symptoms score reduction at least } 4 \text { points (number of responders) at } 13 \text { weeks after baseline } \\
\text { (Results section); } \\
\text { EuroQol at baseline (Table1) and } 13 \text { weeks after baseline (Results section); } \\
\text { Author's conclusion: Acupuncture is relatively ineffective for IBS } \\
\text { Additional outcomes reported in the trial but not extracted: Blinded clinician assessment of global status as "improved", } \\
\text { "unchanged" or "worse" } \\
\text { Adverse effects: "No direct adverse events were elicited. One patient was commenced on antidepressants after psychiatric } \\
\text { consultation, and another on beta-blockers for anxiety. } \\
\text { Six other patients failed to complete the study period. Of these eight withdrawals, five belonged to the acupuncture group } \\
\text { and three to sham" }\end{array}$} \\
\hline Notes & \multicolumn{2}{|c|}{$\begin{array}{l}\text { Comments: Carefully worked, especially for the blinding of evaluator } \\
\text { Weak points: Small sample size } \\
\text { SDs for quality of life outcome at end point were not reported, we estimated the standard deviation as } 25 \% \text { of the range (1- } \\
100) \text {, i.e. } 25 \\
\text { For responder rate of Symptom severity, the denominator for the response rate are the number available for follow-up at that } \\
\text { time-point, not the number randomized } \\
\text { The first author Forbes was contacted by email to request information about allocation concealment. He replied with detailed } \\
\text { information on January } 27,2011 \text { Funding resources: "Supported by the a donation gratefully received from the T-R } \\
\text { Golden Charitable Trust" }\end{array}$} \\
\hline \multicolumn{3}{|l|}{ Risk of bias } \\
\hline Bias & Authors' judgement & Support for judgement \\
\hline $\begin{array}{l}\text { Random } \\
\text { sequence } \\
\text { generation } \\
\text { (selection bias) }\end{array}$ & Low risk & $\begin{array}{l}\text { "Recruited patients were allocated according to computer-generated random numbers concealed in } \\
\text { sealed envelopes" }\end{array}$ \\
\hline $\begin{array}{l}\text { Allocation } \\
\text { concealment } \\
\text { (selection bias) }\end{array}$ & Low risk & $\begin{array}{l}\text { "Recruited patients were allocated according to computer-generated random numbers concealed in } \\
\text { sealed envelopes" } \\
\text { [The envelopes were opaque ... and ... they were numbered (according to the recruitment number } \\
\text { for the study) so that we knew which one to open next] }\end{array}$ \\
\hline $\begin{array}{l}\text { Blinding } \\
\text { (performance } \\
\text { bias and } \\
\text { detection bias) } \\
\text { All outcomes }\end{array}$ & Low risk & $\begin{array}{l}\text { \#x0201C;'Sham' acupuncture points were chosen from three different areas on the body (the } \\
\text { anterior thigh distally, the posterior thigh, and the lateral aspect of the lower back), which do not } \\
\text { correspond to recognized acupuncture points and are deemed to have no therapeutic value. These } \\
\text { were varied to some degree each week as in genuine treatment, including variation in needle } \\
\text { technique and length of time of retention. No deqi needling sensation was sought or obtained at } \\
\text { sham points" } \\
\text { "The second "treating acupuncturist" (TA)... for the duration of the study remained the only } \\
\text { individual aware of treatment allocation" } \\
\text { There was no mention in the eligibility criteria of whether participants were required to be } \\
\text { acupuncture-naïve, so we assume this was not a criterion for participation. Also, there was no } \\
\text { attempt to confirm patient blinding. However, because a needle insertion sham was used, and the } \\
\text { points and needling technique were varied some-what each week, as was also done in the true } \\
\text { acupuncture group, who received individualized point selection, we judged that this sham was } \\
\text { likely to be indistinguishable from the true acupuncture }\end{array}$ \\
\hline $\begin{array}{l}\text { Incomplete } \\
\text { outcome data } \\
\text { (attrition bias) } \\
\text { Short term }\end{array}$ & Low risk & $\begin{array}{l}\text { "Sixty patients ( } 40 \text { female) were recruited; one female withdrew after recruitment but before } \\
\text { treatment" } \\
\text { At } 13 \text { week follow-up, "One patient was commenced on antidepressants after psychiatric } \\
\text { consultation, and another on beta-blockers for anxiety. Six other patients failed to complete the } \\
\text { study period. Of these eight withdrawals, five belonged to the acupuncture group and three to } \\
\text { sham" During the } 13 \text { weeks, } 5(27) \text { drop-outs in acupuncture group and 3(32) in sham acupuncture } \\
\text { group. Although this trial reported withdrawals or loss to follow-up of approximately } 13 \% \text {, we did } \\
\text { not consider this an important source of bias because the drop-outs were approximately evenly } \\
\text { distributed across treatment groups, the withdrawals were unlikely to be related to knowledge of } \\
\text { treatment assignment or effects of the treatment, and the degree of 'missingness' would be unlikely } \\
\text { to affect the estimate of the treatment effect in this individual trial or in the meta-analytic estimates. } \\
\text { The authors reported having conducted an ITT analysis but did not specify whether outcomes from } \\
\text { participants who had withdrawn from treatment were available or unavailable for inclusion, or how } \\
\text { the outcome values, if unavailable, had been imputed for inclusion in the ITT analysis. The authors } \\
\text { reported, however, that when the analysis was restricted to those completing the intended therapy, } \\
\text { the results were unchanged from the ITT analysis reported in the publication }\end{array}$ \\
\hline $\begin{array}{l}\text { Selective } \\
\text { reporting } \\
\text { (reporting bias) }\end{array}$ & Low risk & $\begin{array}{l}\text { "Patients completed weekly symptom diaries, supplemented by psychological and quality of life } \\
\text { scales at entry and at } 12 \text { th wk (or prior exit).... Patients also completed the Hospital Anxiety and } \\
\text { Depression (HAD) scale[17], and the Euro-Qol[18] quality of life questionnaire." } \\
\text { "The principal outcome measure was a change in the symptom score" }\end{array}$ \\
\hline
\end{tabular}


Forbes 2005

\begin{tabular}{l|l|l}
\hline & $\begin{array}{l}\text { "Secondary outcome measures included assessment by one of the blinded investigators at the end } \\
\text { of the study period, which made a simple categorization of patient status as "improved", } \\
\text { "unchanged" or "worse" Symptom score and EuroQol LAS score were reported at baseline and 13 } \\
\text { weeks } \\
\text { The median score of pain, bloating, diarrhea and constipation for those with the respective four } \\
\text { symptom predominance at enrollment were reported at baseline and } 13 \text { weeks } \\
\text { HAD score was reported at baseline } \\
\text { Number with reduction in symptom score and number with reduction in symptom score by at least } \\
\text { four points, assessment by the blinded clinician, comparison of HAD scores between groups were } \\
\text { reported at 13 weeks } \\
\text { This trial reported outcomes for overall IBS symptom severity and health-related quality of life at } \\
\text { the completion of the 13 week treatment period, together with results for each outcome measured } \\
\text { according to the Methods section }\end{array}$ \\
\hline Other bias & Low risk & $\begin{array}{l}\text { "Results were analyzed by intention to treat" } \\
\text { "There was a good balancing of the two groups: for no parameter was there a statistically } \\
\text { significant difference at study entry" }\end{array}$ \\
\hline
\end{tabular}

Lembo 2009

\begin{tabular}{|c|c|}
\hline Methods & $\begin{array}{l}\text { Design: Parallel } \\
\text { Blinding: Yes } \\
\text { Attempt to confirm patient blinding?: Not stated but the author stated that Streitberger needle, which was used in this trial, } \\
\text { has previously been validated in other studies } \\
\text { Dropouts/withdrawals: During the second } 3 \text { weeks, } 8 / 78 \text { drop-outs in acupuncture group and } 5 / 75 \text { in sham acupuncture group } \\
\text { Total duration: } 3 \text { weeks treatment immediately followed by an evaluation, no follow up reported } \\
\text { Type of analysis reported: Intention to treat analysis }\end{array}$ \\
\hline Participants & $\begin{array}{l}\text { Setting: in a single outpatient research centre, USA } \\
\text { Mean age (+/-SD or Range): } 37.5 \text { (14.6) years for acupuncture group, } 38.9 \text { (14.1) years for sham acupuncture group, } 39.0 \\
\text { (14.0) for wait list group } \\
\text { Men/Women (n/n): } 54 / 176 \\
\text { Recruitment method: Participants were recruited from advertisements in media, fliers, and through referrals from health } \\
\text { professionals } \\
\text { Minimum duration of IBS symptoms: Rome II criteria for the last } 3 \text { months with symptom onset at least } 6 \text { months prior to } \\
\text { diagnosis } \\
\text { Actual duration of IBS symptoms before enrollment: IBS was present for > } 1 \text { year in } 96 \% \text { of participants in acupuncture } \\
\text { group, } 91 \% \text { of participants in sham acupuncture group and } 95 \% \text { of participants in wait list group } \\
\text { Diagnosis of IBS required to be eligible? (if yes, describe how patients were verified to have IBS): Rome II criteria with a } \\
\text { score of } \geq 150 \text { on the symptom severity scale } \\
\text { Evaluation to rule out organic gastrointestinal disease: Reported } \\
\text { Predominant symptoms or stool patterns of participants: Alternating symptoms were most common (53\%); diarrhea (25\%) } \\
\text { was slightly more common than constipation }(21 \%) \text {. Diarrhea was most common, and constipation was least common, in the } \\
\text { sham acupuncture group } \\
\text { Hospital inpatients? (Y/N; if Y list number inpatients): No } \\
\text { Were people with a history of acupuncture treatment excluded?: Yes }\end{array}$ \\
\hline Interventions & $\begin{array}{l}\text { ACUPUNCTURE } \\
\text { N allocated to acupuncture: } 78 \\
\text { Style of acupuncture: Chinese } \\
\text { Points selection: Flexible formula for specific symptoms } \\
\text { Points stimulated: Six main fixed acupoints and } 11 \text { optional points. The fixed points are very commonly used in IBS patients } \\
\text { and included Conception Vessel } 10 \text {, Stomach } 25 \text {, Liver } 3 \text {, Spleen } 4 \text {, Pericardium } 6 \text {, and Stomach } 37 \text {. The optional points were } \\
\text { Stomach } 36 \text { and Conception Vessel } 4 \text { (for the Chinese diagnosis of deficiency), Large Intestine } 4 \text { Liver } 14 \text { (for stagnant qi or } \\
\text { energy), Stomach } 40 \text {, Large Intestine } 11 \text { (for dampness), Stomach } 27 \text { (for cold), Conception Vessel } 12 \text { (for "retention of } \\
\text { food“), Gall Bladder } 34 \text { (for "damp heat"), and Spleen } 10 \text { and Spleen } 6 \text { (for "blood stasis") } \\
\text { Description of acupuncturist qualifications: "Four licensed acupuncturists, each with more than } 2,000 \text { hours of professional } \\
\text { training and more than } 4 \text { years of post-graduate experience, performed the acupuncture in this study“ } \\
\text { Total length of treatment period (weeks): } 3 \\
\text { Number of sessions target (mean): } 6 \\
\text { Times per week: } 2 \\
\text { Number of points used (mean): } 6 \text { fixed acupoints plus optional points. If the acupuncturist felt strongly that a fixed main point } \\
\text { would be less desirable than an optimal point, they were allowed to replace a single fixed point with an optional point } \\
\text { Insertion depth: Not reported } \\
\text { Was De Qi reportedly sought?: Yes } \\
\text { Duration (mins): } 20 \text { min } \\
\text { Method of stimulation: Manipulation } \\
\text { CONTROL GROUP A INTERVENTION (sham, if used): Sham acupuncture with Streitberger needles } \\
\text { N allocated to control group A: } 75 \\
\text { Points selection: Predetermined "non-acupuncture“ points in the relative vicinity of the genuine points. At least } 5 \text { and a } \\
\text { maximum of } 11 \text { "non-acupuncture“ points } \\
\text { Points stimulated: Predetermined "non-acupuncture" points in the relative vicinity of the genuine points. At least } 5 \text { and a } \\
\text { maximum of } 11 \text { "non-acupuncture“ points. Acupuncturists were also encouraged to slightly switch or adjust their point } \\
\text { selection within the parameters of the study protocol from treatment to treatment } \\
\text { Total length of treatment period: } 3 \text { weeks }\end{array}$ \\
\hline
\end{tabular}

Cochrane Database Syst Rev. Author manuscript; available in PMC 2013 July 22. 
Lembo 2009

\begin{tabular}{|c|c|c|}
\hline & \multicolumn{2}{|c|}{$\begin{array}{l}\text { Number of sessions target (mean): } 6 \\
\text { Times per week: } 2 \\
\text { Number of points used: At least } 5 \text { and a maximum of } 11 \text { "non-acupuncture“ points } \\
\text { Insertion depth: Non-insertion } \\
\text { Was De Qi sought?: No } \\
\text { Duration (mins): } 20 \\
\text { Method of stimulation: No } \\
\text { CONTROL GROUP B: Waitlist } \\
\text { N allocated to control group B: } 77 \\
\text { Total length of treatment period: } 3 \text { weeks } \\
\text { Number of sessions target (mean): NA } \\
\text { Times per week: NA } \\
\text { Duration (mins): NA } \\
\text { Any co-interventions in all groups?: Participants were allowed to continue their IBS medications (e.g. fiber, anti-spasmodics, } \\
\text { and loperamide) as long as they had been on stable doses for at least } 30 \text { days before entering the study and agreed not to } \\
\text { change medications or dosages during the trial }\end{array}$} \\
\hline Outcomes & \multicolumn{2}{|c|}{ 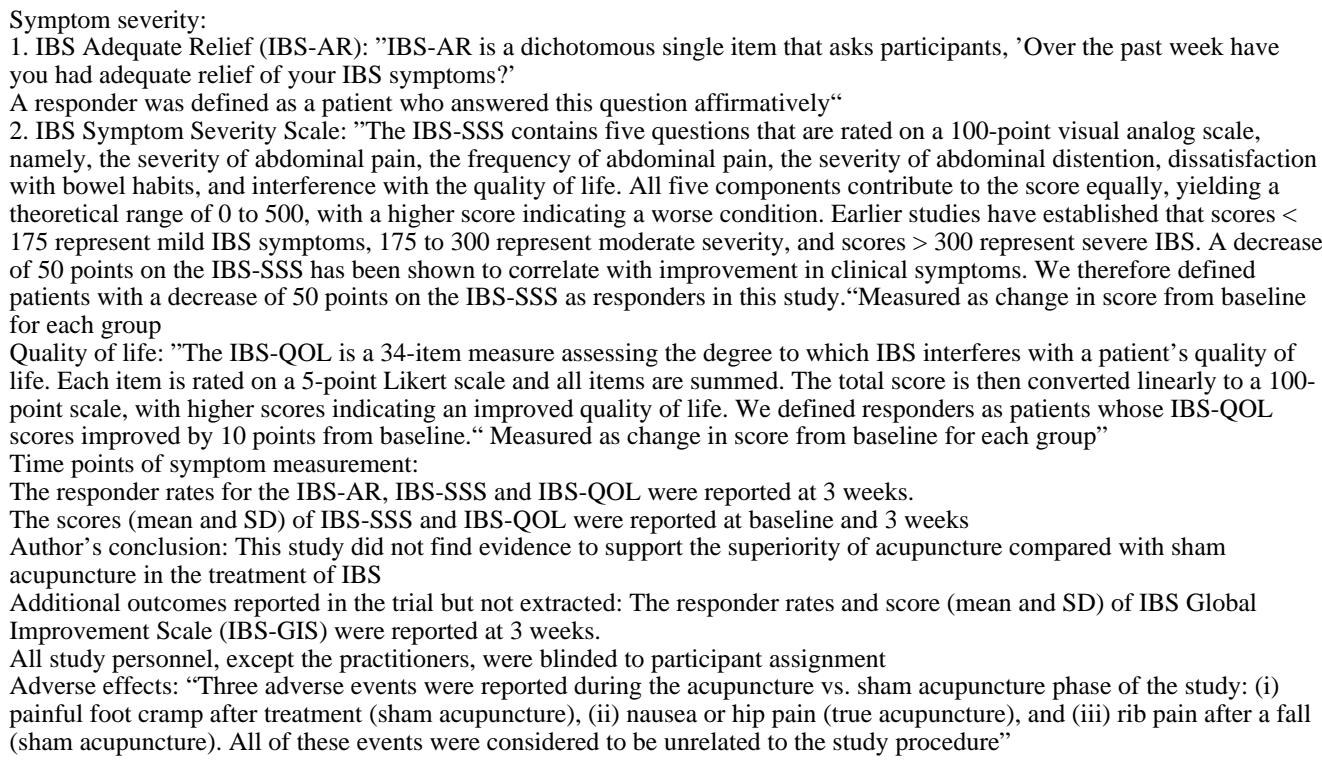 } \\
\hline Notes & \multicolumn{2}{|c|}{$\begin{array}{l}\text { Comments: Carefully worked, especially for the blinding of patients and evaluators } \\
\text { For the quality of life outcome, symptom severity outcome and global improvement outcome, we combined the two } \\
\text { acupuncture groups (i.e. augmented and limited) and the two sham groups (i.e. augmented and limited) shown in Table } 1 \text { by } \\
\text { calculating a weighted mean for combined acupuncture and combined sham. For combining the two SDs for each group, we } \\
\text { used the formula in Table 7.7.a in the Cochrane Handbook for Systematic Reviews of Interventions for combining SDs of } \\
\text { global improvement outcome. } \\
\text { We used the SDs of the baseline measure as an estimate of the SDs of the endpoint measure for symptom severity outcome } \\
\text { and quality of life outcome } \\
\text { For responder rates, the denominator for the response rate are the number available for follow-up at that time-point, not the } \\
\text { number randomized } \\
\text { Funding resources: "This research was made possible by National Institutes of Health (NIH) Grant } 1 \text { R01 AT001414-01 from } \\
\text { the National Center for Complementary and Alternative Medicine (NCCAM) and the National Institutes of Digestive, } \\
\text { Diabetes and Kidney Disease, Grant 1R21 AT002860-01 from NCCAM and the OQ ce of Behavioral and Social Science } \\
\text { Research (OBSSR), and Grants } 1 \text { R21 AT002564 and 1K24 AT004095 from NCCAM. } 2 \text { is research was also supported in } \\
\text { part by Grant RR 01032 to the Beth Israel Deaconess Medical Center (BIDMC) General Clinical Research Center from the } \\
\text { NIH and the Samueli Institute for Informational Biology." }\end{array}$} \\
\hline \multicolumn{3}{|l|}{ Risk of bias } \\
\hline Bias & Authors' judgement & Support for judgement \\
\hline $\begin{array}{l}\text { Random } \\
\text { sequence } \\
\text { generation } \\
\text { (selection } \\
\text { Bias }\end{array}$ & Low risk & $\begin{array}{l}\text { "...at the end of week } 3 \text {, all patients who had received sham } \\
\text { acupuncture were re-randomized blindly to either acupuncture or } \\
\text { continuation of sham acupuncture. This was stratified by the group } \\
\text { assignment for the run-in period (augmented vs. limited) and by the } \\
\text { post run in pain score (< } 30 \text { vs. } 30 \text { on a } 100 \text {-point visual analog } \\
\text { scale)." } \\
\text { "We randomly assigned participants to the three study arms using } \\
\text { permuted block randomization with variable block sizes and } \\
\text { assignments provided in sequentially numbered opaque sealed } \\
\text { envelopes. ... At three weeks, we used similar methods to randomise } \\
\text { patients in the sham acupuncture groups to continue sham acupuncture }\end{array}$ \\
\hline
\end{tabular}


Lembo 2009

\begin{tabular}{|c|c|c|}
\hline & & $\begin{array}{l}\text { or to switch to genuine acupuncture. This randomization was stratified } \\
\text { by the level of abdominal pain at the three week visit }(<30 \mathrm{v} \geq 30 \text { on a } \\
100 \text { point visual analogue scale)" }\end{array}$ \\
\hline $\begin{array}{l}\text { Allocation } \\
\text { concealment } \\
\text { (selection } \\
\text { bias) }\end{array}$ & Low risk & $\begin{array}{l}\text { "We randomly assigned participants to the three study arms using } \\
\text { permuted block randomization with variable block sizes and } \\
\text { assignments provided in sequentially numbered opaque sealed } \\
\text { envelopes. An administrative assistant, not otherwise involved in the } \\
\text { study, opened the assignment envelopes and recorded the assignment } \\
\text { of each participant in a confidential log. At three weeks, we used } \\
\text { similar methods to randomise patients in the sham acupuncture groups } \\
\text { to continue sham acupuncture or to switch to genuine acupuncture" }\end{array}$ \\
\hline $\begin{array}{l}\text { Blinding } \\
\text { (performance } \\
\text { bias and } \\
\text { detection bias) } \\
\text { All outcomes }\end{array}$ & Low risk & $\begin{array}{l}\text { "In this study, we used Streitberger needles (22), a validated sham } \\
\text { acupuncture device. This device has been shown to be } \\
\text { indistinguishable from an actual acupuncture device; the "needle" does } \\
\text { not pierce the skin but creates an illusion of doing so as it retracts into } \\
\text { a hollow handle. Streitberger and true acupuncture needles were } \\
\text { applied for an identical period of time. To avoid acupuncture pressure } \\
\text { effect, sham needles were placed over predetermined "non- } \\
\text { acupuncture" points in the relative vicinity of the genuine points. Our } \\
\text { team's precise method of using the sham needles is described } \\
\text { elsewhere" } \\
\text { "Although the trial was prospectively designed to investigate non- } \\
\text { specific effects in irritable bowel syndrome, its design included a } \\
\text { nested acupuncture substudy that allowed potential participants in } \\
\text { the "treatment" arms to be told, truthfully, that they had a 50\% chance } \\
\text { of receiving genuine acupuncture during the trial. When the study } \\
\text { ended, a letter was sent to all participants explaining the exact purpose } \\
\text { of the study and offering them the opportunity to withdraw their } \\
\text { original consent to use their data. All study personnel, except the } \\
\text { practitioners, were blinded to participant assignment. Blinded } \\
\text { registered nurses who were otherwise unconnected to the study } \\
\text { conducted assessments" } \\
\text { No attempt to confirm patient blinding, although this may not be } \\
\text { necessary, as the Streitberger needle has been previously validated }\end{array}$ \\
\hline $\begin{array}{l}\text { Incomplete } \\
\text { outcome data } \\
\text { (attrition bias) } \\
\text { Short term }\end{array}$ & Low risk & $\begin{array}{l}\text { There were } 8(78) \text { drop-outs in acupuncture group and } 5(75) \text { in sham } \\
\text { acupuncture group }\end{array}$ \\
\hline $\begin{array}{l}\text { Selective } \\
\text { reporting } \\
\text { (reporting } \\
\text { bias) }\end{array}$ & Low risk & $\begin{array}{l}\text { This trial reported outcomes for overall IBS symptom severity (IBS- } \\
\text { SSS) and health-related quality of life (IBS-QOL) at the completion of } \\
\text { the } 3 \text { week treatment period, together with results for each outcome } \\
\text { measured according to the methods section }\end{array}$ \\
\hline Other bias & Low risk & $\begin{array}{l}\text { "All analyses were intent-to-treat" } \\
\text { "Table } 2 \text { displays demographics and baseline symptoms by treatment } \\
\text { group." Although no statistical comparisons are made between the two } \\
\text { groups at baseline, the groups seem comparable on most variables. } \\
\text { Most importantly, the true acupuncture and sham acupuncture groups } \\
\text { had very similar baseline scores for the IBS-SSS and the IBS-QOL }\end{array}$ \\
\hline
\end{tabular}

Li 2009

\begin{tabular}{l|l}
\hline Methods & Design: Parallel \\
Blinding: No \\
Attempt to confirm patient blinding?: No \\
Dropouts/withdrawals: Not reported in the article [There were dropouts during the 70 days treatment, but the author did not \\
record the number of the dropouts for the three groups] \\
Total duration: 70 days treatment followed by an evaluation, no follow up reported \\
Type of analysis reported: not reported
\end{tabular}

Cochrane Database Syst Rev. Author manuscript; available in PMC 2013 July 22. 


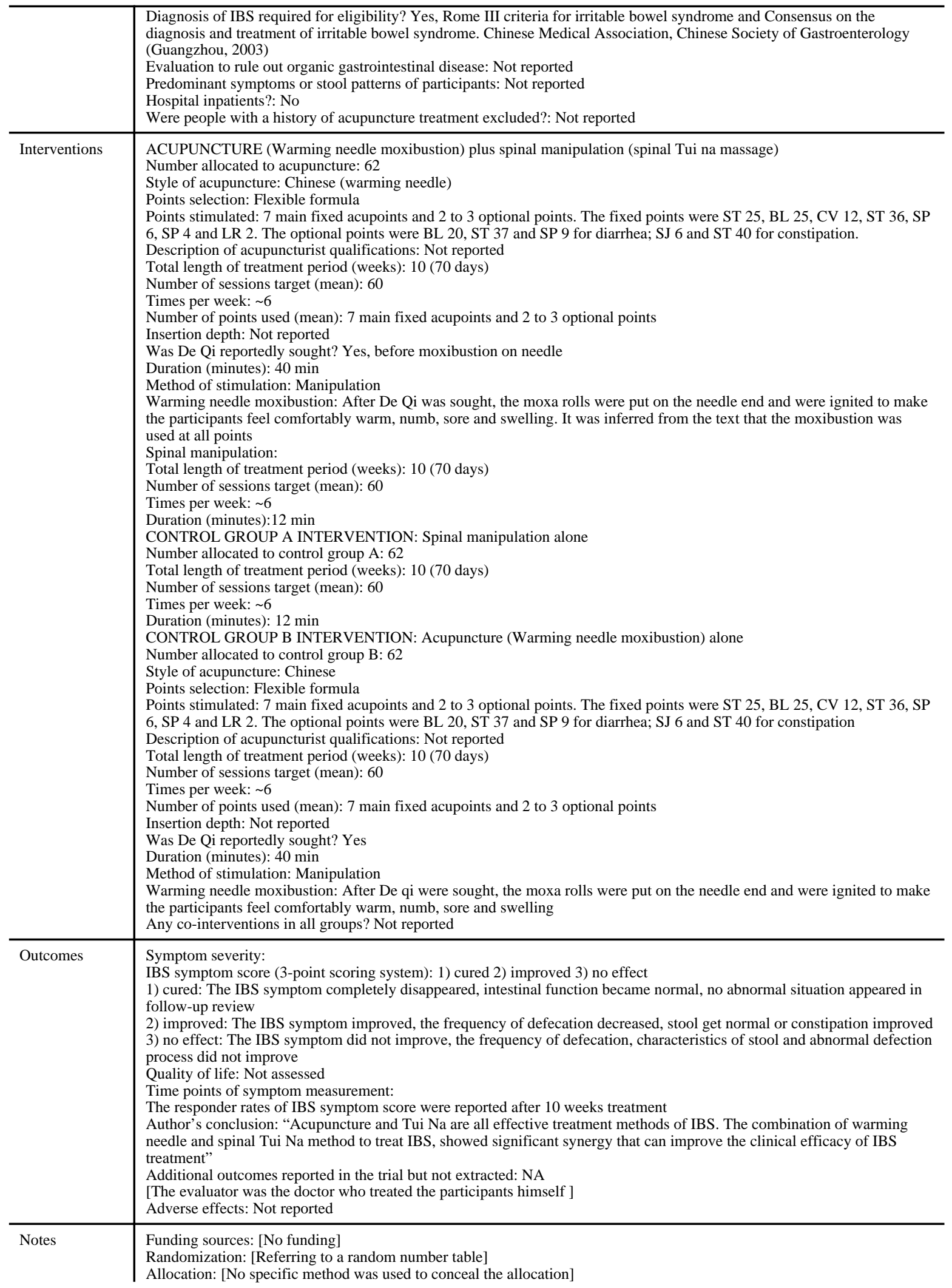




\begin{tabular}{|c|c|c|}
\hline & \multicolumn{2}{|c|}{$\begin{array}{l}\text { Reason for identical numbers assigned to the three groups: [The participants were originally assigned referring a random } \\
\text { number table. When } \mathrm{Li} \mathrm{W} \text { found unequal sample size of the } 3 \text { groups, he further recruited participants to make the sample } \\
\text { size equal finally. } \\
\text { The participants further recruited were not randomly assigned] } \\
\text { Information in square brackets was provided by the first author Li W, in a telephone survey on July } 29,2011 \\
\text { We dichotomized cured, improved and no effect into the } 2 \text { categories of improved or not improved according to the } \\
\text { methods section of the review }\end{array}$} \\
\hline \multicolumn{3}{|l|}{ Risk of bias } \\
\hline Bias & Authors' judgement & Support for judgement \\
\hline $\begin{array}{l}\text { Random } \\
\text { sequence } \\
\text { generation } \\
\text { (selection bias) }\end{array}$ & High risk & $\begin{array}{l}\text { "Sixty IBS cases of liver-qi stagnation with spleen deficiency were randomized into a treatment } \\
\text { and control group by single-blind method" } \\
\text { [We used drawing of lots. If the number of patient of one group started to exceed 30, they assigned } \\
\text { the additional patients into the other group] }\end{array}$ \\
\hline $\begin{array}{l}\text { Allocation } \\
\text { concealment } \\
\text { (selection bias) }\end{array}$ & High risk & [No specific method was used to conceal the allocation] \\
\hline $\begin{array}{l}\text { Blinding } \\
\text { (performance } \\
\text { bias and } \\
\text { detection bias) } \\
\text { All outcomes }\end{array}$ & High risk & $\begin{array}{l}\text { [Quality of life scales were evaluated by participants themselves. The IBS symptom score for } \\
\text { TCM symptom were evaluated by the investigator who knew the group assignment of the } \\
\text { participants }\end{array}$ \\
\hline $\begin{array}{l}\text { Incomplete } \\
\text { outcome data } \\
\text { (attrition bias) } \\
\text { Short term }\end{array}$ & Unclear risk & $\begin{array}{l}\text { Dropouts were not reported or described in the article } \\
\text { [In order to ensure the number of } 30 \text { participants for both groups, the participants who withdrew } \\
\text { during the } 4 \text { weeks treatment were eliminated from the trial and new participants were recruited. } \\
\text { The first author could not recall the number of the dropouts }\end{array}$ \\
\hline $\begin{array}{l}\text { Selective } \\
\text { reporting } \\
\text { (reporting bias) }\end{array}$ & Low risk & $\begin{array}{l}\text { This trial reported outcomes for IBS symptom score for TCM symptom at the completion of the } 4 \\
\text { week treatment period and quality of life scale before and after treatment, together with results for } \\
\text { each outcome measured according to the Observation targets in Chen YQ } 2006 \text { Master's thesis }\end{array}$ \\
\hline Other bias & Unclear risk & $\begin{array}{l}\text { ITT analysis was not reported and the author also could not recall the number of dropouts, so we } \\
\text { could not estimate whether the "missingness" would affect the treatment effect in this trial } \\
\text { "Therewas no significant difference in gender, age and duration between the two groups.". The P } \\
\text { values were } 0.417 \text { for gender, } 1.0 \text { for age and } 0.919 \text { for duration between the two groups. There are } \\
\text { no P values reported for the comparison of quality of life scale and each symptom score between } \\
\text { two groups at baseline, but based on the mean(SD) of quality of life score and symptom score for } \\
\text { each item, the two groups appeared comparable at baseline }\end{array}$ \\
\hline
\end{tabular}

Liu 1997

\begin{tabular}{l|l}
\hline Methods & Design: Parallel group \\
Blinding: No & Attempt to confirm patient blinding?: No \\
Dropouts/withdrawals: At the end of Tx, explicitly no dropouts for all groups, but the number of baseline participants is \\
unreliable; At 26 week follow-up, 27 drop-outs from intervention group (acupuncture and psychological Tx), 25 dropouts \\
from acupuncture group and 25 dropouts from psychological group \\
Total duration: 20 to 120 days for acupuncture treatment, 1 to 12 weeks for psychotherapy treatment, followed by an \\
evaluation; 26 weeks follow-up evaluation after end of treatment, but only for the patients who responded to treatment, and \\
therefore not a randomized comparison \\
Type of analysis reported: NA
\end{tabular}

Cochrane Database Syst Rev. Author manuscript; available in PMC 2013 July 22. 
Liu 1997

\begin{tabular}{|c|c|c|}
\hline & \multicolumn{2}{|c|}{$\begin{array}{l}\text { Points stimulated: ST-36, PC-6, CV-12, ST-25, LR-3, BL-20, BL-23, GV-4 / CV-8 (Moxibustion) } \\
\text { Description of acupuncturist qualifications: No description } \\
\text { Total length of treatment period (weeks): } 3 \text { to } 21 \text { weeks } \\
\text { Number of sessions target (mean): } 10 \text { to } 60 \text { for acupuncture treatment } \\
\text { Times per week: } 3 \\
\text { Number of points used (mean): } 3 \text { to } 4 \\
\text { Insertion depth: Not reported } \\
\text { Was De Qi reportedly sought?: Yes } \\
\text { Duration (mins): } 30 \\
\text { Method of stimulation: Manipulation } \\
\text { Psychotherapy procedure: } 1 \text { to } 2 \text { sessions per week, } 2 \text { sessions comprise } 1 \text { course (Each session was performed ahead of } \\
\text { acupuncture) } \\
\text { CONTROL GROUP A INTERVENTION (sham, if used): Acupuncture only } \\
\text { N allocated to control group A: } 50 \\
\text { Points selection: Flexible formula for specific symptoms } \\
\text { Points stimulated: ST-36, PC-6, CV-12, ST-25, LR-3, BL-20, BL-23, GV-4 / CV-8 (Moxibustion) } \\
\text { Total length of treatment period: } 3 \text { to } 21 \text { weeks } \\
\text { Number of sessions target (mean): } 10 \text { to } 60 \\
\text { Times per week: } 3 \\
\text { Number of points used (mean): } 3 \text { to } 4 \\
\text { Insertion depth: Not stated } \\
\text { Was De Qi sought?: Yes } \\
\text { Duration (mins): } 30 \\
\text { Method of stimulation: Manipulation } \\
\text { CONTROL GROUP B INTERVENTION (sham, if used): Psychotherapy only } \\
\text { N allocated to control group B: } 50 \\
\text { Total length of treatment period: Not stated } \\
\text { Number of sessions target(mean): Not stated } \\
\text { Times per week: } 1 \text { to } 2 \\
\text { Duration (mins): Not reported } \\
\text { Any co-interventions in all groups?: Not reported }\end{array}$} \\
\hline Outcomes & \multicolumn{2}{|c|}{$\begin{array}{l}\text { Symptom severity: } \\
\text { Symptom Improvement (3-point scoring system) at end of treatment: 1) cured: 2) improved 3) no effect } \\
\text { Follow up (6 months after the treatment): 1) symptoms remain improved 2) symptoms reoccurred } \\
\text { Measured as \% responders for each groups } \\
\text { Quality of life: Not assessed } \\
\text { Time points of symptom measurement: the end of treatment, } 26 \text { weeks after treatment } \\
\text { Author's conclusion: Acupuncture plus psychotherapy is better than either alone in the treatment of IBS } \\
\text { Addtional outcomes reported in the trial but not extracted: None } \\
\text { Adverse effects: Not stated }\end{array}$} \\
\hline Notes & \multicolumn{2}{|c|}{$\begin{array}{l}\text { Additional information in square brackets was provided by the first author, Liu GZ in a telephone survey } \\
\text { Comments: Low methodological quality, small sample size } \\
\text { Funding resources: [There was no funding supporting the trial] }\end{array}$} \\
\hline \multicolumn{3}{|l|}{ Risk of bias } \\
\hline Bias & Authors' judgement & Support for judgement \\
\hline $\begin{array}{l}\text { Random } \\
\text { sequence } \\
\text { generation } \\
\text { (selection bias) }\end{array}$ & Low risk & [Random number table] \\
\hline $\begin{array}{l}\text { Allocation } \\
\text { concealment } \\
\text { (selection bias) }\end{array}$ & Unclear risk & $\begin{array}{l}\text { [The random numbers were concealed in sealed envelopes. The author did not specify whether or } \\
\text { not the envelopes were numbered and opaque] }\end{array}$ \\
\hline $\begin{array}{l}\text { Blinding } \\
\text { (performance } \\
\text { bias and } \\
\text { detection bias) } \\
\text { All outcomes }\end{array}$ & High risk & [The outcome assessor was blinded to the intervention] \\
\hline $\begin{array}{l}\text { Incomplete } \\
\text { outcome data } \\
\text { (attrition bias) } \\
\text { Short term }\end{array}$ & High risk & Patient dropouts and withdrawals from treatment were not reported \\
\hline $\begin{array}{l}\text { Selective } \\
\text { reporting } \\
\text { (reporting bias) }\end{array}$ & Low risk & $\begin{array}{l}\text { The only outcome collected was the improvement at the end of treatment and follow up: } \\
\text { At the end of treatment: Improvement (3-point scoring system. 1) cured: } 2 \text { ) improved 3) no effect } \\
\text { Follow up ( } 6 \text { months after the treatment): 1) symptoms remain improved 2) symptoms reoccurred } \\
\text { The number and response rate for each scoring item were reported at end of treatment and at } 6 \\
\text { months follow up (only for responded patients) }\end{array}$ \\
\hline
\end{tabular}


Liu 1997

\begin{tabular}{l|l|l}
\hline & & $\begin{array}{l}\text { Outcomes were reported for overall IBS symptom severity (response to treatment in three } \\
\text { categories) at the completion of the treatment periods. This categorization is a standard way of } \\
\text { assessing treatment success in Chinese trials of IBS }\end{array}$ \\
\hline Other bias & High risk & $\begin{array}{l}\text { The author did not report whether groups were similar at baseline regarding the most important } \\
\text { prognostic indicators. Timing of the outcome assessment in all groups appears to vary, because } \\
\text { the number of treatment sessions for patients is dependent on their disease condition. Intention-to- } \\
\text { treat analysis was not reported }\end{array}$ \\
\hline
\end{tabular}

Liu 2010

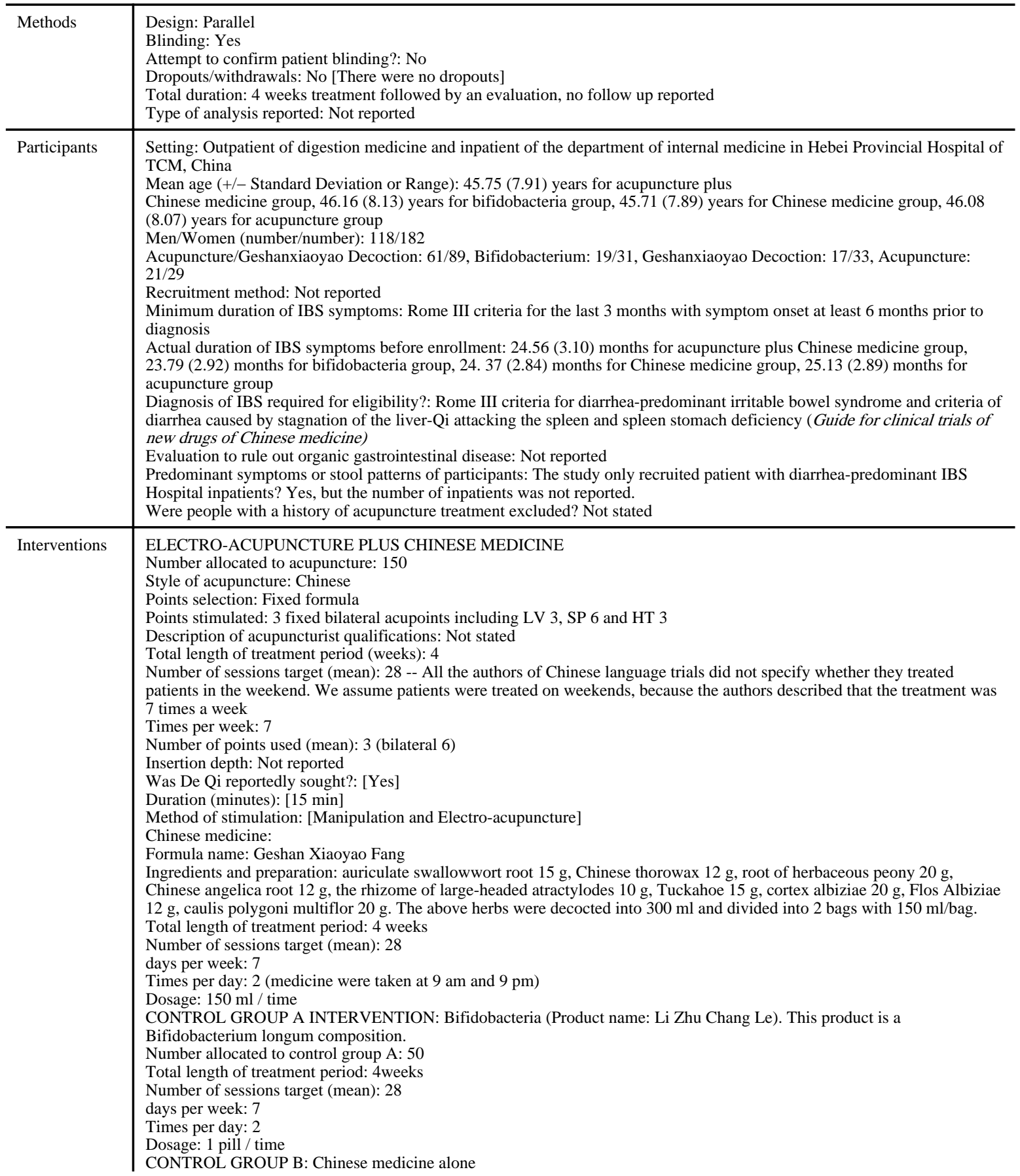


Liu 2010

\begin{tabular}{|c|c|c|}
\hline & \multicolumn{2}{|c|}{$\begin{array}{l}\text { Number allocated to control group B: } 50 \\
\text { Formula name: Geshan Xiaoyao Fang (as described above) } \\
\text { Total length of treatment period: } 4 \text { weeks } \\
\text { Number of sessions target (mean): } 28 \\
\text { days per week: } 7 \\
\text { Times per day: } 2 \text { (medicine were taken at } 9 \text { am and } 9 \mathrm{pm} \text { ) } \\
\text { Dosage: } 150 \mathrm{ml} \text { / time } \\
\text { CONTROL GROUP C: Electro-Acupuncture alone } \\
\text { Number allocated to control group C: } 50 \\
\text { Style of acupuncture: Chinese } \\
\text { Points selection: Fixed formula } \\
\text { Points stimulated: } 3 \text { fixed bilateral acupoints including LV 3, SP } 6 \text { and HT } 3 \\
\text { Description of acupuncturist qualifications: Not reported Total length of treatment period (weeks): } 4 \\
\text { Number of sessions target (mean): } 28 \\
\text { Times per week: } 7 \\
\text { Number of points used (mean): } 3 \text { (bilateral 6) } \\
\text { Insertion depth: Not reported } \\
\text { Was De Qi reportedly sought? [Yes] } \\
\text { Duration (minutes): [15 min] } \\
\text { Method of stimulation: [Manipulation and Electro-acupuncture] } \\
\text { Any co-interventions in all groups?: Not reported }\end{array}$} \\
\hline Outcomes & \multicolumn{2}{|c|}{ 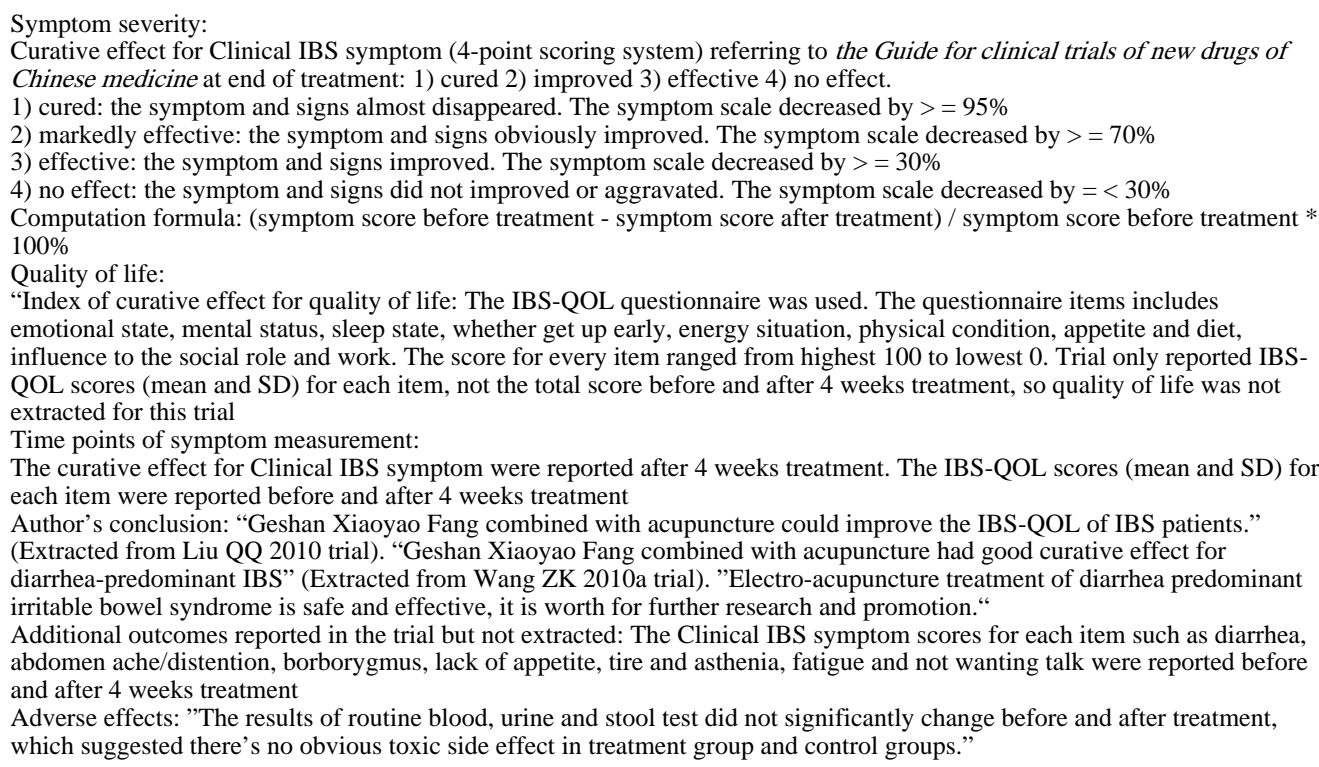 } \\
\hline Notes & \multicolumn{2}{|c|}{$\begin{array}{l}\text { Funding sources: Hebei provincial sci-tech support plan (No. 072761825) } \\
\text { Reason for identical numbers assigned to the two groups: [We did not use any specific method to ensure the same number of } \\
\text { participants assigned to the two groups. It might be a coincidence] } \\
\text { Information in square brackets was provided by one of the first authors, Liu QQ, in a telephone survey on July } 29,2011 \text { and } \\
\text { by the other first author Wang ZK, in a telephone survey on September } 26,2011 \\
\text { We dichotomized cured, improved, effective and no effect into the } 2 \text { categories of improved or not improved according to the } \\
\text { methods section of the review }\end{array}$} \\
\hline \multicolumn{3}{|l|}{ Risk of bias } \\
\hline Bias & Authors' judgement & Support for judgement \\
\hline $\begin{array}{l}\text { Random } \\
\text { sequence } \\
\text { generation } \\
\text { (selection } \\
\text { bias) }\end{array}$ & Unclear risk & $\begin{array}{l}\text { [Random number table method was used. We assigned } 300 \\
\text { participants into a treatment group ( } 150 \text { participants }) \text { and } 3 \text { control } \\
\text { groups, } 50 \text { participants in each] }\end{array}$ \\
\hline $\begin{array}{l}\text { Allocation } \\
\text { concealment } \\
\text { (selection } \\
\text { bias) }\end{array}$ & High risk & $\begin{array}{l}\text { [The allocation procedure was open. We did not use any method } \\
\text { to conceal the allocation] }\end{array}$ \\
\hline $\begin{array}{l}\text { Blinding } \\
\text { (performance } \\
\text { bias and } \\
\text { detection bias) }\end{array}$ & High risk & [The evaluators were not blind to the participant assignment] \\
\hline
\end{tabular}

Cochrane Database Syst Rev. Author manuscript; available in PMC 2013 July 22. 
Liu 2010

\begin{tabular}{|c|c|c|}
\hline All outcomes & & \\
\hline $\begin{array}{l}\text { Incomplete } \\
\text { outcome data } \\
\text { (attrition bias) } \\
\text { Short term }\end{array}$ & Unclear risk & $\begin{array}{l}\text { [There were no dropouts in the study]. We scored this as unclear } \\
\text { because it is unlikely that there would be zero drop-outs in a } 4 \\
\text { week trial of } 300 \text { participants }\end{array}$ \\
\hline $\begin{array}{l}\text { Selective } \\
\text { reporting } \\
\text { (reporting } \\
\text { bias) }\end{array}$ & Low risk & $\begin{array}{l}\text { This trial reported outcomes for clinical IBS symptoms at the } \\
\text { completion of the } 4 \text { week treatment period, together with results } \\
\text { for each outcome measured based on the "Observational targets" } \\
\text { section in both Liu } 2010 \text { and Wang } 2010 \text { a articles }\end{array}$ \\
\hline Other bias & Unclear risk & $\begin{array}{l}\text { Although ITT analysis was not reported, there were reportedly no } \\
\text { drop-outs, although this does not seem plausible, as described } \\
\text { above } \\
\text { "The two groups were comparable at baseline in terms of sex, age, } \\
\text { disease duration }(\mathrm{P}>0.05) \text { " } \\
\text { There are no P values reported for the comparison of symptom } \\
\text { score or IBS-QOL score among } 4 \text { groups at baseline, but the } \\
\text { groups appeared comparable at baseline }\end{array}$ \\
\hline
\end{tabular}

Lowe 2000

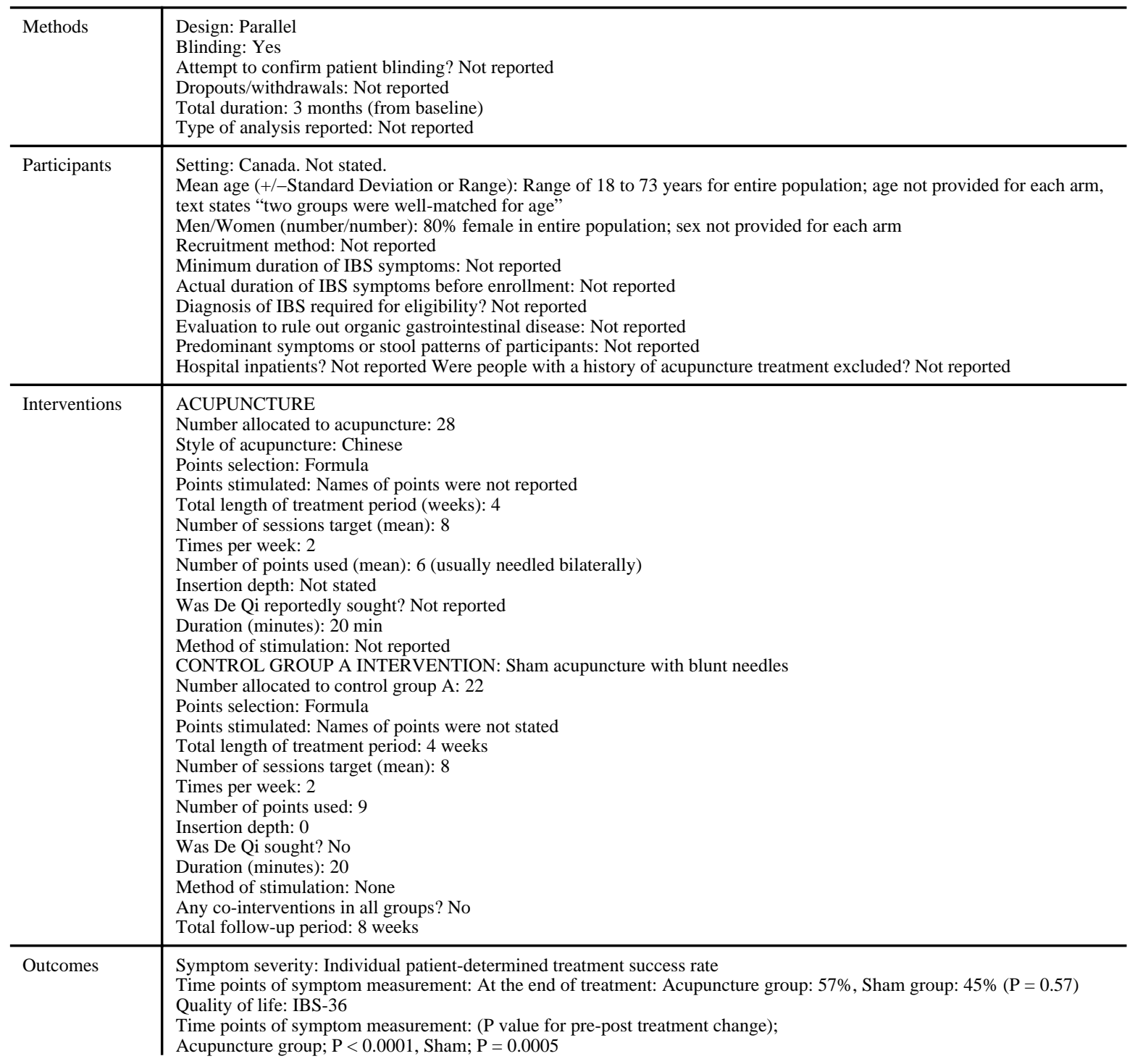


Lowe 2000

\begin{tabular}{|c|c|c|}
\hline & \multicolumn{2}{|c|}{$\begin{array}{l}\text { Type of outcome data reported: Difference post treatment value between acupuncture and control groups. Change from } \\
\text { baseline reported in publication } \\
\text { Author's conclusion: } \\
\text { Acupuncture has no method-specific therapeutic benefit for the treatment of IBS } \\
\text { Additional outcomes reported in the trial but not extracted: Barostat rectal thresholds, McGill pain score. } \\
\text { Adverse effects: Not reported }\end{array}$} \\
\hline Notes & \multicolumn{2}{|c|}{$\begin{array}{l}\text { Weak points: small sample size, lack of described information } \\
\text { Improvement in pain scores and quality of life in both the treatment and control groups suggests that aspects of sham and } \\
\text { true acupuncture may positively influence these measures - or that these are the effects of enrollment in the clinical trial } \\
\text { In the patients who did not attain their individual "success goals" there is no data presentation to indicate whether they } \\
\text { experienced worsening of symptoms or adverse effects during the trial } \\
\text { Funding sources: Not reported } \\
\text { Additional information provided by William Depew on September } 20,2011\end{array}$} \\
\hline \multicolumn{3}{|l|}{ Risk of bias } \\
\hline Bias & Authors' judgement & Support for judgement \\
\hline $\begin{array}{l}\text { Random } \\
\text { sequence } \\
\text { generation } \\
\text { (selection bias) }\end{array}$ & Low risk & $\begin{array}{l}\text { Quote: "This randomized double-blind study compared acupuncture to a validated placebo } \\
\text { acupuncture technique in } 50 \text { patients with ROME positive IBS" } \\
\text { Comment: No specific description of sequence generation in the abstract text } \\
\text { [The study employed computer generated random number sequencing to determine assignment. } \\
\text { The sequence and codes were held by a third party unassociated with the clinical conduct of the } \\
\text { trial. The code was revealed only after the final consecutive case was finished the entire trial } \\
\text { observation period] }\end{array}$ \\
\hline $\begin{array}{l}\text { Allocation } \\
\text { concealment } \\
\text { (selection bias) }\end{array}$ & Low risk & $\begin{array}{l}\text { Quote: "This randomized double-blind study compared acupuncture to a validated placebo } \\
\text { acupuncture technique in } 50 \text { patients with ROME positive IBS" } \\
\text { Comment: No specific description of allocation concealment in the abstract text } \\
\text { [The study employed computer generated random number sequencing to determine assignment. } \\
\text { The sequence and codes were held by a third party unassociated with the clinical conduct of the } \\
\text { trial. The code was revealed only after the final consecutive case was finished the entire trial } \\
\text { observation period] }\end{array}$ \\
\hline $\begin{array}{l}\text { Blinding } \\
\text { (performance } \\
\text { bias and } \\
\text { detection bias) } \\
\text { All outcomes }\end{array}$ & Unclear risk & $\begin{array}{l}\text { Quote: "This randomized double-blind study compared acupuncture to a validated placebo } \\
\text { acupuncture technique (tapping a blunt needle on the skin and taping in place at the same points) } \\
\text {..." } \\
\text { Comment: There's no description about whether the patients in this trial were required to have } \\
\text { never used acupuncture (i.e. to be acupuncture naive) or not. There were no tests for checking the } \\
\text { success of the blinding either. In addition, there was no reference for a study of the validation of } \\
\text { this sham procedure, and we are unfamiliar with any study that has validated this procedure }\end{array}$ \\
\hline $\begin{array}{l}\text { Incomplete } \\
\text { outcome data } \\
\text { (attrition bias) } \\
\text { Short term }\end{array}$ & Unclear risk & Comment: Dropouts/withdrawals were not reported or described \\
\hline $\begin{array}{l}\text { Selective } \\
\text { reporting } \\
\text { (reporting bias) }\end{array}$ & Low risk & $\begin{array}{l}\text { This trial reported outcomes for individual patient-determined treatment success and IBS- } 36 \text { (only } \\
\mathrm{P} \text { value) at the completion of the } 4 \text { week treatment period, together with results for each outcome } \\
\text { measured, according to the Abstract }\end{array}$ \\
\hline Other bias & Unclear risk & $\begin{array}{l}\text { Quote: "The two groups were well matched for age, symptom scores, Beck depression and State- } \\
\text { Trait anxiety scores." However, there were no statistical tests or P values reported for these } \\
\text { comparisons, probably because of the abstract format } \\
\text { Comment: ITT analysis was not reported and the drop-outs were not reported either, so we } \\
\text { couldn't know the degree of "missingness" and whether it would be to affect the estimate of the } \\
\text { treatment effect in this trial } \\
\text { Comment: It's an abstract and the reporting about methods and outcomes was unclear and } \\
\text { incomplete }\end{array}$ \\
\hline
\end{tabular}

\section{Reynolds 2008}

\begin{tabular}{|c|c|}
\hline Methods & $\begin{array}{l}\text { Design: Parallel } \\
\text { Blinding: No } \\
\text { Attempt to confirm patient blinding?: No } \\
\text { Dropouts/withdrawals: } 1 / 10 \text { was lost to follow up from the acupuncture group; } 3 / 20 \text { were lost to follow up in the usual GP } \\
\text { care group } \\
\text { Total duration: } 3 \text { months treatment followed by an evaluation, no follow-up reported } \\
\text { Type of analysis reported: Intention to treat analysis }\end{array}$ \\
\hline Participants & $\begin{array}{l}\text { Setting: "The acupuncture was provided at independent clinics" in UK } \\
\text { Mean age (+/-SD or Range): } 37.5 \text { (13.5) years in GP care only group, } 34 \text { (7.1) years in acupuncture plus GP group } \\
\text { Men/Women (n/n): } 7 / 23 \\
\text { Recruitment method: "Patients were identified via the databases of four GP practices in Birmingham." "Patients were invited } \\
\text { to participate by postal questionnaire which included screening questions..." }\end{array}$ \\
\hline
\end{tabular}

Cochrane Database Syst Rev. Author manuscript; available in PMC 2013 July 22. 
Reynolds 2008

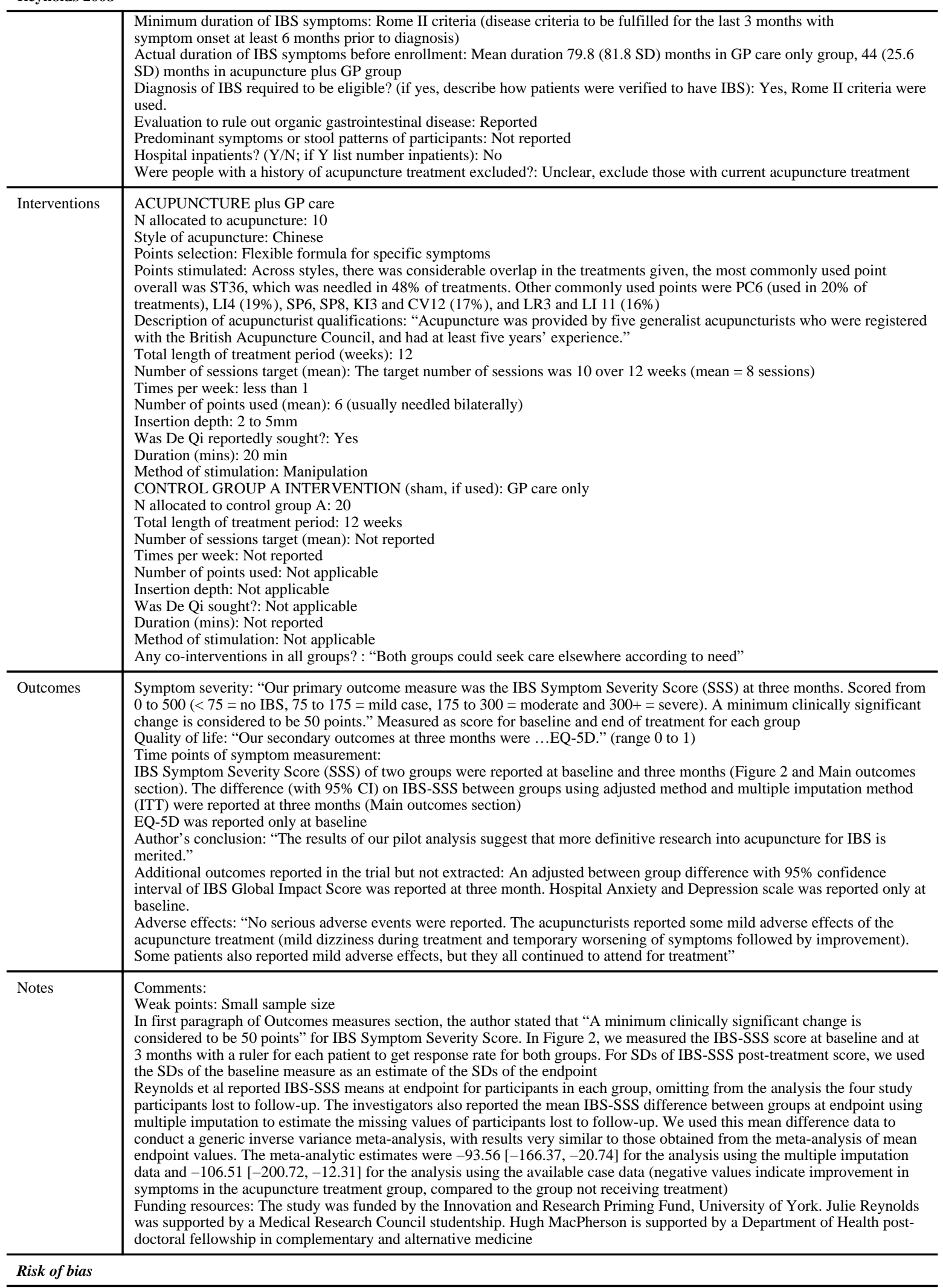


Reynolds 2008

\begin{tabular}{|c|c|c|}
\hline Bias & Authors' judgement & Support for judgement \\
\hline $\begin{array}{l}\text { Random } \\
\text { sequence } \\
\text { generation } \\
\text { (selection } \\
\text { bias) }\end{array}$ & Low risk & $\begin{array}{l}\text { "The randomization sequence was computer generated by an } \\
\text { independent researcher and concealed allocation was achieved by } \\
\text { remote central telephone contact" }\end{array}$ \\
\hline $\begin{array}{l}\text { Allocation } \\
\text { concealment } \\
\text { (selection } \\
\text { bias) }\end{array}$ & Low risk & $\begin{array}{l}\text { "The randomization sequence was computer generated by an } \\
\text { independent researcher and concealed allocation was achieved by } \\
\text { remote central telephone contact" }\end{array}$ \\
\hline $\begin{array}{l}\text { Blinding } \\
\text { (performance } \\
\text { bias and } \\
\text { detection bias) } \\
\text { All outcomes }\end{array}$ & High risk & This study was not blinded \\
\hline $\begin{array}{l}\text { Incomplete } \\
\text { outcome data } \\
\text { (attrition bias) } \\
\text { Short term }\end{array}$ & Low risk & $\begin{array}{l}\text { "One patient }(1 / 10) \text { was lost to follow up from the acupuncture } \\
\text { group: a female with no treatment preference, a moderate severity } \\
\text { score at baseline, who had only received two treatments. Three } \\
\text { (3/20) were lost to follow up in the usual GP care group, they were } \\
\text { all male, had more severe baseline IBS severity scores and a } \\
\text { preference for acupuncture." Given the small percentage lost to } \\
\text { follow-up, and the use of multiple methods to assess sensitivity to } \\
\text { missing outcomes data (last observation carried forward, assigning } \\
\text { the overall mean to missing values, and multiple imputation based } \\
\text { on the standard best subset regression method) we judged that } \\
\text { incomplete outcome data were appropriately addressed }\end{array}$ \\
\hline $\begin{array}{l}\text { Selective } \\
\text { reporting } \\
\text { (reporting } \\
\text { bias) }\end{array}$ & High risk & $\begin{array}{l}\text { This trial reported outcomes for overall IBS symptom severity } \\
\text { (IBS-SSS) at the completion of the treatment period. However two } \\
\text { outcome measures (i.e. Hospital Anxiety and Depression scale and } \\
\text { EQ-5D) reported at baseline were not reported at the end of } \\
\text { treatment, which raises the possibility that there could have been } \\
\text { outcome reporting bias }\end{array}$ \\
\hline Other bias & Low risk & $\begin{array}{l}\text { "Analysis was by intention-to-treat, and multiple imputation was } \\
\text { used for missing data." } \\
\text { Baseline patient characteristics in the two groups were comparable, } \\
\text { but no P values were reported. "There were some differences at } \\
\text { baseline in Non-Colonic Symptom Score, working status, anxiety } \\
\text { and depression, differences that can be expected in a sample of this } \\
\text { size." The two groups were comparable on mean baseline IBS } \\
\text { symptom severity scores, the outcome extracted for our meta- } \\
\text { analysis }\end{array}$ \\
\hline
\end{tabular}

\section{Schneider 2006}

\begin{tabular}{|c|c|}
\hline Methods & $\begin{array}{l}\text { Design: Parallel } \\
\text { Blinding: Yes } \\
\text { Attempt to confirm patient blinding?: Not reported } \\
\text { Dropouts/withdrawals: During } 5 \text { weeks treatment, } 1 / 22 \text { drop-outs in acupuncture group and } 1 / 21 \text { in sham acupuncture group } \\
\text { Total duration: } 5 \text { weeks treatment followed by an evaluation, additional follow-up evaluation at } 3 \text { months after end of } \\
\text { treatment } \\
\text { Type of analysis reported: NA }\end{array}$ \\
\hline Participants & $\begin{array}{l}\text { Setting: at the outpatient clinic of the Department of Gastroenterology, University Medical Hospital, Germany } \\
\text { Mean age (+/-SD or Range): } 47.63 \text { (14.71) years in acupuncture group, } 47.14 \text { (16.01) years for sham acupuncture group } \\
\text { Men/Women (n/n): } 9 / 34 \\
\text { Recruitment method: "Patients were recruited at the outpatient clinic of the Department of Gastroenterology, University } \\
\text { Medical Hospital, via gastroenterology specialists in private practice in the Heidelberg area, and via advertisements in local } \\
\text { newspapers" } \\
\text { Minimum duration of IBS symptoms: } 12 \text { weeks out of the last } 12 \text { months } \\
\text { Duration of IBS symptoms before enrollment: < } 2 \text { years in } 3 \text { patients, } 2 \text { to } 10 \text { years in } 14 \text { patients, > } 10 \text { years in } 25 \text { patients } \\
\text { Diagnosis of IBS required to be eligible? (if yes, describe how patients were verified to have IBS): Rome II criteria } \\
\text { Evaluation to rule out organic gastrointestinal disease: Reported } \\
\text { Predominant symptoms or stool patterns of participants: Alternating symptoms (17/43) and diarrhea (17/43) were more } \\
\text { common than constipation (5/43) or normal stool habits (4/43) } \\
\text { Hospital inpatients? (Y/N; if Y list number inpatients): No } \\
\text { Were people with a history of acupuncture treatment excluded?: Assumedly no, only patients who received AC treatment } \\
\text { within the last three months were excluded }\end{array}$ \\
\hline Interventions & $\begin{array}{l}\text { ACUPUNCTURE } \\
\mathrm{N} \text { allocated to acupuncture: } 22\end{array}$ \\
\hline
\end{tabular}

Cochrane Database Syst Rev. Author manuscript; available in PMC 2013 July 22. 
Schneider 2006

\begin{tabular}{|c|c|c|}
\hline & \multicolumn{2}{|c|}{$\begin{array}{l}\text { Style of acupuncture: Chinese } \\
\text { Points selection: Fixed formula } \\
\text { Points stimulated: Liver 3, Stomach 36, Spleen 6, Conception 12, Stomach 21, Stomach 25, Heart 7, Du Mai } 20 . \\
\text { Description of acupuncturist qualifications: "AC was performed by an experienced female acupuncturist (SB) and by a } \\
\text { trained female research assistant (CW)" } \\
\text { Total length of treatment period (weeks): } 5 \\
\text { Number of sessions target (mean): } 10 \\
\text { Times per week: } 2 \\
\text { Number of points used (mean): } 8 \text { points (14 needles for both sides) } \\
\text { Insertion depth: Not reported Was De Qi reportedly sought?: Yes } \\
\text { Duration (mins): Not reported } \\
\text { Method of stimulation: Manipulation } \\
\text { CONTROL GROUP A INTERVENTION (sham, if used): Sham acupuncture with a blunted telescopic placebo needle } \\
\text { N allocated to control group A: } 21 \\
\text { Points selection: fixed formula } \\
\text { Points stimulated: } 2 \text { cm adjacent to the real AC point, the AC point LG } 20 \text { was not needled } \\
\text { Total length of treatment period: } 5 \text { weeks } \\
\text { Number of sessions target (mean): } 10 \\
\text { Times per week: } 2 \\
\text { Number of points used: } 7 \text { points (13 needles for both sides) } \\
\text { Insertion depth: Non-insertion } \\
\text { Was De Qi sought?: No } \\
\text { Duration (mins): Not reported } \\
\text { Method of stimulation: Not applicable } \\
\text { Any co-interventions in all groups?: Not reported }\end{array}$} \\
\hline Outcomes & \multicolumn{2}{|c|}{$\begin{array}{l}\text { Symptom severity: Not assessed } \\
\text { Quality of life: "Patients completed two QOL questionnaires that were used to assess any effects of symptomatic } \\
\text { improvement by AC on their overall QOL: (a) FDDQL assesses disease related impact of bowel symptoms on quality of life, } \\
\text { measured with } 43 \text { items on eight subscales: daily activity disease related anxiety, diet, sleep, discomfort, health perception, } \\
\text { coping with disease, and impact of stress. Scores for subscales are added to a global QOL scale ranging from } 0 \text { to } 100 \text {. } \\
\text { FDDQL has an internal consistency of } 0.94 \text { (Cronbach's alpha); (b) the health related quality of life questionnaire (SF-36) is } \\
\text { a validated global measure of health related quality of life unrelated to specific diseases that has been widely used in a variety } \\
\text { of diseases. It uses } 36 \text { items to assess eight scales (bodily function, bodily role, bodily pain, general health, vitality, social } \\
\text { function, emotional role, and physical well being)." Measured as score for each time points for each group } \\
\text { Time points of symptom measurement: "Both questionnaires (FDDQL and SF-36) were given prior to treatment (t1), } \\
\text { immediately after } 10 \text { AC treatments (t2=five weeks after the first treatment), and three months after the last treatment (t3). } \\
\text { Improvement in the global score of FDDQL immediately after the } 10 \text { treatments (t2) was the primary end point of the study. } \\
\text { The other subscales of the FDDQL and the SF-36 were defined as secondary end points. Outcome measures at t3 were also } \\
\text { defined as secondary end points" } \\
\text { Author's conclusion: Acupuncture in IBS is primarily a placebo response } \\
\text { Adverse effects: Not reported }\end{array}$} \\
\hline Notes & \multicolumn{2}{|c|}{$\begin{array}{l}\text { Comments: Carefully worked, especially for the blinding of evaluator } \\
\text { Weak points: small sample size } \\
\text { Means and SEMs of quality of life could be measured with a ruler in Fig.1 for short term and long term. SDs were calculated } \\
\text { following the formula: SD = SEM * sqrt (N) } \\
\text { No information about response rate was reported } \\
\text { The first author Antonius Schneider was contacted by email to request information about randomization. He replied with } \\
\text { detailed information on January } 27,2011 \\
\text { Funding sources: "The trial was financially supported by the German Medical Acupuncture Association (DAGFA). The } \\
\text { funding source had no involvement in design, performance, or analysis of the study" }\end{array}$} \\
\hline \multicolumn{3}{|l|}{ Risk of bias } \\
\hline Bias & Authors' judgement & Support for judgement \\
\hline $\begin{array}{l}\text { Random } \\
\text { sequence } \\
\text { generation } \\
\text { (selection } \\
\text { bias) }\end{array}$ & Low risk & $\begin{array}{l}\text { "Block randomization was done by a central telephone centre" } \\
\text { [Computer generated random list (randomization with Excel)] }\end{array}$ \\
\hline $\begin{array}{l}\text { Allocation } \\
\text { concealment } \\
\text { (selection } \\
\text { bias) }\end{array}$ & Low risk & $\begin{array}{l}\text { "Block randomization was done by a central telephone centre so that } \\
\text { neither the patient nor the investigator (AS) knew whether the patient } \\
\text { would receive AC or SAC. The randomization result was told to the } \\
\text { acupuncturist (SB, CW) directly after informed consent" }\end{array}$ \\
\hline $\begin{array}{l}\text { Blinding } \\
\text { (performance } \\
\text { bias and } \\
\text { detection bias) } \\
\text { All outcomes }\end{array}$ & Low risk & $\begin{array}{l}\text { "In the control group, patients received SAC with a blunted telescopic } \\
\text { placebo needle (Asia Med) that simulates an AC procedure without } \\
\text { penetrating the skin. The efficiency of this method has been shown in } \\
\text { various studies. Each SAC procedure was performed } 2 \mathrm{~cm} \text { adjacent to } \\
\text { the real AC point to avoid acupressure effects. In the SAC group, the } \\
\text { AC point LG } 20 \text { was not needled as fixation of the plaster is not possible } \\
\text { on the head due to hair." }\end{array}$ \\
\hline
\end{tabular}


Schneider 2006

\begin{tabular}{|c|c|c|}
\hline & & $\begin{array}{l}\text { "Only one patient in the entire study population had received AC in the } \\
\text { past. She was able to identify SAC and declined to participate in the } \\
\text { study after the third treatment" } \\
\text { No attempt to confirm patient blinding, although this may not be } \\
\text { necessary in this case because the Streitberger needle has been } \\
\text { previously validated. The Asia Med needle is the same as the } \\
\text { Streitberger needle, which has previously been validated in other studies } \\
\text { (Streitberger 1998; Kleinhenz 1999; Streitberger 2004) and the } \\
\text { Streitberger needles were placed close to the genuine points. Therefore, } \\
\text { the sham was likely to be indistinguishable from the true acupuncture }\end{array}$ \\
\hline $\begin{array}{l}\text { Incomplete } \\
\text { outcome data } \\
\text { (attrition bias) } \\
\text { Short term }\end{array}$ & Low risk & $\begin{array}{l}\text { "Only one patient in the entire study population had received AC in the } \\
\text { past. She was able to identify SAC and declined to participate in the } \\
\text { study after the third treatment. Another female patient declined to } \\
\text { participate after five treatments due to time constraints. Thus two } \\
\text { patients dropped out during the course of the study" } \\
\text { During } 5 \text { weeks treatment, } 1 / 22 \text { drop-outs in acupuncture group and } 1 / 21 \\
\text { drop-outs in sham acupuncture group }\end{array}$ \\
\hline $\begin{array}{l}\text { Selective } \\
\text { reporting } \\
\text { (reporting } \\
\text { bias) }\end{array}$ & Low risk & $\begin{array}{l}\text { "Both questionnaires (FDDQL and SF-36) were given prior to treatment } \\
\text { (t1), immediately after } 10 \text { AC treatments ( } 2 \text { = five weeks after the first } \\
\text { treatment), and three months after the last treatment ( } \mathrm{t} 3 \text { ). Improvement } \\
\text { in the global score of FDDQL immediately after the } 10 \text { treatments ( } 2 \text { ) } \\
\text { was the primary end point of the study. The other subscales of the } \\
\text { FDDQL and the SF-36 were defined as secondary end points. Outcome } \\
\text { measures at t3 were also defined as secondary end points" } \\
\text { Global scale and subscales of FDDQL were reported at baseline, } 5 \\
\text { weeks and } 17 \text { weeks } \\
\text { Differences of FDDQL global and sub scales between two groups were } \\
\text { reported at } 5 \text { weeks and } 17 \text { weeks } \\
\text { Only statistical comparison of SF-36 scales between and within the two } \\
\text { groups were reported in Results section } \\
\text { Results were reported for each outcome measured according to the } \\
\text { Methods section, and a health-related quality of life outcome (the } \\
\text { FDDQL) was reported at end of treatment and at follow up }\end{array}$ \\
\hline Other bias & Low risk & $\begin{array}{l}\text { Although ITT analysis was not reported, there were very few drop-outs, } \\
\text { so the degree of "missingness" would be unlikely to affect the estimate } \\
\text { of the treatment effect in this trial } \\
\text { "There were no differences in age or sex between the groups at entry" } \\
\text { The "Symptoms at study entry" section/paragraph includes the following } \\
\text { text: "The BDQ illustrates the degree and severity of bowel symptoms } \\
\text { among the patients... No differences were seen between those who } \\
\text { received AC or SAC after assessment" }\end{array}$ \\
\hline
\end{tabular}

Shi 2010

\begin{tabular}{|c|c|}
\hline Methods & $\begin{array}{l}\text { Design: Parallel } \\
\text { Blinding: No } \\
\text { Attempt to confirm patient blinding?: No } \\
\text { Dropouts/withdrawals: During the } 4 \text { weeks treatment, } 1 / 32 \text { drop-outs in acupuncture group and } 1 / 38 \text { in pinaverium bromide } \\
\text { group } \\
\text { Total duration: } 4 \text { weeks treatment immediately followed by an evaluation, } 1 \text { week follow up reported } \\
\text { Type of analysis reported: Intention to treat analysis }\end{array}$ \\
\hline Participants & $\begin{array}{l}\text { Setting: Outpatients of digestion medicine and integrative medicine in Hunan Provincial } \\
\text { Hospital of TCM and Xiangya Hospital of Central South University, China Mean age ( }+/- \text { Standard Deviation or Range): } \\
38.51(14.65) \text { years for acupuncture group, } 38.68 \text { (15.72) years for pinaverium bromide group } \\
\text { Men/Women (number/number): } 13 / 57 \\
\text { Acupuncture: } 7 / 25 \text {, Medication: } 6 / 32 \\
\text { Recruitment method: Not reported } \\
\text { Minimum duration of IBS symptoms: Rome III criteria for the last } 3 \text { months with symptom onset at least } 6 \text { months prior to } \\
\text { diagnosis } \\
\text { Actual duration of IBS symptoms before enrollment: } 10.62(9.23) \text { months for acupuncture group, } 10.80(7.86) \text { months for } \\
\text { pinaverium bromide group } \\
\text { Diagnosis of IBS required for eligibility?: Rome III criteria for diarrhea-predominant irritable bowel syndrome } \\
\text { Evaluation to rule out organic gastrointestinal disease: Reported - colonoscopy or barium enema examination } \\
\text { Predominant symptoms or stool patterns of participants: The study only recruited patient with diarrhea-predominant IBS } \\
\text { Hospital inpatients?: No } \\
\text { Were people with a history of acupuncture treatment excluded?: Not reported }\end{array}$ \\
\hline Interventions & $\begin{array}{l}\text { ELECTRO-ACUPUNCTURE } \\
\text { Number allocated to acupuncture: } 32 \\
\text { Style of acupuncture: Chinese } \\
\text { Points selection: Flexible formula for specific symptoms }\end{array}$ \\
\hline
\end{tabular}

Cochrane Database Syst Rev. Author manuscript; available in PMC 2013 July 22. 
Shi 2010

\begin{tabular}{|c|c|c|}
\hline & \multicolumn{2}{|c|}{$\begin{array}{l}\text { Points stimulated: } 7 \text { main fixed acupoints and } 3 \text { optional points. The fixed points included ST 25, ST 36, BL 20, BL 21, BL } \\
23 \text {, BL } 25 \text { and ST } 37 \text {. The optional points were PC } 6, \text { LV } 3 \text { and EX-HN1 (for the diagnosis of psychological symptoms such } \\
\text { as depression, anxiety and insomnia, etc) } \\
\text { Description of acupuncturist qualifications: "All manipulations were practiced by professional acupuncturists with more } \\
\text { than } 5 \text { years of clinical experience" } \\
\text { Total length of treatment period (weeks): } 4 \\
\text { Number of sessions target (mean): } 28 \text { (daily session, for } 28 \text { days) } \\
\text { Times per week: } 7 \\
\text { Number of points used (mean): } 7 \text { fixed bilateral acupoints plus } 3 \text { optional points } \\
\text { Insertion depth: } 1 \text { cun oblique insertion for ST } 25 \text { and BL } 20 ; 1 ~ 1.5 \text { cun for ST } 36, \text { ST } 37, \text { BL } 23 \text { and BL } 25 ; 0.5 \text { to } 1 \text { cun } \\
\text { for PC } 6 \text { and LV } 3 ; 0.5 \text { to } 0.8 \text { cun horizontal insertion for EX-HN } 1 \\
\text { Was De Qi reportedly sought?: Yes, before electro-stimulation } \\
\text { Duration (minutes): } 15 \text { min } \\
\text { Method of stimulation: Manipulation and Electro-acupuncture } \\
\text { Electro-acupuncture procedure: After De Qi, G6805-2A electro-acupuncture device was connected, ST-25, PC-6, LR-3 with } \\
\text { continuous-wave, ST-36, ST-37, BL-20, BL-23, BL-25, with the dense-sparse wave, EX-HN1 Sishencong with intermittent } \\
\text { waves. } \\
\text { According to the patients' sensitivity and tolerance to adjust the stimulation intensity and frequency. There was a close } \\
\text { observation during electro-acupuncture treatment, to prevent accident } \\
\text { CONTROL GROUP A INTERVENTION: Pinaverium bromide (Product name: Deshute) } \\
\text { Number allocated to control group A: } 38 \\
\text { Total length of treatment period: } 4 \text { weeks } \\
\text { Number of sessions target (mean): } 28 \\
\text { days per week: } 7 \\
\text { Times per day: } 3 \\
\text { Dosage: } 50 \text { mg/time } \\
\text { Any co-interventions in all groups? Not reported }\end{array}$} \\
\hline Outcomes & \multicolumn{2}{|c|}{$\begin{array}{l}\text { Symptom severity: } \\
\text { 1. Overall IBS symptom VAS score: Overall IBS symptom VAS score was rated on a 10-point visual analog scale } \\
\text { 2. SRI: SRI is an efficacy index based on overall IBS symptom VAS score. A responder was defined as a patient whose SRI } \\
\text { was more than } 60 \% \\
\text { SRI = (symptom score before treatment - symptom score after treatment) / symptom score before treatment } \\
\text { Quality of life: Not assessed } \\
\text { Time points of symptom measurement: } \\
\text { The Overall IBS symptom VAS scores (mean and SD) were reported at baseline, } 1 \text { week, } 2 \text { week, } 3 \text { week, } 4 \text { week and } 5 \\
\text { weeks (i.e. } 1 \text { week after the treatment). [The VAS scores were presented as mean and SD] The responder rates of IBS } \\
\text { symptom based on SRI for both groups were: "Based on patients SRI level, at the end of treatment, effective rate in } \\
\text { treatment group is } 81,3 \% \text {, in the control group } 52,6 \% \text { " (end of Section } 4.3 \text { ) } \\
\text { Author's conclusion: "Electro-acupuncture was safe and effective for diarrhea-predominant IBS and is worth further } \\
\text { researching and popularizing. This study found evidence to support the superiority of electro-acupuncture compared with } \\
\text { pinaverium bromide" } \\
\text { Additional outcomes reported in the trial but not extracted: The diarrhea VAS score were reported at baseline, } 1 \text { week, } 2 \\
\text { week, } 3 \text { week, } 4 \text { week and } 5 \text { week (Figure } 1 \text { ). The abdominal pain/discomfort VAS score were reported at baseline, } 1 \text { week, } \\
2 \text { week, } 3 \text { week, } 4 \text { week and } 5 \text { week (Figure 2). The evaluators who administered the VAS tests to the patients were blind to } \\
\text { the participant assignment } \\
\text { Adverse effects: "One participant in electro-acupuncture group withdrew due to acupuncture syncope and one participant in } \\
\text { pinaverium bromide group withdrew due to itch and skin rash caused by allergic reaction. There's no obvious adverse effect } \\
\text { in other participants" }\end{array}$} \\
\hline Notes & \multicolumn{2}{|c|}{$\begin{array}{l}\text { Funding sources: [No funding] } \\
\text { Information in square brackets was provided by the first author Shi XH and second author Luo JK, in telephone surveys on } \\
\text { Jul } 21 \text { y and 22, } 2011 \\
\text { Since the numerical data were not in the text, we measured the Overall IBS symptom VAS scores (mean and SD) with a } \\
\text { ruler at each time points for both groups using Figure } 3\end{array}$} \\
\hline \multicolumn{3}{|l|}{ Risk of bias } \\
\hline Bias & Authors' judgement & Support for judgement \\
\hline & Low risk & [We referred to a random number table] \\
\hline & Low risk & [We used sequentially numbered, opaque, sealed envelopes] \\
\hline & High risk & [The evaluators were blind to the participant assignment] \\
\hline
\end{tabular}


Shi 2010

\begin{tabular}{l|l|l}
\hline $\begin{array}{l}\text { Incomplete } \\
\text { outcome data } \\
\text { (attrition bias) } \\
\text { Short term }\end{array}$ & Low risk & $\begin{array}{l}\text { "One participant in electro-acupuncture group withdrew due to acupuncture } \\
\text { syncope and one participant in pinaverium bromide group withdrew due to itch } \\
\text { and skin rash caused by allergic reaction" }\end{array}$ \\
\hline $\begin{array}{l}\text { Selective } \\
\text { reporting } \\
\text { (reporting bias) }\end{array}$ & Low risk & $\begin{array}{l}\text { This trial reported outcomes for overall IBS symptom VAS score and responder } \\
\text { rate at the completion of the 4 week treatment period, together with results for } \\
\text { each outcome measured according to the observational targets section }\end{array}$ \\
\hline Other bias & Low risk & $\begin{array}{l}\text { ITT analysis was reported. It was not clear how the data were imputed for the 2 } 2 \\
\text { dropouts. However, this trial had a large, statistically significant effect size (i.e. } \\
\text { RR 1.54, 95\%CI 1.09 to 2.18) and any assumptions made about the treatment } \\
\text { response of these 2 drop-outs would not impact the overall results of this trial or } \\
\text { the results of the meta-analysis that included this trial } \\
\text { The two treatment groups were comparable at baseline in terms of the } \\
\text { demographic characteristics, diarrhea VAS score, abdominal pain/discomfort VAS } \\
\text { score and overall IBS symptom VAS scores }\end{array}$ \\
\hline
\end{tabular}

Sun 2011

\begin{tabular}{|c|c|}
\hline Methods & $\begin{array}{l}\text { Design: Parallel } \\
\text { Blinding: No } \\
\text { Attempt to confirm patient blinding?: No } \\
\text { Dropouts/withdrawals: Three cases, } 1 \text { from the treatment group and } 2 \text { from the control group, were dropped out due to loss } \\
\text { in the follow-up. A total of } 60 \text { patients completed the study“ }\end{array}$ \\
\hline Participants & $\begin{array}{l}\text { Setting: "The } 63 \text { patients enrolled were outpatients of special IBS-D clinics of Chinese } \\
\text { Medicine Hospital of Jiangsu province from July } 2009 \text { to November } 2010 \text { " } \\
\text { Mean age (+/- Standard Deviation or Range): "The } 31 \text { patients in the treatment group were ....aged } 18 \text { to } 61 \text { years ( } 38.81+/ \\
-11.80 \text { years on average)...The } 32 \text { patients in the [drug] treatment group were....aged } 18 \text { to } 59 \text { years ( } 38.59+/-11.45 \text { years } \\
\text { on average)" } \\
\text { Men/Women (number/number):Acupuncture group: } 13 \text { males; } 18 \text { females; Drug group: } 20 \text { males; } 12 \text { females } \\
\text { Recruitment method: Not reported } \\
\text { Minimum duration of IBS symptoms: Rome III criteria for the last } 3 \text { months with symptom onset at least } 6 \text { months prior to } \\
\text { diagnosis } \\
\text { Actual duration of IBS symptoms before enrollment: The duration for acupuncture group was } 1 \text { to } 20 \text { years }(4.23+/-3.96 \\
\text { on average); the duration for western medication group was } 1 \text { to } 38 \text { years (5.63 +/- } 7.35 \text { on average) } \\
\text { Diagnosis of IBS required for eligibility?: Diagnosis of IBS-D based on the Rome III classification } \\
\text { Evaluation to rule out organic gastrointestinal disease: Yes } \\
\text { Predominant symptoms or stool patterns of participants: Diarrhea-predominant IBS } \\
\text { Hospital inpatients?: No } \\
\text { Were people with a history of acupuncture treatment excluded?: Not reported }\end{array}$ \\
\hline ntions & $\begin{array}{l}\text { ACUPUNCTURE (plus mild moxibustion) } \\
\text { Number allocated to acupuncture: } 31 \\
\text { Style of acupuncture: Chinese } \\
\text { Points selection: Fixed formula } \\
\text { Points stimulated: "Points selection: bilateral Tianshu (ST25), Zusanli (ST36), Shangjuxu (ST37), Sanyinxiao (SP6), } \\
\text { Taichong (LR3), Baihui (DU20), and Yintang (EX-HN 3) points" } \\
\text { Description of acupuncturist qualifications: Not reported } \\
\text { Total length of treatment period (weeks): } 4 \\
\text { Number of sessions target (mean): } 20 \\
\text { Times per week: } 5 \\
\text { Number of points used (mean): } 7 \text { fixed points. } \\
\text { Insertion depth: } 12 \text { to } 25 \mathrm{~mm} \\
\text { Was De Qi reportedly sought? Yes } \\
\text { Duration (minutes): } 30 \text { min } \\
\text { Method of stimulation: "Twist lifting-inserting gentle reinforcing-purging manipulation was applied after de qi (getting qi) } \\
\text { C." } \\
\text { CONTROLGROUP A INTERVENTION: Western medication "Dicetel (Pinaverium bromide tablets, product of Solvay } \\
\text { Pharmaceuticals, France, batch No. H20080424) was given orally } 50 \mathrm{mg}, 3 \text { times a day for a total of } 4 \text { weeks" } \\
\text { Number allocated to control group A: } 32 \\
\text { Total length of treatment period: } 4 \text { weeks } \\
\text { Number of sessions target (mean): } 28 \\
\text { days per week: } 7 \\
\text { Times per day: } 3 \text { times/day } \\
\text { Dosage: } 50 \text { mg } \\
\text { Any co-interventions in all groups? Not reported }\end{array}$ \\
\hline Outcomes & $\begin{array}{l}\text { Symptom severity: } \\
\text { Overall IBS symptom score (4-point scoring system) referring to the Guiding Principle of Clinical Research on New Drugs } \\
\text { of Traditional Chinese Medicine at end of treatment: 1) cured 2) improved 3) effective 4) no effect. } \\
\text { 1) clinically remitted: the symptom disappeared. Effect index }=295 \% \text {. } \\
\text { 2)markedly effective: symptoms and signs markedly relieved. } 70 \% \leq \text { Effect index }<95 \% \\
\text { 3) effective: the symptoms and signs improved. } 30 \% \leq \text { Effect index }<70 \%\end{array}$ \\
\hline
\end{tabular}

Cochrane Database Syst Rev. Author manuscript; available in PMC 2013 July 22. 
Sun 2011

\begin{tabular}{|c|c|c|}
\hline & \multicolumn{2}{|c|}{$\begin{array}{l}\text { 4) no effect: the symptom did not importantly improve. Effect index }=<30 \% \\
\text { Computation formula: Effect index = (symptom score before treatment - symptom score after treatment) / symptom score } \\
\text { before treatment* } 100 \% \\
\text { Quality of life: } \\
\text { Drossman (IBS-QOL), adapted with Han modification, which consisted of } 34 \text { items in } 8 \text { domains. "Every item was } \\
\text { differentiated into } 5 \text { grades (none, mild, moderate, lean to severe, severe) which were recorded as } 5,4,3,2 \text {, and } 1 \text { scores, } \\
\text { respectively. The records were made before and after the } 4 \text { week treatment." } \\
\text { Time points of symptom measurement: } \\
\text { The responders for overall IBS symptom were reported at pre-treatment, week 1, week } 2 \text {, and week } 4 \\
\text { The quality of life was reported at baseline and at end of treatment (week } 4) \\
\text { Author's conclusion: "acupuncture treatment could effectively alleviate the degree and frequency of symptoms' attack in } \\
\text { IBS-D patients... with the efficacy better than that of pinaverium bromide, showing a preponderance in improving patients' } \\
\text { QOL" } \\
\text { Additional outcomes reported in the trial but not extracted: Scores on the individual domains of the quality of life measure, } \\
\text { before and after treatment } \\
\text { Adverse effects: "No any adverse reaction occurred" }\end{array}$} \\
\hline Notes & \multicolumn{2}{|c|}{$\begin{array}{l}\text { Funding sources: "Supported by the funds of Chinese Medicine Hospital of Jiangsu Province, China (No. Y09039-1) and } \\
\text { Chinese Medicine Leading Talent Project of Jiangsu Province, China (No. LJ 200905)" } \\
\text { Reason for identical numbers assigned to the two groups: [A block randomization was used, where there are equal numbers } \\
\text { in the blocks. The block sizes were } 8 \text {, with four assigned to acupuncture and } 4 \text { assigned to drug treatment in each block. } \\
\text { There were } 63 \text { total randomized, and } 8 \text { blocks of } 8 \text { were used (with } 1 \text { assignment left over)] } \\
\text { Allocation concealment: Not reported in the article. [Sequentially numbered, opaque envelopes]. This method does not } \\
\text { entirely meet the Cochrane Handbook standard for allocation concealment, which requires that the envelopes by "sealed" } \\
\text { Evaluation blinding: [IBS-QOL was evaluated by participants themselves. Participants' symptoms were asked by staff who } \\
\text { did not know the group assignment] } \\
\text { Information in square brackets was provided by the author Wu XL, in a telephone survey, followed by an e-mail for } \\
\text { clarification, sent from Wu to Ke Cheng on December } 2,2011 \\
\text { We dichotomized cured, improved, effective and no effect into the } 2 \text { categories of improved or not improved according to } \\
\text { the methods section of the review }\end{array}$} \\
\hline \multicolumn{3}{|l|}{ Risk of bias } \\
\hline Bias & Authors' judgement & Support for judgement \\
\hline $\begin{array}{l}\text { Random } \\
\text { sequence } \\
\text { generation } \\
\text { (selection bias) }\end{array}$ & Low risk & $\begin{array}{l}\text { "The patients were assigned by a random number table to two groups, the acupuncture } \\
\text { treatment group and the drug control group." } \\
\text { [A block randomization was used, where there are equal numbers in the blocks. The block } \\
\text { sizes were } 8 \text {, with four assigned to acupuncture and } 4 \text { assigned to drug treatment in each } \\
\text { block. There were } 63 \text { total randomized, and } 8 \text { blocks of } 8 \text { were used (with } 1 \text { assignment left } \\
\text { over)] }\end{array}$ \\
\hline $\begin{array}{l}\text { Allocation } \\
\text { concealment } \\
\text { (selection bias) }\end{array}$ & High risk & $\begin{array}{l}\text { [We used envelope method. The envelopes were sequentially numbered, opaque, unsealed] } \\
\text { We scored this trial as High Risk because the Cochrane Handbook requires that all } 3 \\
\text { criteria (i.e. sequentially numbered, opaque, sealed) must be met for the envelope method } \\
\text { to score a Low Risk of bias }\end{array}$ \\
\hline $\begin{array}{l}\text { Blinding } \\
\text { (performance } \\
\text { bias and } \\
\text { detection bias) } \\
\text { All outcomes }\end{array}$ & High risk & $\begin{array}{l}\text { [IBS-QOL was evaluated by participants themselves. Participants' symptoms were asked } \\
\text { by staff who did not know the group assignment] }\end{array}$ \\
\hline $\begin{array}{l}\text { Incomplete } \\
\text { outcome data } \\
\text { (attrition bias) } \\
\text { Short term }\end{array}$ & Low risk & $\begin{array}{l}\text { "Three cases, } 1 \text { from the treatment group and } 2 \text { from the control group, were dropped out } \\
\text { due to loss in the follow-up. A total of } 60 \text { patients completed the study" }\end{array}$ \\
\hline $\begin{array}{l}\text { Selective } \\
\text { reporting } \\
\text { (reporting bias) }\end{array}$ & Low risk & $\begin{array}{l}\text { This trial reported outcomes for overall IBS symptom responders and quality of life at the } \\
\text { completion of the } 4 \text { week treatment period, which are standard outcomes and the outcomes } \\
\text { described as being measured in the Methods section }\end{array}$ \\
\hline Other bias & Unclear risk & $\begin{array}{l}\text { ITT was not used } \\
\text { "The scores of symptoms in the two groups were insignificantly different before treatment } \\
(\mathrm{t}=1.824, \mathrm{P}=0.074) \ldots \text { The IBS-QOL scores in the two groups were similar at pre- } \\
\text { treatment }(\mathrm{t}=1.327, \mathrm{P}=0.19) \text { " }\end{array}$ \\
\hline
\end{tabular}

Xiong 2008a

\begin{tabular}{l|l}
\hline Methods & Design: Parallel \\
& Blinding: No \\
Attempt to confirm patient blinding?: No \\
Dropouts/withdrawals: During the 4 weeks treatment, no drop-outs mentioned in any of the three groups (acupuncture + \\
Chinese herbal medicine group, Chinese herbal medicine group and acupuncture) \\
Total duration: 4 weeks of treatment, evaluation after treatment, but the specific time point of evaluation was not stated \\
Type of analysis reported: NA
\end{tabular}


Xiong 2008a

Setting: Not very specific. " 120 patients from outpatient or inpatient were randomly divided into 3 groups." China Mean age (+/-SD or Range): 39.15 (15) years for Chinese herbal medicine group, 38.3 (16) years for acupuncture group, $38.6(15)$ years for acupuncture + Chinese herbal medicine group

Men/Women (n/n): 48/72

Recruitment method: "120 patients from outpatient or inpatient were randomly divided into 3 groups"

Minimum duration of IBS symptoms: 1 year

Actual duration of IBS symptoms before enrollment: 53.7 (5.1) months for Chinese herbal medicine group, 52.6 (5.4)

months for acupuncture group, $54.2+/-4.9$ months for acupuncture + Chinese herbal medicine group

Diagnosis of IBS required to be eligible? (if yes, describe how patients were verified to have IBS): Rome II criteria and

diagnostic criteria of liver-qi stagnation and spleen deficiency in "The principle of clinical research for new drug of

traditional Chinese herbal medicine (in Chinese)" were used

Evaluation to rule out organic gastrointestinal disease: Reported. "Subjects with other organic gastrointestinal disease were excluded"

Predominant symptoms or stool patterns of participants: Diarrhea

Hospital inpatients? (Y/N; if $\mathrm{Y}$ list number inpatients): Yes, the number of inpatients was not reported Were people with a history of acupuncture treatment excluded?: Not reported

Interventions $\quad$ ACUPUNCTURE+ CHINESE HERBAL MEDICINE

$\mathrm{N}$ allocated to acupuncture: 42

Style of acupuncture: Chinese

Points selection: Fixed formula

Points stimulated: CV-12, bilateral ST-25, LI-4, ST-36, LR-3

Ingredient of Chinese herbal medicine: Thorowax root $12 \mathrm{~g}$, white peony root $15 \mathrm{~g}$, bitter orange immature $6 \mathrm{~g}$, turmeric

root, tuckahoe $15 \mathrm{~g}$, tangerine peel $6 \mathrm{~g}$, divaricate saposhnikovia root $9 \mathrm{~g}$, bighead atractylodes rhizome $15 \mathrm{~g}$, aucklandia root

$6 \mathrm{~g}$, natgrass galingale rhizome $6 \mathrm{~g}$, oriental waterplantain rhizome $15 \mathrm{~g}$, licorice root $3 \mathrm{~g}$

Description of acupuncturist qualifications: No description.

Total length of treatment period (weeks): 4

Number of sessions target (mean): 28

Times per week: 7

Number of points used (mean): 9 points

Insertion depth: Not reported

Was De Qi reportedly sought?: Yes

Duration (mins): $30 \mathrm{~min}$

Method of stimulation: Manipulation.

Moxibusiton procedure: Moxibustion with warming needle procedure were performed on bilateral ST-25 and ST-36

CONTROL GROUP A INTERVENTION (sham, if used): Chinese herbal medicine only group

$\mathrm{N}$ allocated to control group A: 40

Total length of treatment period: 4 weeks

Number of sessions target (mean): 28

Times per week: 7

Ingredient of Chinese herbal medicine: same as described above

CONTROL GROUP B INTERVENTION (sham, if used): Acupuncture only group

$\mathrm{N}$ allocated to control group $\mathrm{B}: 38$

Points selection: Fix

Points stimulated: CV-12, bilateral ST-25, LI-4, ST-36, LR-3

Total length of treatment period: 4 weeks

Number of sessions target (mean): 28

Times per week: 7

Number of points used: 9 points

Insertion depth: Not stated

Was De Qi sought?: Yes

Duration (mins): 30

Method of stimulation: Manipulation

Moxibusiton procedure: Moxibustion with warming needle procedure were performed on bilateral ST-25 and ST-36 Any co-interventions in all groups?: Not reported

\begin{tabular}{l|l}
\hline Outcomes & Quality of life: Not assessed
\end{tabular}

Symptom severity: Symptom Improvement (4-point scoring system) at end of treatment: 1) cured: 2) improved 3) effective 4) no effect

"Measurements: Abdominal pain, diarrhea, abdominal distension, stool frequency and properties were assessed According to "The principle of clinical research for new drug of traditional Chinese herbal medicine (in Chinese)", no symptom (0 score) means well-formed motions, soft stool, 1 to 2 times a day; mild symptom ( 1 score) means life and work are not influenced, mushy stool or stool with a little mucus, 2 to 3 times a day; moderate symptom ( 2 score) means the symptom influences life and work but can be tolerated, moderate mucous stool, 4 to 5 times a day; severe symptom ( 3 score): the symptom interfere with life and work and can not be tolerated, rice-water stool or stool with lots of mucous, above 6 times a day"

"1)Cured: disappearance of main symptoms, well-formed stool, disappearance of mucus, improvement of score $>=95 \%$; 2) Improved: disappearance of most main symptoms, well-formed stool, significantly decrease of mucus, improvement of symptom score $>=70 \%$ and $<95 \%$;

3) Effective: improvement of main symptoms, watery stool, decrease of mucus, improvement of symptom score $>=30 \%$; 4) No effect: no improvement of symptoms, improvement of symptom score $<30 \%$

Improvement of symptom score $=($ total symptom score before treatment - total symptom score after treatment $) /$ total symptom score before treatment

Total symptom score $=$ abdominal pain score + abdominal distension score + diarrhea score + stool frequency score + stool properties score"

Time points of symptom measurement: Before and after the treatment 
Xiong 2008a

\begin{tabular}{|c|c|c|}
\hline & \multicolumn{2}{|c|}{$\begin{array}{l}\text { Additional outcomes reported in the trial but not extracted: Table 2, 3, } 4 \text { and } 5 \text { showed the number of responders of } \\
\text { improvement of diarrhea, abdominal pain, abdominal distension and stool frequency respectively for each group after } \\
\text { treatment } \\
\text { Author's conclusion: "The findings indicate that the combination of acupuncture and Chinese herbal medicine shows } \\
\text { promise in the treatment of patients with diarrhea-predominant IBS" } \\
\text { Adverse effects: Not reported }\end{array}$} \\
\hline Notes & \multicolumn{2}{|c|}{$\begin{array}{l}\text { We extracted data for acupuncture + Chinese herbal medicine versus Chinese herbal medicine only } \\
\text { Additional information in square brackets was provided by the first author Xiong, in an telephone conversation with Ke } \\
\text { Cheng from September } 18,2009 \text {, and translated by Ke Cheng in an e-mail to Eric Manheimer and L. Susan Wieland on } \\
\text { February } 28,2011 \\
\text { Funding resources: When the first author Xiong was telephoned, she stated there was no funding supporting the trial }\end{array}$} \\
\hline \multicolumn{3}{|l|}{ Risk of bias } \\
\hline Bias & Authors' judgement & Support for judgement \\
\hline $\begin{array}{l}\text { Random } \\
\text { sequence } \\
\text { generation } \\
\text { (selection bias) }\end{array}$ & Low risk & $\begin{array}{l}\text { "120 patients from outpatient or inpatient were randomly divided } \\
\text { into } 3 \text { groups." } \\
\text { [The generation of the sequence was referred to a random number } \\
\text { table] }\end{array}$ \\
\hline $\begin{array}{l}\text { Allocation } \\
\text { concealment } \\
\text { (selection bias) }\end{array}$ & High risk & $\begin{array}{l}\text { [No, we only used the random number table, we didn't use } \\
\text { envelope method or central allocation] }\end{array}$ \\
\hline $\begin{array}{l}\text { Blinding } \\
\text { (performance } \\
\text { bias and } \\
\text { detection bias) } \\
\text { All outcomes }\end{array}$ & High risk & Open study. Treatment allocation was not blinded \\
\hline $\begin{array}{l}\text { Incomplete } \\
\text { outcome data } \\
\text { (attrition bias) } \\
\text { Short term }\end{array}$ & High risk & $\begin{array}{l}\text { "Both trials didn't explicitly report the } 100 \% \text { follow up in the } \\
\text { paper or report to me by the author." }\end{array}$ \\
\hline $\begin{array}{l}\text { Selective } \\
\text { reporting } \\
\text { (reporting } \\
\text { bias) }\end{array}$ & Low risk & $\begin{array}{l}\text { Outcomes were reported for overall IBS symptom severity } \\
\text { (response to treatment in four categories) at the completion of the } \\
\text { treatment period. This categorization is a standard way of } \\
\text { assessing treatment success in Chinese trials of IBS. Abdominal } \\
\text { pain, diarrhea, abdominal distension, stool frequency and } \\
\text { properties were assessed at baseline and the number of responders } \\
\text { for each symptom were described after treatment }\end{array}$ \\
\hline Other bias & High risk & $\begin{array}{l}\text { Intention-to-treat analysis was not reported } \\
\text { There was a good balancing of the three groups at baseline for the } \\
\text { age and duration of IBS, but there was no information about other } \\
\text { baseline variables related to symptom severity }\end{array}$ \\
\hline
\end{tabular}

Xue 2009

\begin{tabular}{|c|c|}
\hline Methods & $\begin{array}{l}\text { Design: Parallel } \\
\text { Blinding: No } \\
\text { Attempt to confirm patient blinding?: No } \\
\text { Dropouts/withdrawals: Not reported in the article. [ } 3 / 103 \text { withdrew from the acupuncture group, } 5 / 105 \text { withdrew from the } \\
\text { sulfasalazine group] } \\
\text { Total duration: } 23 \text { to } 49 \text { days treatment followed by an evaluation, no follow up reported. } \\
\text { ("A course of treatment included } 10 \text { sessions (days) acupuncture and there was a break of } 3 \text { days between two courses. } \\
\text { Participants were administrated totally } 2 \text { to } 4 \text { courses") } \\
\text { Type of analysis reported: Not specified }\end{array}$ \\
\hline Participants & $\begin{array}{l}\text { Setting: Outpatient and inpatient in Gansu Provincial Tumor Hospital and Gansu } \\
\text { Provincial Hospital of Traditional Chinese Medicine, China } \\
\text { Mean age (+/- Standard Deviation or Range): } 37.77 \text { (9.70) years for acupuncture group, } 38.40 \text { (9.65) years for sulfasalazine } \\
\text { group } \\
\text { Men/Women (number/number): } 99 / 101 \\
\text { Acu/Moxa: } 48 / 52 \text {, Medication: } 51 / 49 \\
\text { Recruitment method: Not reported } \\
\text { Minimum duration of IBS symptoms: Rome II criteria for the last } 3 \text { months with symptom onset at least } 6 \text { months prior to } \\
\text { diagnosis } \\
\text { Actual duration of IBS symptoms before enrollment: } 5.17 \text { (3.19)months for acupuncture group, } 5.12 \text { (3.66) years for } \\
\text { sulfasalazine group } \\
\text { Diagnosis of IBS required for eligibility?: Rome II criteria } \\
\text { Evaluation to rule out organic gastrointestinal disease: type-B ultrasonic, endoscopy, colonoscopy to exclude other digestive } \\
\text { disease }\end{array}$ \\
\hline
\end{tabular}

Cochrane Database Syst Rev. Author manuscript; available in PMC 2013 July 22. 
Xue 2009

\begin{tabular}{|c|c|c|}
\hline & \multicolumn{2}{|c|}{$\begin{array}{l}\text { Predominant symptoms or stool patterns of participants: Not reported } \\
\text { Hospital inpatients? Yes, the number of inpatients was not reported } \\
\text { Were people with a history of acupuncture treatment excluded?: Not reported }\end{array}$} \\
\hline Interventions & \multicolumn{2}{|c|}{$\begin{array}{l}\text { ACUPUNCTURE + Moxibustion } \\
\text { Number allocated to acupuncture: } 103 \text { [ } 210 \text { participants were randomly assigned to two groups, } 105 \text { for both groups } \\
\text { originally, which was different with that documented in article (i.e. } 100 \text { participants). During the trial, } 3 \text { withdrew in } \\
\text { acupuncture group, } 5 \text { withdrew in sulfasalazine group. To reach an equal sample size in both groups, two participants who } \\
\text { should have been assigned to acupuncture group were not recruited] } \\
\text { Style of acupuncture: Chinese } \\
\text { Points selection: Fixed } \\
\text { Points stimulated: Six fixed acupoints including ST } 25, \text { CV } 8 \text {, ST 36, PC 6, LI } 4 \text { and LV } 3 \\
\text { Description of acupuncturist qualifications: Not reported “ } \\
\text { Total length of treatment period (weeks): } 23 \text { to } 49 \text { days (“A course of treatment included } 10 \text { sessions (days) acupuncture and } \\
\text { there was a break of } 3 \text { days between two courses. } \\
\text { Participants were administrated totally } 2 \text { to } 4 \text { courses.") } \\
\text { Number of sessions target (mean): } 20 \text { to } 40 \\
\text { Times per week: } 7 \\
\text { Number of points used (mean): } 6 \text { fixed acupoints, } 5 \text { of which are bilateral } \\
\text { Insertion depth: Not reported } \\
\text { Was De Qi reportedly sought? Not reported } \\
\text { Duration (minutes): [20 min] } \\
\text { Method of stimulation: Manipulation with even method (Ping bu ping xie) } \\
\text { Moxibustion procedure: Moxibustion was administrated on CV } 8 \text { for } 5 \text { min } \\
\text { CONTROL GROUP A INTERVENTION: } \\
\text { Sulfasalazine (Company: Shanghai Sanwei Pharmaceutical Co., Ltd) } \\
\text { Number allocated to control group A: } \\
105 \text { (as described above) } \\
\text { Total length of treatment period: } 20 \text { to } 40 \text { days Medication - Sulfasalazine (SASP), } 10 \mathrm{mg} / \mathrm{kg} \text {, once daily, course of } 10 \text { days, } \\
\text { total } 2 \text { to } 4 \text { courses } \\
\text { Number of sessions target (mean): } 20 \text { to } 40 \\
\text { Days per week: } 7 \\
\text { Times per day: } 1 \\
\text { Dosage: } 10 \text { mg/kg } \\
\text { Any co-interventions in all groups? Not reported }\end{array}$} \\
\hline Outcomes & \multicolumn{2}{|c|}{$\begin{array}{l}\text { Symptom severity: } \\
\text { Overall IBS symptom (3-point scoring system) at end of treatment: 1) cured 2) improved 3) no effect. The outcome was } \\
\text { measured as responder rates for both groups, but there's no clear description of the evaluation basis or procedure } \\
\text { Quality of life: Not assessed } \\
\text { Time points of symptom measurement: The responder rates of overall IBS symptom were reported at the end of treatmen } \\
\text { ( } 23 \text { to } 49 \text { days) for both groups } \\
\text { Author's conclusion: "Evident Acupuncture treatment effect on patients with IBS." (Abstract) } \\
\text { Additional outcomes reported in the trial but not extracted: The SOD, MDA and NO in patient plasma were reported at } \\
\text { baseline and end of treatment.. The evaluators who asked the patients the symptom score questions were blind to the } \\
\text { participant assignment } \\
\text { Adverse effects: Not reported. }\end{array}$} \\
\hline Notes & \multicolumn{2}{|c|}{$\begin{array}{l}\text { [The number of participants assigned to either group was originally } 105 \text {, which was different from that documented in the } \\
\text { article (i.e., the article stated that } 100 \text { participants were assigned to each group), but the investigator could not describe } \\
\text { clearly the method used to ensure exactly the same number of participants assigned to either treatment group. During the } \\
\text { trial, } 3 \text { withdrew in acupuncture group, } 5 \text { withdrew in sulfasalazine group, leaving } 102 \text { in the acupuncture group and } 100 \text { in } \\
\text { the sulfasalazine group. To reach an equal sample size in both groups, } 2 \text { participants who were assigned to the acupuncture } \\
\text { group were not included in the analysis. So finally, there were } 100 \text { participants analyzed in the acupuncture group and } 100 \\
\text { participants analyzed in the sulfasalazine group] } \\
\text { Funding sources: Natural science foundation of Gansu Province, China (Grant No. } 3 Z S 041 \text { - A } 25 \text { - } 071 \text { ) } \\
\text { Information in square brackets was provided by one of the study personnel Kou Suotang, in telephone surveys on July } 25 \text { and } \\
28,2011 \\
\text { We dichotomized cured, improved and no effect into the } 2 \text { categories of improved or not improved according to the methods } \\
\text { section of the review }\end{array}$} \\
\hline \multicolumn{3}{|l|}{ Risk of bias } \\
\hline Bias & uthors' judgement & Support for judgement \\
\hline & Unclear risk & [We referred to a random number table] \\
\hline $\begin{array}{l}\text { Allocation } \\
\text { concealment } \\
\text { (selection bias) }\end{array}$ & Unclear risk & [We used sequentially numbered, opaque, sealed envelopes] \\
\hline & High risk & [The evaluators were blind to the participant assignment] \\
\hline
\end{tabular}


Xue 2009

\begin{tabular}{l|l|l}
\hline $\begin{array}{l}\text { bias and } \begin{array}{l}\text { detection bias) } \\
\text { All outcomes }\end{array} \\
\begin{array}{l}\text { Incomplete } \\
\text { outcome data } \\
\text { (attrition bias) }\end{array}\end{array}$ & Low risk & $\begin{array}{l}\text { [The number of participants assigned to either group was } \\
\text { originally 105, which was different with that documented in } \\
\text { article (i.e. 100 participants). During the trial, 3 withdrew in } \\
\text { acupuncture group, 5 withdrew in sulfasalazine group. To reach } \\
\text { an equal sample size in both groups, 2 participants who should be } \\
\text { assigned to acupuncture group were finally not been recruited. So } \\
\text { finally, there were 103 participants assigned to acupuncture group } \\
\text { and 105 participants assigned to sulfasalazine group] }\end{array}$ \\
\hline $\begin{array}{l}\text { Selective } \\
\text { reporting } \\
\text { (reporting } \\
\text { bias) }\end{array}$ & Low risk & $\begin{array}{l}\text { This trial reported outcomes for overall IBS symptom at the } \\
\text { completion of the treatment period, together with results of SOD, } \\
\text { MDA and NO in patients' plasma before and after treatment } \\
\text { according to the Observation item and methods section }\end{array}$ \\
\hline $\begin{array}{l}\text { Other bias } \\
\text { and }\end{array}$ & Unclear risk & $\begin{array}{l}\text { Although ITT analysis was not reported, there were few drop- } \\
\text { outs, so the degree of "missingness" would be unlikely to affect } \\
\text { the estimate of the treatment effect in this trial. The two groups } \\
\text { were comparable at baseline }\end{array}$ \\
\hline
\end{tabular}

Zeng 2010

\begin{tabular}{|c|c|}
\hline Methods & $\begin{array}{l}\text { Design: Parallel } \\
\text { Blinding: No } \\
\text { Attempt to confirm patient blinding?: No } \\
\text { Dropouts/withdrawals: During the } 4 \text { weeks treatment, } 4 / 33 \text { drop-outs in acupuncture group and 1/32 intrimebutine maleate } \\
\text { group } \\
\text { Total duration: } 4 \text { weeks treatment immediately followed by an evaluation, } 2 \text { month follow up reported } \\
\text { Type of analysis reported: Not specified }\end{array}$ \\
\hline Participants & $\begin{array}{l}\text { Setting: Acupuncture outpatient and inpatient in Hangzhou Hospital of TCM from } 2008 \text { to 2009, China } \\
\text { Mean age (+/- Standard Deviation or Range): } 35.15 \text { (7.23) years for acupuncture group, } 34.70 \text { (6.45) years for trimebutine } \\
\text { maleate group } \\
\text { Men/Women (number/number): } 27 / 38 \text { Acu/Moxa: } 13 / 20 \text {, Medication: } 14 / 18 \\
\text { Recruitment method: Not reported } \\
\text { Minimum duration of IBS symptoms: Rome III criteria for the last } 3 \text { months with symptom onset at least } 6 \text { months prior to } \\
\text { diagnosis } \\
\text { Actual duration of IBS symptoms before enrollment: } 15.24 \text { (7.85) months for acupuncture group, } 14.86 \text { ( } 7.77) \text { months for } \\
\text { trimebutine maleate group } \\
\text { Diagnosis of IBS required for eligibility?: Rome III criteria for diarrhea-predominant irritable bowel syndrome } \\
\text { Evaluation to rule out organic gastrointestinal disease: Reported - exclusion criterion was no organic bowel disease and no } \\
\text { other biochemical abnormalities } \\
\text { Predominant symptoms or stool patterns of participants: The study only recruited patients with diarrhea-predominant IBS } \\
\text { Hospital inpatients?: Yes, the number of inpatients was not reported } \\
\text { Were people with a history of acupuncture treatment excluded?: Not reported }\end{array}$ \\
\hline Interventions & $\begin{array}{l}\text { ACUPUNCTURE + MOXIBUSTION } \\
\text { Number allocated to acupuncture: } 33 \\
\text { Style of acupuncture: Chinese } \\
\text { Points selection: Flexible formula } \\
\text { Points stimulated: } 5 \text { main fixed acupoints and } 6 \text { optional points. The fixed points are GV 7, CV 12, CV 4, CV } 6 \text { and ST } 37 \text {. } \\
\text { The optional points were LV 3, SP 9, BL } 20, \text { BL } 21, \text { BL } 23 \text { and BL } 25 \\
\text { Description of acupuncturist qualifications: Not reported } \\
\text { Total length of treatment period (weeks): } 4 \text { weeks ( } 30 \text { days) } \\
\text { Number of sessions target (mean): } 30 \\
\text { Times per week: } 7 \\
\text { Number of points used (mean): } 5 \text { fixed acupoints plus } 6 \text { optional points } \\
\text { Insertion depth: Not reported } \\
\text { Was De Qi reportedly sought?: Not reported } \\
\text { Duration (minutes): } 20 \text { min } \\
\text { Method of stimulation: Manipulation with even method (Ping bu ping xie) } \\
\text { Moxibustion procedure: After acupuncture, moxibustion was administrated mainly on CV 12, CV 6, CV 4, BL 20, BL } 21 \\
\text { and BL } 23 \text {. The moxa was made into a hemisphere with diameter of } 4 \text { cm and height of } 2.5 \text { cm, then it was put into a } \\
\text { moxibustion box and ignited. The duration of moxibustion on each acupoint was } 30 \text { min (The duration of moxibustion was } \\
\text { not reported in the article. The information was provided by the } 3^{\text {rd }} \text { author Chu JM, in a telephone survey on July 26, 2011) } \\
\text { CONTROL GROUP A INTERVENTION: trimebutine maleate (product name: Niweifu) } \\
\text { Number allocated to control group A: } 32 \\
\text { Total length of treatment period: } 4 \text { weeks ( } 30 \text { days) } \\
\text { Number of sessions target (mean): } 30 \\
\text { days per week: } 7 \\
\text { Times per day: } 3 \\
\text { Dosage: } 100 \text { mg / time }\end{array}$ \\
\hline
\end{tabular}

Cochrane Database Syst Rev. Author manuscript; available in PMC 2013 July 22. 
Zeng 2010

\begin{tabular}{|c|c|c|}
\hline & \multicolumn{2}{|c|}{ Any co-interventions in all groups? Not reported } \\
\hline Outcomes & \multicolumn{2}{|c|}{$\begin{array}{l}\text { Symptom severity: } \\
\text { 1. Overall abdominal symptom scale. } \\
\text { 2. Symptom improvement( } 3 \text {-point scoring system) at end of treatment: 1) markedly effective } 2 \text { ) effective } 3 \text { ) no effect. The } \\
\text { evaluation of symptom improvement was based on an intestinal symptoms scale. } 1 \text { ) markedly effective: the decrease of } \\
\text { intestinal symptom scale }>80 \%, 2 \text { ) effective: the decrease of intestinal symptom scale is between } 50 \% \text { and } 80 \% ; 3 \text { ) no } \\
\text { effect: the decrease of intestinal symptom scale }<50 \% \text { or worsening symptoms. Measured as number of responders for both } \\
\text { groups } \\
\text { Quality of life: Not assessed } \\
\text { Time points of symptom measurement: } \\
\text { The Overall abdominal symptom scale (mean and SD)were reported at baseline, } 4 \text { weeks ( } 30 \text { days) and } 2 \text { months follow up } \\
\text { The numbers of responders for symptom improvement were reported at } 4 \text { weeks } \\
\text { Author's conclusion: "Moxibustion in dog days could improve the symptom of diarrhea-predominant IBS patients" } \\
\text { Additional outcomes reported in the trial but not extracted: The Bristol score (mean and SD) were reported at baseline, } 4 \\
\text { weeks (30 days) and } 2 \text { months follow up (Table 2). [the evaluators were blind to the participant assignment] } \\
\text { Adverse effects: Not reported }\end{array}$} \\
\hline Notes & \multicolumn{2}{|c|}{$\begin{array}{l}\text { Funding sources: [No funding] } \\
\text { Information in square brackets was provided by the second author Bao YH, in a telephone survey on July } 22,2011 \\
\text { We dichotomized improved, effective and no effect into the } 2 \text { categories of improved or not improved according to the } \\
\text { methods section of the review }\end{array}$} \\
\hline \multicolumn{3}{|l|}{ Risk of bias } \\
\hline Bias & Authors' judgement & Support for judgement \\
\hline $\begin{array}{l}\text { Random } \\
\text { sequence } \\
\text { generation } \\
\text { (selection bias) }\end{array}$ & Low risk & [Referred to a random number table] \\
\hline $\begin{array}{l}\text { Allocation } \\
\text { concealment } \\
\text { (selection bias) }\end{array}$ & Low risk & [We used sequentially numbered, opaque, sealed envelopes] \\
\hline $\begin{array}{l}\text { Blinding } \\
\text { (performance } \\
\text { bias and } \\
\text { detection bias) } \\
\text { All outcome }\end{array}$ & High risk & [The evaluators were blind to the participant assignment] \\
\hline $\begin{array}{l}\text { Incomplete } \\
\text { outcome data } \\
\text { (attrition bias) } \\
\text { Short term }\end{array}$ & Low risk & $\begin{array}{l}\text { " } 4 \text { participants in acupuncture group withdrew and } 1 \text { participant } \\
\text { in trimebutine mleate group withdrew during the treatment." } \\
\text { There is no information about the missing outcome data }\end{array}$ \\
\hline $\begin{array}{l}\text { Selective } \\
\text { reporting } \\
\text { (reporting } \\
\text { bias) }\end{array}$ & Low risk & $\begin{array}{l}\text { This trial reported outcomes for overall abdominal symptom scale } \\
\text { and the number of responders at the completion of the } 30 \text { days } \\
\text { treatment period, together with results for each outcome } \\
\text { measured according to the observational targets }\end{array}$ \\
\hline Other bias & Unclear risk & $\begin{array}{l}\text { Although ITT analysis was not reported, there were few drop- } \\
\text { outs, so the degree of "missingness" would be unlikely to affect } \\
\text { the estimate of the treatment effect in this trial } \\
\text { The two treatment groups were comparable at baseline in terms of } \\
\text { the variables Bristol scale and overall abdominal symptom scale. } \\
\text { The two treatment groups were also comparable at baseline in } \\
\text { terms of demographic characteristics and duration of IBS }\end{array}$ \\
\hline
\end{tabular}


Characteristics of excluded studies [ordered by study ID]

\begin{tabular}{|c|c|}
\hline Study & Reason for exclusion \\
\hline Chan 1997 & Non-randomized pilot study with 7 patients \\
\hline Chen 2005 & $\begin{array}{l}\text { Co-intervention of ear acupressure was only given to acupuncture group. This trial is the same as the Li } 2005 \text { trial with } \\
\text { regard to acupuncture method, treatment duration, age range, sex ratio and disease duration of participants, however it has a } \\
\text { different control intervention and different results. It is a possible duplicate of the Li } 2005 \text { trial }\end{array}$ \\
\hline Chu 2009 & $\begin{array}{l}\text { According to the description on Clinicaltrials.gov (http://clinicaltrials.gov/ct2/show/NCT00900965), this study, which was } \\
\text { ongoing at the time of the original } 2006 \text { Cochrane review and has since been completed, involves only one acupuncture } \\
\text { treatment and does not measure any of the outcomes relevant to this review (i.e. its purpose is to investigate the effects of } \\
\text { acupuncture on rectal sensation and brain activity in patients with IBS) }\end{array}$ \\
\hline Ding 2004 & $\begin{array}{l}\text { The first author Ding was telephoned. She said she could not recall if the random sequence was used and also said that some } \\
\text { participants were treated with both acupuncture and western medicine }\end{array}$ \\
\hline Fireman 2001 & $\begin{array}{l}\text { One of the co-authors, Rafael Carasso, stated (to Eric Manheimer during a telephone interview on December 20, 2011) that } \\
\text { participants were assigned to comparison groups according to the order in which they came into the clinic, which is not a } \\
\text { randomization procedure }\end{array}$ \\
\hline Fu 1993 & The second author Cai was telephoned. He said the participants were assigned based on their admission order \\
\hline Gabuzian 1994 & $\begin{array}{l}\text { This study did not appear to be eligible based on the translated abstract, but we did not translate the full report to confirm this } \\
\text { (language barrier to Russian) }\end{array}$ \\
\hline Guo 2010 & $\begin{array}{l}\text { According to a telephone survey of the first author Guo GL on Jul 22, 2011, the participants were assigned by odd or even } \\
\text { hospital record number. This trial was published first in Apr } 2010 \text { in Hebei Journal of Traditional Chinese Medicine, and as a } \\
\text { duplicate publication in Jun } 2010 \text { in Modern Journal of Integrated Traditional Chinese and Western Medicine }\end{array}$ \\
\hline Hou 2011 & $\begin{array}{l}\text { According to a telephone survey of the first author Hou BG on Dec 1,2011, the participants were assigned according to their } \\
\text { preference }\end{array}$ \\
\hline Huang 1999 & The trial compared acupuncture plus Chinese medicine plus psychological counselling versus Chinese medicine alone \\
\hline Huang 2006 & $\begin{array}{l}\text { According to the survey from the first author, they referred to a random number table, but some patients were assigned } \\
\text { according to their will } \\
\text { The authors compared acupuncture with a different form of Chinese medicine which is Tuina (i.e. Acupuncture plus Tuina } \\
\text { versus Acupuncture versus Tuina) }\end{array}$ \\
\hline Kang 2006 & $\begin{array}{l}\text { The trial compared ear-acupressure versus western medication. Ear-acupressure alone does not meet our inclusion criteria for } \\
\text { type of intervention }\end{array}$ \\
\hline Kunze 1990 & $\begin{array}{l}\text { We could not determine whether this study was eligible based on the translated abstract (the full publication was in German } \\
\text { and there was a language barrier to German.) }\end{array}$ \\
\hline Li 2005 & $\begin{array}{l}\text { Co-intervention of ear acupressure was only given to acupuncture group. Note this is a possible duplicate of the Chen } 2005 \\
\text { trial }\end{array}$ \\
\hline Li 2007 & $\begin{array}{l}\text { The authors didn't report a measure of overall IBS symptoms, overall IBS response, or health-related quality of life but only } \\
\text { had an improvement measure for each of the individual symptoms (e.g. diarrhea, abdominal pain etc.) }\end{array}$ \\
\hline Liao 2000 & The author was telephoned and it was confirmed that this was not a real randomized trial \\
\hline Liu 1995 & The author could not recall any of the methods used in the trial so we cannot assume that this was a true randomized trial \\
\hline Long 2006 & $\begin{array}{l}\text { The trial compared acupuncture plus bifidobacteria versus bifidobacteria plus patented Chinese medicine versus acupuncture } \\
\text { alone, which does not meet our inclusion criteria for type of intervention }\end{array}$ \\
\hline Ma 2009 & The trial compared warming needle moxibustion plus acupoint injection therapy versus western medicine \\
\hline Ouyang 2003 & $\begin{array}{l}\text { The trial compared ear-acupressure plus pinaverium bromide versus ear-acupressure alone versus pinaverium bromide alone. } \\
\text { Ear-acupressure alone does not meet our inclusion criteria for type of intervention }\end{array}$ \\
\hline Ouyang 2006 & $\begin{array}{l}\text { According to the description on Clinicaltrials.gov (http://clinicaltrials.gov/ct2/show/NCT00219505), this study, which was } \\
\text { ongoing at the time of the original review, was terminated and not completed }\end{array}$ \\
\hline Qian 2011 & $\begin{array}{l}\text { This trial clearly states in the text, on page } 258 \text {, column } 2 \text {, last line, that the patients were not blinded as to whether they got } \\
\text { true or sham acupuncture, which is the purpose of using a sham control. Therefore this trial cannot be compared or combined } \\
\text { with other sham-controlled trials }\end{array}$ \\
\hline Shi 2011 & $\begin{array}{l}\text { According to a telephone survey of the first author Shi ZM on Jul 22, 2011, the participants were assigned casually, not using } \\
\text { any specific randomization method. This trial was published first in Oct } 2010 \text { in Hebei Journal of Traditional Chinese } \\
\text { Medicine, and as duplicate publications in Apr } 2011 \text { in Liaoning Journal of Traditional Chinese Medicine and in Jul } 2011 \text { in } \\
\text { Chinese Acupuncture \& Moxibustion }\end{array}$ \\
\hline
\end{tabular}




\begin{tabular}{|c|c|}
\hline Study & Reason for exclusion \\
\hline Song 2005 & $\begin{array}{l}\text { According to a telephone survey of the first author Song JY on Jul 23, 2011, the participants were inpatient and were } \\
\text { administrated with western medicine. If the symptoms of patients were not improved, they were treated with acupuncture } \\
\text { after consultation }\end{array}$ \\
\hline Song 2011 & $\begin{array}{l}\text { The trial compared ear-acupressure plus otilonium bromide versus otilonium bromide alone. Ear-acupressure alone does not } \\
\text { meet our inclusion criteria for type of intervention }\end{array}$ \\
\hline Sun 2009 & The trial compared acupuncture plus Chinese medicine versus western medicine \\
\hline Wang 2002 & $\begin{array}{l}\text { Complicated intervention: acupuncture with moxa on the tip of the needle, plus intra-rectum enema with Chinese herb } \\
\text { solution }\end{array}$ \\
\hline Wang 2007 & $\begin{array}{l}\text { According to the survey from the first author, patients were assigned according to their will. This trial compared acupuncture } \\
\text { versus western medicine plus Traditional Chinese herbal medicine }\end{array}$ \\
\hline Wang 2008a & $\begin{array}{l}\text { The authors didn't report an outcome for overall IBS symptom severity or health-related quality of life but only had an } \\
\text { improvement measure for each of the individual symptoms (e.g. diarrhea, abdominal pain etc.) }\end{array}$ \\
\hline Wang 2008b & We are unable to contact the only author for information about randomization \\
\hline Wang 2009 & The authors used a kind of trigger point therapy which does not meet our inclusion criteria for types of intervention \\
\hline Wang 2011 & $\begin{array}{l}\text { The trial used eye-acupuncture, which is a type of micropuncture that is not considered traditional Chinese acupuncture, and } \\
\text { has not been approved popularly }\end{array}$ \\
\hline Wu 2004 & $\begin{array}{l}\text { The trial compared acupuncture plus ear-acupressure vs. acupuncture alone, which does not meet our inclusion criteria for } \\
\text { types of intervention }\end{array}$ \\
\hline Wu 2008 & The trial compared acupuncture on ST25 versus acupuncture on SP15 \\
\hline Xiao 2003 & $\begin{array}{l}\text { According to a telephone survey with the first author Xiao FT on Nov 25, 2011, the participants were assigned based on the } \\
\text { doctor's judgment. The outcome of the trial was recurrence rate which does not meet our inclusion criteria for types of } \\
\text { outcome measures }\end{array}$ \\
\hline Xiao 2004 & Evaluation of the therapeutic effect of acupoint transcutaneous electrical nerve stimulation (TENS) \\
\hline Xiong 2008b & $\begin{array}{l}\text { According to a telephone survey of the first author Xiong JW on Jul 22, 2011, the participants were assigned by alternation. } \\
\text { Note: Although the author last name and year is the same as the Xiong X } 2008 \text { trial included in our review, they are not the } \\
\text { same author or trial }\end{array}$ \\
\hline Xu 2009 & According to a telephone survey of the first author Xu MF on Jul 21, 2011, the participants were assigned by their preference \\
\hline Yang 2000 & Intervention was Vit B1 point (ST-36) injection and Chinese massage \\
\hline Yu 2007 & $\begin{array}{l}\text { According to the survey from the first author, the patients were assigned according to alternation or rotation The authors } \\
\text { compared acupuncture with a different form of Chinese medicine which is Chinese herbal medicine (i.e. acupuncture plus } \\
\text { Chinese medicine versus Chinese medicine versus western medicine.) }\end{array}$ \\
\hline Yu 2011 & $\begin{array}{l}\text { The trial compared ear-acupressure plus Chinese medicine versus Chinese medicine alone versus ear-acupressure alone. Ear- } \\
\text { acupressure alone does not meet our inclusion criteria for type of intervention }\end{array}$ \\
\hline Zhang 1996 & $\begin{array}{l}\text { The trial used tapping acupuncture which was not inserted into human body, so it does not meet our inclusion criteria for } \\
\text { types of interventions. This trial was published first in } 1996 \text { in Chinese Acupuncture \& Moxibustion, and as a duplicate } \\
\text { publication in } 1997 \text { in Journal of Jiamusi Medical College (former name of Heilongjiang Medicine and Pharmacy) }\end{array}$ \\
\hline Zhang 2000 & According to the telephone survey from the first author Zhang, he said he didn't use any random method of allocation \\
\hline Zhang 2010 & The trial compared acupuncture versus Chinese medicine \\
\hline Zhang 2011a & According to a telephone survey of the first author Zhang Y on Jul 22, 2011, the participants were assigned by rotation \\
\hline Zhang $2011 \mathrm{~b}$ & $\begin{array}{l}\text { According to a telephone survey of the first author Zhang HC on Dec 1, 2011, some participants were assigned according to } \\
\text { the patients' preference }\end{array}$ \\
\hline Zhao 2003 & The trial compared needle acupuncture versus moxibustion \\
\hline Zheng 2003 & $\begin{array}{l}\text { According to the telephone survey from the first author Zheng, he stated they used random method of allocation, but he could } \\
\text { not recall the details of the generation of random sequence. He also could not explain why the patient numbers of the two } \\
\text { groups were not comparable ( } 41 \text { for Bifidobacterium capsule+pinaverium plus acupuncture group, } 28 \text { for Bifidobacterium } \\
\text { capsule+pinaverium group) }\end{array}$ \\
\hline
\end{tabular}


Characteristics of ongoing studies [ordered by study ID]

\begin{tabular}{|c|c|}
\hline Trial name or title & Acupuncture/Moxibustion for Irritable Bowel Syndrome (IBS) \\
\hline \multicolumn{2}{|l|}{ Methods } \\
\hline Participants & Patients with IBS (N=171) \\
\hline Interventions & $\begin{array}{l}\text { Double Blind RCT comparing } \\
\text { 1: Standard Acu/Moxa (fixed protocol) } \\
\text { 2: Individualized Acupuncture/Moxibustion } \\
\text { 3. Sham Acupuncture/Placebo Moxibustion }\end{array}$ \\
\hline Outcomes & $\begin{array}{l}\text { Primary outcome: Patient-rated abdominal pain/discomfort and IBS-Secondary symptom rating: intestinal } \\
\text { gas, bloating and stool consistency [Time Frame:Six months] }\end{array}$ \\
\hline Starting date & Start date: July 2009; Expected date of completion: March 2013 \\
\hline Contact information & $\begin{array}{l}\text { Ann M Chung } \\
\text { 212-922-7038 } \\
\text { amc20@nyu.edu }\end{array}$ \\
\hline Notes & $\begin{array}{l}\text { ClinicalTrials.gov identifier: NCT00945074 } \\
\text { Location: New York University, Division of Special Studies in Symptom Management } \\
\text { Sponsor: New York University, National Institutes of Health (NIH) } \\
\text { Other Study ID numbers: } 7833948 ; \text { R01NR010730 }\end{array}$ \\
\hline
\end{tabular}

\begin{tabular}{|c|c|}
\hline Trial name or title & Acupuncture for Irritable Bowel Syndrome (IBS) \\
\hline \multicolumn{2}{|l|}{ Methods } \\
\hline Participants & Patient with IBS $(\mathrm{N}=220)$ \\
\hline Interventions & RCT comparing acupuncture plus usual GP care versus usual GP care alone \\
\hline Outcomes & $\begin{array}{l}\text { Primary outcome measures: } \\
\text { 1. IBS Symptom Severity Score (IBS SSS) at } 3 \text { months } \\
\text { 2. Cost-effectiveness study: European quality of life questionnaire (EQ-5D) at } 12 \text { months } \\
\text { 3. Medication use at baseline, } 3 \text { months, } 6 \text { months, } 9 \text { months and } 12 \text { months } \\
\text { 4. Health services used at baseline, } 3 \text { months, } 6 \text { months, } 9 \text { months and } 12 \text { months } \\
\text { 5. Days lost from work at baseline, } 3 \text { months, } 6 \text { months, } 9 \text { months and } 12 \text { months }\end{array}$ \\
\hline Starting date & Start date: 01/10/2008, Expected date of completion: 30/09/2011 \\
\hline Contact information & $\begin{array}{l}\text { Dr Hugh MacPherson } \\
+44(0) 1904321394 \\
\text { hm18@york.ac.uk }\end{array}$ \\
\hline Notes & $\begin{array}{l}\text { Location:United Kingdom } \\
\text { Sponsor details: c/o Mrs S Final, Heslington, York, United Kingdom, YO10 5DD (smf3@york.ac.uk, +44 } \\
\text { (0)1904 430000) } \\
\text { Link to record in ISRCTN Register: ISRCTN08827905 }\end{array}$ \\
\hline
\end{tabular}

